$\mathrm{D} \cap \mathrm{C}^{\prime \prime}=\mathrm{R}-0013$


\title{
MASTER
}

\section{Materials Sciences Programs FISCAL YEAR 1978} OFFICE OF BASIC ENERGY SCIENCES

\section{U.S. Department of Energy Office of Energy Research}

September 1978 


\section{DISCLAIMER}

This report was prepared as an account of work sponsored by an agency of the United States Government. Neither the United States Government nor any agency Thereof, nor any of their employees, makes any warranty, express or implied, or assumes any legal liability or responsibility for the accuracy, completeness, or usefulness of any information, apparatus, product, or process disclosed, or represents that its use would not infringe privately owned rights. Reference herein to any specific commercial product, process, or service by trade name, trademark, manufacturer, or otherwise does not necessarily constitute or imply its endorsement, recommendation, or favoring by the United States Government or any agency thereof. The views and opinions of authors expressed herein do not necessarily state or reflect those of the United States Government or any agency thereof. 


\section{DISCLAIMER}

Portions of this document may be illegible in electronic image products. Images are produced from the best available original document. 


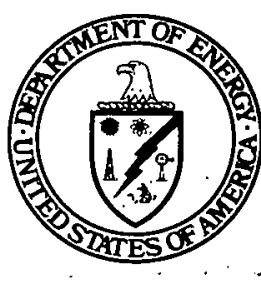

\section{Materials Sciences Programs FISCAL YEAR 1978 OFFICE OF BASIC ENERGY SCIENCES}

\section{U.S. Department of Energy Office of Energy Research Washington, DC 20545}

\section{September 1978}


Available from:

National Technical Information Service (NTIS)

U.S. Department of Commerce.

5285 Port Roya1 Road

Springfield, Virginia 22161

Price:

Printed Copy: $\quad \$ 8.00$

Microfiche: $\quad \$ 3.00$ 
On October 1, 1977 a new Department of Energy was established. The Energy Research and Development Administration was transferred to the Department of Energy together with other agencies and parts of agencies within the Federal government. The organizational structure of the new Department of Energy is given in an accompanying chart. The Offices of Basic Energy Science and High Energy and Nuclear Physics report to the Director of the D.0.E. Office of Energy Research. The Director of this Office is appointed by the President with Senate consent. The Director advises the Secretary on the physical research program; monitors the Department's R\&D programs; advises the Secretary on management of the multipurpose laboratories under the jurisdiction of the Department excluding laboratories that constitute part of the nuclear weapon complex; and advises the Secretary on basic and applied research activities of the Department.

The Materials Sciences Division constitutes one portion of a wide range of research supported by the DOE Office of Basic Energy Sciences. Other programs are administered by the Office's Chemical Sciences, Nuclear Sciences, Engineering, Mathematical and Geosciences and Exploratory Energy Concepts Divisions. Materials Sciences research is supported primarily at DOE National Laboratories and Universities. The research covers a spectrum of scientific and engineering areas of interest to the Department of Energy and is conducted generally by personnel trained in the disciplines of Solid State Physics, Metallurgy, Ceramics and Chemistry. The structure of the Division is given in an accompanying chart.

The Materials Sciences Division conducts basic research on materials properties and phenomena important to all energy systems. The aim is to provide the necessary base of materials knowledge required to advance the nation's energy programs.

This report contains a listing of all research underway in FY 1978 together with a convenient index to the program.

Donald K. Stevens, Director Division of Materials Sciences Office of Basic Energy. Sciences 


\section{INTRODUCTION}

The purpose of this report is to provide a convenient compilation and index of the DOE Materials Sciences Division programs. This compilation is intended for use by administrators, managers, and scientists to help coordinate research and as an aid in selecting new programs.

The report is divided into Sections $A$ and $B$, listing all the projects, Section C, a summary of funding levels, and Section D, an index (the investigator index is in two parts - laboratory and contract research).

Each project carries a number (underlined) for reference purposes. The FY 1978 funding level, title, personnel, budget activity number (e.g., 01-2), and key words and phrases accompany the project number. The first two digits of the budget number refer to either Metallurgy and Ceramics (01), Solid State Physics (02), or Materials Chemistry (03). The budget numbers carry the following tities:

$$
\begin{aligned}
& 01-1 \text { - Structure of Materials } \\
& 01-2 \text { - Mechanical Properties } \\
& 01-3 \text { - Physical Properties } \\
& 01-4 \text { - Radiation Effects } \\
& 01-5 \text { - Engineering Materials } \\
& 02-1 \text { - Neutron Scattering } \\
& 02-2 \text { - Experimental Research } \\
& 02-3 \text { - Theoretical Research } \\
& 02-4 \text { - Particle-Solid Interactions } \\
& 02-5 \text { - Engineering Physics } \\
& 03-1 \text { - Chemical Structure } \\
& 03-2 \text { - Engineering Chemistry } \\
& 03-3 \text { - High Temperature and Surface Chemistry }
\end{aligned}
$$

Section $C$ summarizes the total funding level in a number of selected categories. Obviously most projects can be classified under more than one category and, therefore, it should be remembered that the categories are not mutually exclusive.

In Section $D$ the references are to the project numbers appearing in Sections $A$ and $B$ and are grouped by (1) investigators, (2) materials, (3) technique, (4) phenomena, and (5) envtronment.

It is impossible to include in this report all the technical data available for such a large program. By the time it could be compiled it would be outdated. The best method for obtaining more detailed information about a given research project is to contact directly the investigators listed.

Louts C. Iariniello 


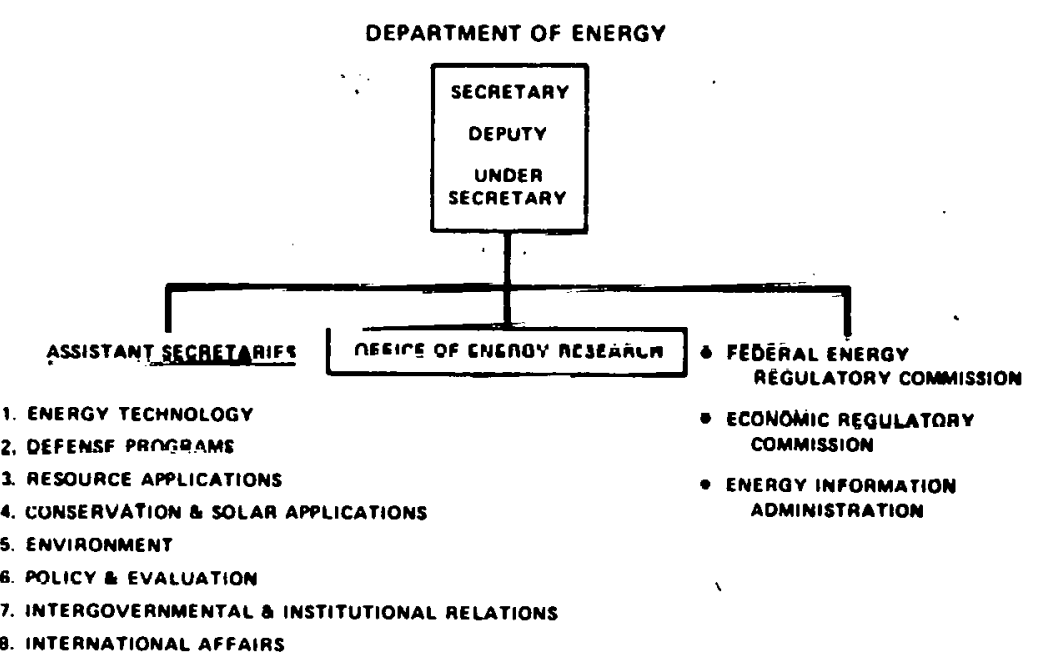

OFFICE OF ENFRISV RESEARCH

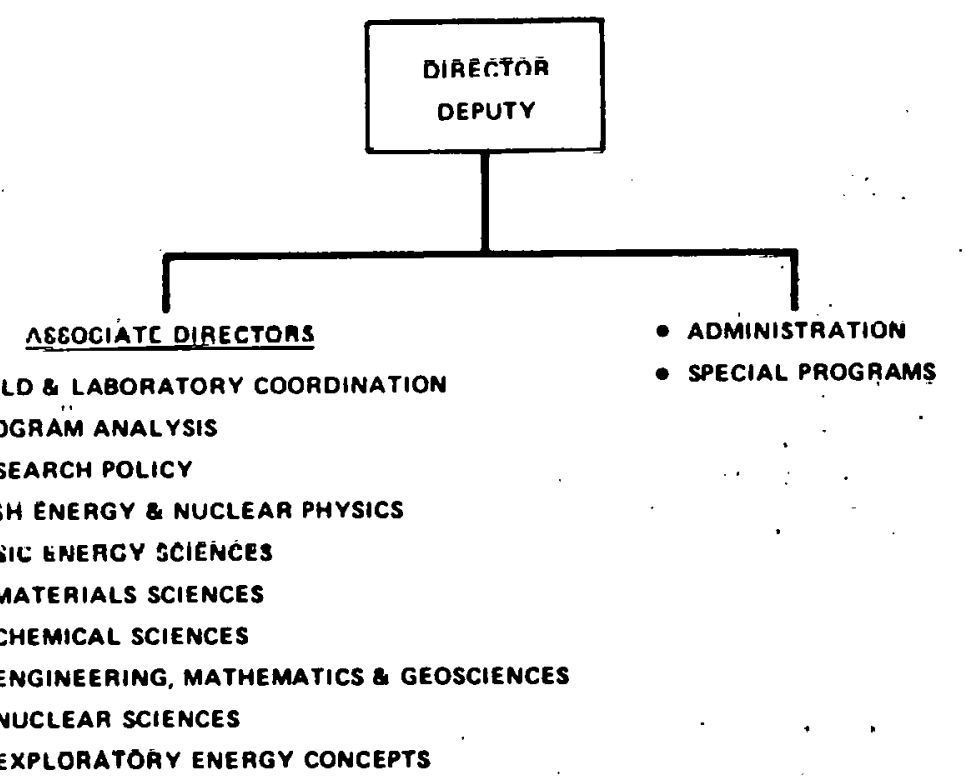




\section{STRUCTURE}

OF THE

DIVISION OF MATERIALS SCIENCES

Office of Basic Energy Sciences

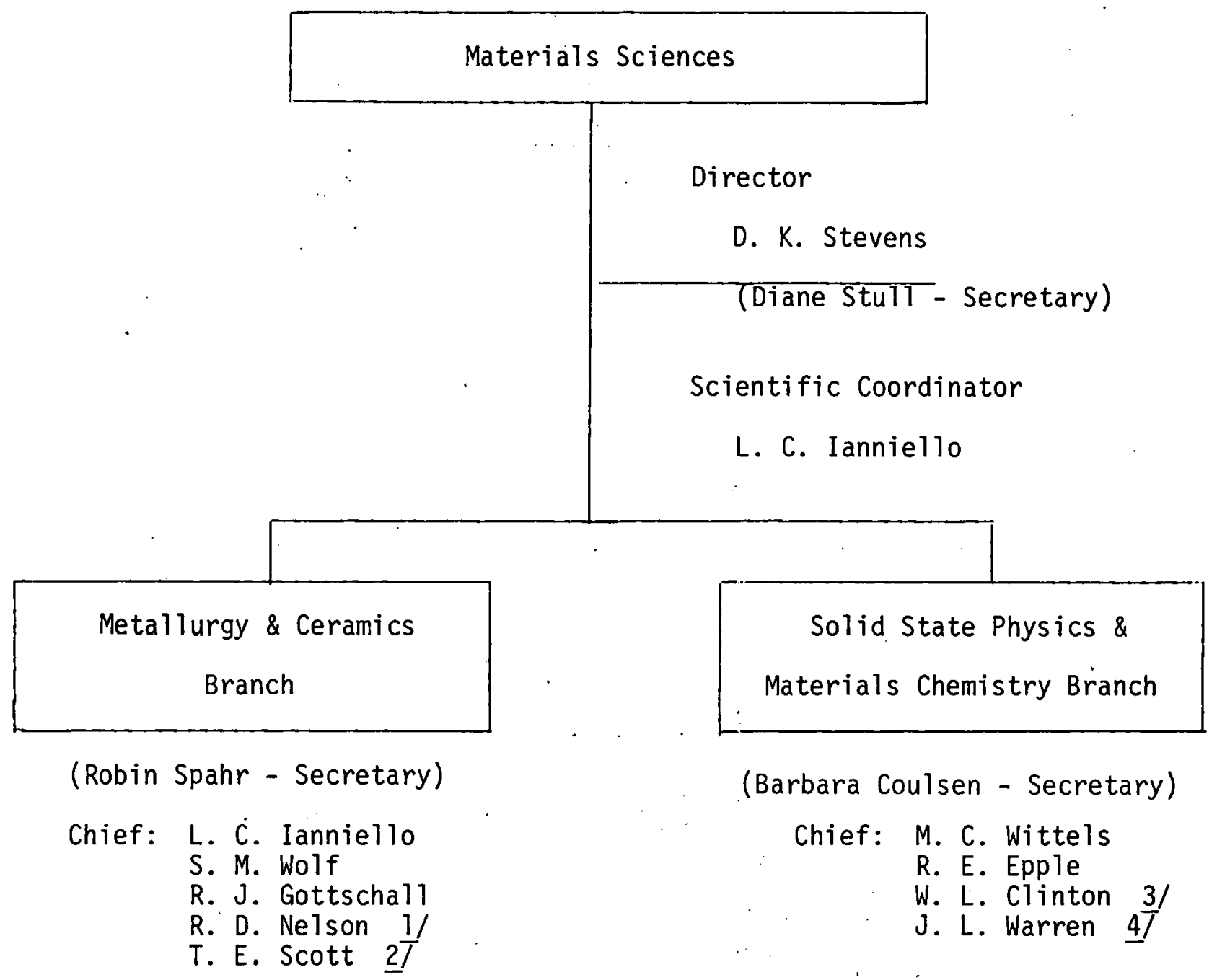

Notes: 1/ Returned to Pacific Northwest Laboratory - 9/78

2) On Leave from Ames Laboratory

3/ On Leave from Georgetown University

4/ On Leave from Los Alamos Scientific Laboratory 


\section{SECTION A - Laboratories}

$\underline{\text { Page }}$

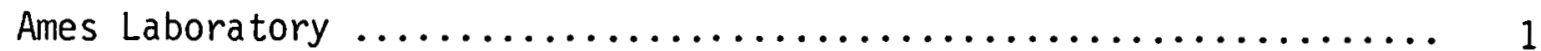

Argonne National Laboratory ............................. 11

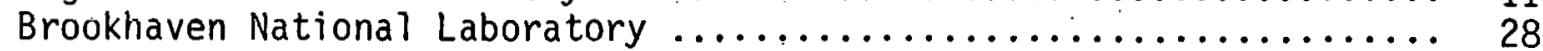

Idaho National Engineering Laboratory ..................... 35

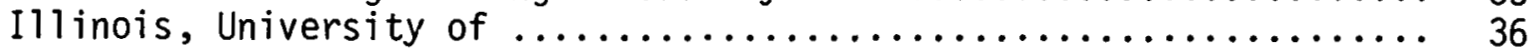

Lawrence Berkeley Laboratory ......................... 40

Lawrence Livermore Laboratory $\ldots \ldots \ldots \ldots \ldots \ldots \ldots \ldots \ldots \ldots \ldots . \ldots . \ldots . \ldots . \ldots$

Los Alamos Scientific Laboratory $\ldots \ldots \ldots \ldots \ldots \ldots \ldots \ldots \ldots \ldots \ldots . \ldots \ldots \ldots \ldots$

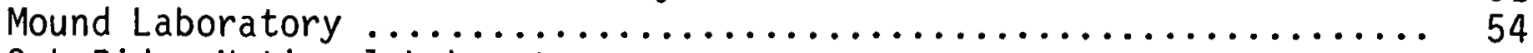

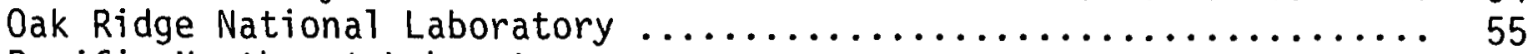



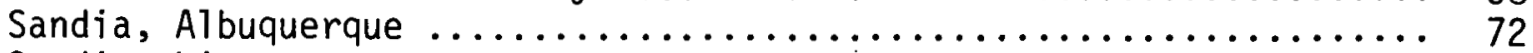

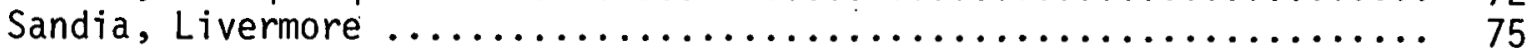

\section{SECTION B - Universities}

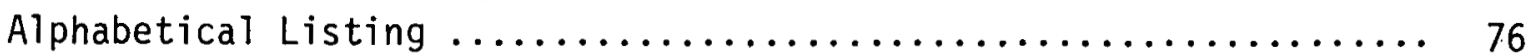

\section{SECTION C - Funding Levels}

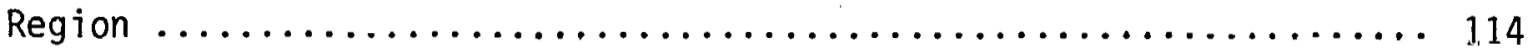

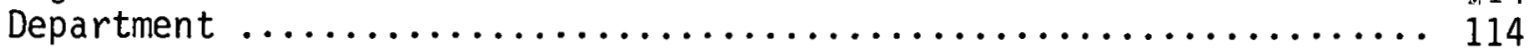



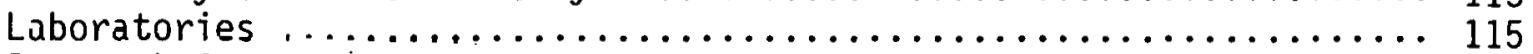

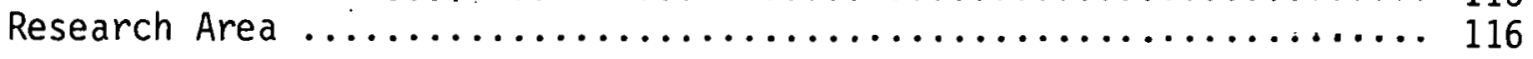

SECTION D - Index

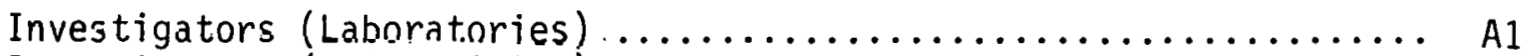

Investigators (Universities) $\ldots \ldots \ldots \ldots \ldots \ldots \ldots \ldots \ldots \ldots \ldots \ldots, n 7$



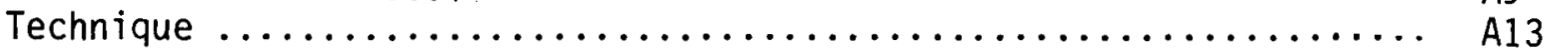

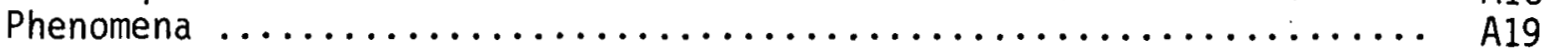

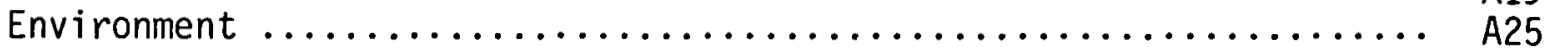


SECTION A

Laboratories

The information was taken from current Laboratory program budget submissions. Most projects are of a continuing nature although specific problems and some projects were concluded in FY 1978. 
AMES LABORATORY

Iowa State University

Ames, Iowa 50011

R. S. Hansen - Phone: (FTS) $865-2770$ or 515 294-2770

Metallurgy and Ceramics -01-

K. A. Gschneidner, Jr. - Phone: (FTS) 865-2272 or 515-294-2272

1. PHOTOVOLTAIC AND THERMOELECTRIC MATERIALS

$\$ 113,000$

$01-1$

B. J. Beaudry, K. A. Gschneidner, Jr.,

F. A. Schmidt, R. K. Trivedi, D. E. Williams

Preparation of Schottky barrier-type solar cells by the ultra high vacuum deposition of thin films of semiconducting materials on metal substrates and characterization of the resulting devices; current work involves silicon films on tantalum, tungsten and hafnium substrates. Investigation of the application of rare earth sulfides as high efficiency photovoltaic and thermoelectric materials; heat capacity and optical properties are being studied as a function of changing atomic number in a series of rare earth sesquisulfides. Theoretical and experimental studies of the effects of growth rate and impurities upon the defect structure of photoelectric materials.
2. HIGH TEMPERATURE AND HIGH STRENGTH MATERIALS
$\$ 109,000$
$01 \div-1$
0. N. Carlson, F. A. Schmidt,
R. K. Trivedi

Determination of phase relationships in ferritic alloys and the investigation of microstructural characteristics responsible for their favorable mechanical properties. Studies concerning the migration, due to thermotransport and chemical diffusion, of interstitial solutes in complex, high strength alloys. Surface self diffusion coefficients are being measured for vanadium and other refractory metals at high temperatures. The effects of temperature and interstitial concentration on the strain rate sensitivity and the critical resolved shear stress in vanadium are being studied.
3. PREPARATION AND CHARACTERIZATION OF HIGH PURITY MATERIALS
B. J. Beaudry, 0. N. Carlson,
K. A. Gschneidner, Jr., F. A. Schmidt

$\$ 218,000$

01-1

Preparation of ultra pure metals and the study of effects of trace impurities on properties. Determination of diffusion and electrotransport behavior of oxygen and nitrogen in thorium and the rare earths. The relationship between atomic size and activation energies for diffusion is being developed for solutes in $\alpha$ and $\beta$ thorium. High purity rare earth alloys in both single crystal and polycrystalline form are prepared to provide materials for critical scientific programs at Ames Laboratory and other sites. 
AMES LABORATORY

Metallurgy and Ceramics -01- (Continued)

4. MECHANICAL PROPERTIES OF CERAMICS

0 . Hunter

$\$ 124,000 \quad 01-2$

Development of stabilized and partially stabilized oxides with improved mechanical properties for application in MHD systems, batteries, coal gasification reactors and other energy generating schemes; $\mathrm{ZrO}_{2}$ and $\mathrm{HfO}_{2}$ are being studied currently. The nature of the electrical conductivity of stabilized $\mathrm{ZrO}_{2}$ and $\mathrm{HfO}_{2}$ is being evaluated with the objective of determining ways to decrease the ionic conductivity and increase the electronic conductivity thus minimizing the possibility of electrolytic decomposition of the oxides were they to be placed in service as electrodes for MHD channels.

5. METAL HYDRIDES AND HYDROGEN IN METALS \$290;000: 01-2 D. T. Peterson, T. E. Scott

Studies are being conducted of the mechanisms involved in hydrogen attack and hydrogen embrittlement in an effort to develop methods for alleviating the often catastrophic effects which hydrogen and $i$ ts isotopes have on some metals; work is specifically concerned with the refractory metals and steels. Vanadium, niobium and tantalum doped with nitrogen or oxygen are being tested to determine the effects of interstitial atoms on the hydrogen embrittlement of refractory metals. Bonding studies of metal hydrides, using photoelectron spectroscopy, and the consequent determination of the electron energy levels associated with hydrogen in metals are being conducted. Thermotransport measurements for hydrogen and duterium in vanadium and other refractory metals are being made to yield information regarding the heat of transport $\left(Q^{*}\right)$ and the effective charge $\left(Z^{*}\right)$ in these systems.
6. STRESS CORROSION STUDIES
$\$ 26,000$
$01-2$
T. F. Scott

Microstrain experiments are being initiated as part of an interdisciplinary effort to understand stress corrosion cracking; planned work includes localized plastic deformation studies, and the observation of surface as well as near-surface characteristics of alpha brass under stress in air and ammoniacal solutions.
7. SHAPE-MEMORY ALLOYS
M. S. Wechsler.
$\$ 10,000$
$07-2$

Initial experiments are being conducted concerning the use of shapememory alloys for low temperature heat engines. Thermomechanical treatments have been developed which permit the fabrication of tube shapes of Ni-Ti shape-memory alloy. Transformation studies and the determination of the effects of mechanical treatment and composition changes on the shape-memory charäcteristics and fatigue life are planned. 
8. DIFFUSION AND FABRICATION STUDIES

$\$ 60,000$

$01-3$

OF CERAMIC SYSTEMS

M. F. Berard

Development of methods for producing sintered refractory oxides (pure and doped) of near theoretical density; current work involves $\mathrm{Gd}_{2} \mathrm{O}_{3}$, $\mathrm{Er}_{2} \mathrm{O}_{3}, \mathrm{Y}_{2} \mathrm{O}_{3}, \mathrm{Sc}_{2} \mathrm{O}_{3}, \mathrm{Eu}_{2} \mathrm{O}_{3}$ and $\mathrm{Eu}_{2} \mathrm{O}_{3}$ doped with $\mathrm{HfO}_{2}$ and $\mathrm{MgO}$. Investi = gations concerning the diffusion of $\mathrm{Hf}$ and $\mathrm{Er}$ in pure and $\mathrm{HfO}_{2}$-doped $\mathrm{Er}_{2} \mathrm{O}_{3}$, self-diffusion of $\mathrm{Gd}$ in $\mathrm{Gd}_{2} \mathrm{O}_{3}$, and thermally induced diffusion in $\mathrm{CaF}_{2}-\mathrm{SrF}_{2}$, and $\mathrm{CaF}_{2}-\mathrm{YF}_{3}$ systems. Study of interface reactions between. tantalum and $\mathrm{Er}_{2} \mathrm{O}_{3}$.

9. ALLOYING AND PHASE CONTROL STUDIES

$\$ 135,000$

$01-3$

0 . D. McMasters, K. A. Gschneidner, Jr.

Studies of the influence of electron concentration and magnetic impurities on the density of states curve for scandium; electronic specific heat constants are determined for zirconium, magnesium and iron additions. Low temperature heat capacity measurements of $\left(\mathrm{La}_{3}-\mathrm{x}_{\mathrm{x}} \mathrm{R}\right)$ $\left(I_{1}-y M_{y}\right)$ materials at zero and high magnetic fields are conducted to determine the effects of alloying and magnetic field on the superconducting transition temperature.

10. CONTROL OF MICROST̈TUCTURE AND

$\$ 181,000$

$01-3$

SOLIDIFICATION STUDIES

J. D. Verhoeven

Development of methods for the production of superconducting wire by the application of solidification techniques and phase transformation control; $\mathrm{Nb}_{3} \mathrm{Sn}$ and $\mathrm{Nb}_{3} \mathrm{Sn}-\mathrm{Cu}$. composites are being studied. Directional. solidification studies of $\mathrm{Pd}-\mathrm{Cd}, \mathrm{Nb}-\mathrm{Ti}-\mathrm{Th}$, and $\mathrm{Nb}-\mathrm{Ti}-\mathrm{Y}$ alloys are planned in an effort to produce useful superconducting wires from these systems.

II." INTERSTITIAL SOLUTE EFFECTS

K. A. Gschneidner, Jr., J. F. Smith

$\$ 70,000$

$01-3$

Effects of hydrogen on the elastic behavior of Group $V$ metals. Study: of the effects of oxygen. on the elastic behavior of vanadium over the temperature range 4.2-300 K. Effects of hydrogen on the electronic specific heat constant and Debye temperature of Lu metal are being studied and the influence of hydrogen, nitrogen, oxygen, and carbon on the low temperature heat capacity of Lu will be observed.

12. DETERMINATION OF PHASE DIAGRAMS

$\$ 56,000$

$01-3$

BY USE OF COMPUTERS

D. M. Bailey, J.F. Smith

Calculation of multicomponent phase equilibria from binary thermodynamic data. Perfection of computer programs to generate phase diagrams for binary, ternary and quaternary systems and extension of methods to quinary and higher order systems. 
AMES LABORATORY

Metallurgy and Ceramics -01- (Continued)

13. PREPARATION AND PROPERTIES OF RARE

EARTH COMPOUNDS AND SINGLE CRYSTALS

$\$ 98,000$

$01-3$

K. A. Gschneidner, Jr., O. D. McMasters

Preparation of rare earth single crystals and intermetallic compounds by horizontal levitation zone melting, the Bridgman technique, and the strain-anneal recrýstallization method. Resulting Crystals and compounds are used as specimen materials in numerous other physical and mechanical property investigations both within the Ames Laboratory and off site.

14. THERMODYNAMIC STUDIES

$\$ 18,000$

$01-3$

P. Chiotti

Basic thermodynamic measurements in the uranium-mercury system are being conducted to resolve discrepancies contained in the literature and because of possible interest in this system for fuel reprocessing applications. An effort has been maintained to develop a process for the removal of pyrite sulfur from coal based on the high pressure oxidation of the pyrite.

15. MAGNETIC MATERIALS

C. W. Chen

$\$ 42,000$

$01-3$

Amorphous iron alloys are being evaluated in a search for materials with saturation magnetization values greater than 16,000 gauss; glassy films or ribbon of $\mathrm{Fe}_{1-G_{K}}$ systems (where $G$ is the glass-forming constituent) are being prepared and will be subjected to coerceive force, remanence; permeability and energy loss studies.

16. DOPED ALUMINUM THIN FILM SOLAR . ' $\$ 42,000 \cdot 01-3$ COLLECTORS

C. W. Chen

Spectrophotometric studies on thin films of aluminum doped with $\mathrm{Si}, \mathrm{Mn}$, $\mathrm{Zn}$, $\mathrm{Ge}$ or Ag; determination of the efficiency of these materials as solar energy collectors.

17. ORDERED ALLOYS

F. X. Kayser

$\$ 98,000$

$01-3$

Studies of the mechanical properties and elastic constants of $\mathrm{Ni}_{3} \mathrm{Al}_{\mathrm{Al}}: \mathrm{Ni}_{3} \mathrm{Ti}$ are being conducted with the objective of understanding the strengthening mechanisms which are operating in nickel base superalloys. Lattice parameter vs. composition studies of ferromagnetic $\mathrm{DO}_{3}$-ordered $\mathrm{Fe}-\mathrm{Al}-\mathrm{Si}$ alloys; these materials are expected to have superior soft magnetic properties. 
AMES LABORATORY

Metallurgy and Ceramics -01- (Continued)

18. HELIUM BUBBLE, VOID, AND DEFECT

DEFECT CLUSTER FORMATION

$\$ 118,000 \quad 01-4$

C. W. Chen

Development of methods for suppressing void formation in neutron-

irradiated metals by vacancy trapping with carbon atoms. Effects of $\mathrm{Zr}$ and $\mathrm{Be}$ solute atoms on the formation of He bubbles in $\mathrm{Ni+t}$ irradiated $\mathrm{V}-\mathrm{Ti}$ alloys; the morphology and distribution mode of the He gas bubbles are being studied as functions of alloy composition and damage profile. Study of geometry and dislocation characteristics of interstitial clusters in neutron-irradiated $\mathrm{Nb}$.
19. RADIATION HARDENING THEORY
$\$ 46,000$
$01-4$

M. S. Wechsler

Computer simulation studies analyzing the dependence of radiationinduced increase in yield stress on the density and size distribution of defect clusters.

20. RADIATION DAMAGE IN METALS AND ALLOYS $\$ 36,000 \quad 01-4$ M. S. Wechster

Electron irradiation of vanadium; the oxygen trapping by defect clusters produced by $3 \mathrm{MeV}$ electrons is being evaluated and compared to the effects observed earlier in the neutron-irradiated material. Tensile tests are being conducted on neutron-irradiated thorium and thorium carbon alloys as part of the study of the effects of irradiation on the mechanical properties of thorium.

21. NON-DESTRUCTIVE EVALUATION

$\$ 70,000$

$07-5$

C. P. Burger, K. G. McConnell,

L. W. Schmerr, J. F. Smith, D. R. Wilder,

L. W. Zachary

Project was initiated during FY 1978. Work involves flaw characterization by ultrasonic spectroscopy and the boundary integral equation method to provide a basis for evaluating internal flaws in materials in service situations. Method will be developed that use ultrasonic Rayleigh waves for the quantitative evaluation of surface cracks and breaking near surface flaws. A method for the non-destructive evaluation of the tenstion in large bolts has been perfected; the technique is based on the measurement of ultrasonic wave velocities by the pulse-echo-overlap method. 
AMES LABORATORY

Solid State Physics Division -02-

K. L. Kliewer - Phone: (FTS) 865-4037 or 515-294-4037

22. NEUTRON SCATTERING

W. A. Kamitakahara, J. Khatamian,

$\$ 340,000$

$02-1$

G. R. Kline, C. Stassis

Study of the thermodynamic properties and structural transformations of solids at high temperatures ( $\mathrm{Zr}, \mathrm{Ti}, \mathrm{TC}$ ); effect of hydrogen and carbon impurities in metals ( Th-C, Th-H, Y-H); electron-phonon interaction and its relation to superconductivity $\left(\mathrm{La}_{3} \mathrm{~S}_{4}, \mathrm{La}\right)$; mixed valence compounds $\left(\operatorname{CeS} n_{3}, r-\operatorname{Ce}\right)$.

23. MAGNETIC PROPERTIES OF SOLIDS S. Legvold

$\$ 54,000 \quad 02-2$

Experimental magnetic studies of localized and conduction band electrons in rare earth alloys; Seebeck effect near the Lifshitz bicritical point of alloys (Gd-Y, Gd-Sc, Tb-Th); magnetic ordering temperatures of light rare earth alloys (Ce-La, Nd-La); crystal field effects in light-heavy rare earth single crystals (Tb-Pr, Dy-Pr); spin disorder scattering in cubic La alloys (La-Gd, La-Tb, La-Dy, etc.); easy direction of magnetization for Er.

24. NUCLEAR RESONANCE IN SOLIDS

R. G. Barnes, D. R. Torgeson

$\$ 176,000$

$02-2$

Applications of nuclear magnetic resonance, nuclear quadrupole resonance, and Mossbauer effect to: determination of hydrogen-isotope locations and diffusion parameters in hydride and deuteride phases of refractory metals (e.g., $\mathrm{V}, \mathrm{Nb}, \mathrm{Ta}$ ), alloys (e.g., $\mathrm{Nb}-\mathrm{Ti}, \mathrm{Nb}-\mathrm{V}$ ), and compounds (e.g., $\mathrm{Ta}_{6} \mathrm{~W}, \mathrm{~V}_{2} \mathrm{C}$ ); electronic and structural phase transitions in refractory metal hydrides; interactions between hydrogen isotopes and interstitial impurities such as $0, \mathrm{~N}$, and $\mathrm{C}$ in refractory metals ( $\mathrm{V}, \mathrm{Nb}, \mathrm{Ta})$; electronic structure, charge density wave effects, and structural transformations in one and two-dimensional metallic compounds (e.g., $\mathrm{ScCl}, \mathrm{CsScCl}_{3}, \mathrm{BaVS}_{3}$ ).

25. SUPERCONDUCTIVITY

D. K. Finnemore, T. Y. Hsiang,

$\$ 320,700$. $\quad 02-2$

J. W. Osmun, J. E. Ostenson,

E. L. Wolf, R. J. Noer

Superconductivity in A-15 composites having dimensions on the order of $100 \AA$. Electron tunneling of strong-coupling transition metal, transitionmetal alloy, and transition-metal compound superconductors using ultrathin normal-superconductor proximity junctions; preparation and investigation of oriented ( $\mathrm{Pb}-\mathrm{Cd}$ and $\mathrm{Nb}-\mathrm{Th})$, superconductor-normal metal, composites by directional solidification; critical currents and critical magnetic fields in $\mathrm{Nb}-\mathrm{Th}$ and $\mathrm{Nb}-\mathrm{Y}$ superconductor-normal metal composites; flux pinning and thermal transport. Auger analysis and photoemission of getter sputtered and surface grown $V_{3} G a$ and other $A-15$ superconducting films. 
AMES LABORATORY

Solid State Physics Division -02- (Continued)

26. THERMODYNAMIC AND TRANSPORT

$\$ 410,400$

$02-2$

PROPERTIES OF SOLIDS

M. S. Anderson, A. J. Bevolo

G. C. Danielson, H. R. Shanks,

C. A. Swenson

Electrocatalytic activity of tungsten bronzes $\left(\mathrm{Na}_{x} \mathrm{WO}_{3}\right)$; capacitancedilatometer thermal-expansion measurements on amorphous solids at low temperatures (organic polymers, fused silica); high pressure studies of the heat capacities of solid hydrogen and solid deuterium, and of the equations of state of the alkaline earth metals; growth of crystals of tungsten bronzes: $\left(\mathrm{Na}_{x} \mathrm{WO}_{3}, \mathrm{~K}_{\mathrm{x}} \mathrm{WO}_{3}, \mathrm{H}_{\mathrm{x}} \mathrm{WO}_{3}, \mathrm{Rb}_{\mathrm{x}} \mathrm{WO}_{3}\right)$ and layer compounds ( $\mathrm{NbSe}_{2}, \mathrm{TaSe}_{2}, \mathrm{NbS}_{2}$, InSe, InTe); electrical resistivity, thermal conductivity and Seebeck coefficient of high purity vanadium and tantalum; low temperature heat capacity of perovskite compounds.

SURFACE ANALYSIS LABORATORY: Auger and SIMS studies of surfaces and interfaces: surface composition and depth profiles of tungsten bronzes $\left(\mathrm{Na}_{x} \mathrm{WO}_{3}, \mathrm{H}_{\mathrm{X}} \mathrm{WO}_{3}, \mathrm{Pt}\right.$-doped $\left.\mathrm{Na}_{x} \mathrm{WO}_{3}\right)$; corrosion of surfaces; evaporated and sputtered thin films, Schottky-barrier, and metal-oxide-semiconductor interfaces; Schottky-barrier solar cells; amorphous silicon-metal interfaces; ohmic contacts.

27. OPTICAL AND SPECTROSCOPIC PROPERTIES OF SOLIDS AND LIQUIDS

$\$ 188,900$

$02-2$

T. E. Furtak, A. Habenschuss,

D. W. Lynch, C. G. Olson,

F. H. Spedding, R. Rosei,

J. H. Weaver

Optical properties (transmission, reflection, thermoreflection, thermotransmission, electroreflection) of solids in the near infrared, visible, vacuum ultraviolet, and soft $x$-ray region (using synchrotron radiation): transition metal alloys and compounds (e.g.,. FeTi), transition metalhydrogen systems, noble metals, II, and II-VI semiconductors. Photoemission into liquid electrolytes, electrochemical modulation spectroscopy, microspectro-electrochemistry, and photoelectrochemistry: binary alloys susceptible to localized corrosion, surface excitation, and adsorption phenomena on model systems (e.g., noble metals). Photoelectrolysis. Infrared and visible emissivity at high temperatures of materials suitable for photothermal conversion and other solar energy applications; transition-metal alloys, Al-Fe alloys, superalloys. Optical properties of rare earth chelates for solar cell applications. Raman scattering and $x$-ray diffraction in aqueous solutions. HDO, $\mathrm{D}_{2} \mathrm{O}$ and rare earth chlorides and perchlorates. Raman scattering from adsorbates (hetercyclic amines on noble and transition metals). 
AMES LABORATORY

Solid State Physics Division -02- (Continued)

28. OPTICAL AND SURFACE PHYSICS THEORY

R. Fuchs, K. L. Kliewer,

J. Reyes

$\$ 157,500$

$02-3$

Optical properties of metals, semiconductors, and insulators; studies of surfaces, thin films, layered systems, small particles, and powders; effects of surface roughness, nonlocality, and local field corrections on optical properties; collective excitations: phonons, plasmons, and excitons. Photoemission with emphasis on effects associated with the presence of a surface, evanescent and surface states. Photoemission into liquid electrolytes and related catalytic, electrochemical, adsorption, and corrosion effects; anodic photocurrents; the liquidmetal interface. Solar energy studies: electrochemical photovoltaic cells, photolysis, high-temperature absorbers, and optical properties of phase-change materials for solar applications.

29. SUPERCONDUCTIVITY THEORY

$\$ 66,800$

$02-3$

E. H. Brandt, J. R. Clem,

R. A. Klemm, K. Machida

Properties of magnetic flux in type-I and type-II superconductors; induced voltages and energy dissipation due to flux motion, flux vortex nucleation, and surface pinning; behavior of arrays of nonparallel vortices; critical currents and flux pinning in inhomogeneous superconductors; instabilities; ac losses; the influence of reduced dimensionality on the superconducting properties of highly anisotropic systerns; new mechanisms for superconductivity in linear conductors; triplet superconductivity and its physical properties; static and dynamic properties of spin glasses.

30. MAGNETIC AND ELECTRONIC PROPERTIES OF SOLIDS THEORY

$\$ 135,700$

$02-3$

B. N. Harmon, S. H. LiU

Electronic properties of transition metals and compounds $\left(\mathrm{ScH}_{2}, \mathrm{YH}_{2}\right.$, $\left.\mathrm{ZrCl}, \mathrm{NaWO}_{3}, \mathrm{PtWO}_{3}\right)$. Theory of soft modes, phonon anomalies, charge density waves, and displacive lattice transformations and their relation to the electron-phonon interaction ana superconductivity (e.g., $\mathrm{Nb}, \mathrm{NbC}$, $\left.\mathrm{Zr}, \mathrm{Na}_{x} \mathrm{WO}_{3}\right)$. High temperature materials and properties including bonding, melting, and ion transport. Thermal fluctuation and energy transport in thin films ( $1 / f$ noise). Induced and intrinsic magnetization densities in metals ( $\mathrm{Gd}, \mathrm{Cr}, \mathrm{Pd}, \mathrm{Lu}$ ), compounds, and alloys, spin waves and other excitations in disordered magnetic systems: the d-f exchange interaction in rare earth-metallic materials. Modeling of the metal-electrolyte interface. 
AMES LABORATORY

Materials Chemistry Division -03-

J. D. Corbett - Phone: (FTS) 865-3086 or 515-294-3086

31. X-RAY AND NEUTRON CRYSTALLOGRAPHY

$\$ 214,000$

$03-1$

R. A. Jacobson, J. E. Benson,

B. J. Helland

Development of diffraction techniques and service facilities especially those designed for the novice user; indirect methods and refinement techniques; structural studies of intercalated transition metal dichalcogenides; metal complex structures with emphasis on mode? homogeneous catalysts and polymetal species; intramolecular solid state interactions which modify properties of parent species; diffraction studies of coal-quantitative identification of mineral species on-line; radial distribution function analysis of coal's amorphous scattering.

32. METAL-METAL BONDING IN SOLIID STATE

$\$ 129,000$ 03-1 MATERIALS

J. D. Corbett

Synthesis and characterization of new types of reduced inorganic compounds a.t high temperature (e.g., of $\mathrm{Sc}, \mathrm{Ti}, \mathrm{Zr}$, Nb, Mo, rare earths); extended metal-metal bonding; catalytic activity of new types of reduced compounds; stress-corrosion-cracking by zirconium iodides; homopolyatomic ions (e.g., of $\mathrm{Ge}, \mathrm{Sn}, \mathrm{Sb}, \mathrm{Bi}, \mathrm{Te}$ ); ionic intermetallic phases..

33. CHEMISTRY OF HEAVY TRANSITION METALS

$\$ 147,000$

03-1

R. E. McCarley, V. Katovic

Chemistry of heavy transition elements, especially Nb, Ta; Mo, W, controlled synthesis and characterization of compounds with strong metal-metal bonds in dimers, clusters, and extended structures; electronic structure related to properties and reactions of metal clusters; catalytic applications; compounds with unusual reactivity.

34. 'METALS FROM "FLY ASH

G. Burnet, M. J. Murtha

$\$ 115,000$

$03-2$

N. K. Roy.

Recovery of iron oxide from power plant fly ash by magnetic separation and of alumina using calcination, selective chlorination and hydrochemical processing:

35. LIQUID METALS

$\$ 57,000$

R. G. Bautista

Heat capacities and heat content of liquid Cu-Ce alloys. Correlation and prediction of liquid alloy heat contents. 
AMES LABORATORY

Materials Chemistry Division -03- (Continued)

36. EMITTANCE PROPERTIES OF MATERIALS

$\$ 41,000$

$03-2$

AT HIGH TEMPERATURES

R. G. Bautista

Normal spectral emittance of liquid iron, nickel, and $\mathrm{Cu}-\mathrm{Ce}$ alloys.

Practical temperature measurements by optical pyrometry.

37. CORROSION AT HIGII TLMPLRATURES

$03-2$ R. R. Rạutistia

Modelling of corrosion of high chromium alloys by $\mathrm{O}_{2}$ and $\mathrm{SO}_{2}$ including scale resistance and chemical reactions. To be initiated in FY 1979.

38. PARTICULATE PROCESSING.

$\$ 107,000$

03-2

L. E. Burkhart

Particle and fluid motion in mass transfer systems by high-speed photography; experimental techniques, and mathematical modeling; transport near interfaces, especially drops, bubbles, and solid particles; theoretical analysis, kinetics and control of particle size distribution, growth rate, and morphology in operations involving the preparation of ceramic powders; reaction kinetics and mixing in multicomponent mass transfer systems involving chemical reactions with emphasis on correlation between theory and experiment.

39. - HIGH TEMPERATURE CHEMISTRY

H. F. Franzen, A. V. Hariharan

$\$ 167,000$

03-3

J. Anderegg, C. E. Myers

Structure and bonding in refractory and corrosion-resistant compounds, particularly metal-rich transition metal chalcogenides, phosphides and aluminides; high temperature stability, phase equilibria and electronic properties; X-ray photoelectron spectroscopy and band structures of refractory solids; X-ray diffraction and mass spectrometry at high temperatures.

40. SURFACE CHEMISTRY AND CATALYSIS

$\$ 293,000$

03-3

R. S. Hansen, B. C. Gerstein,

K. G. Baikerikar, T. Taki

Heterogeneous catalysis by metals and metal oxides. Reactions at clean surfaces associated with coal liquifaction and gasification. Field emission, flash desorption, LEED and Auger spectroscopy. Single crystal face catalysis. Electrical double layer properties and their alteration by adsorption. Mechanical flow properties of interfaces. Pulse and multiple pulse NMR studies of surface sites and of electronic structures of adsorbed molecules on high surface area substrates. Heteronuclear dipolar oscillation NMR and geometries of absorbed molecules. 
ARGONNE NATIONAL LABORATORY

9700 South Cass Avenue

Argonne, Illinois 60439

Materials Science Division -01-

B. R. T. Frost - Phone (FTS) $972-4928$ or 312-972-4928

F. Y. Fradin - Phone (FTS) $972-4966$ or 312-972-4966

41. ALLOY PROPERTIES.

D. J. Lam, G. S. Knapp,

$\$ 284,000$

$01-1$

B. W. Veal, Jr., P. Jena,

H. Chen

Fundamental studies of electronic structure and its relationship to physical properties and bondings in alloys and compounds. XPS and extended $x$-ray absorption fine structure studies of the structural and electronic properties of $\mathrm{Fe}_{2} \mathrm{O}_{3}$ in sodium disilicate glass. XPS study of bonding of uranium in sodium-silicate glasses and the study of electronic structure and hydrogen bonding in transition metal hydrides. Theoretical study of conduction electron polarization in PuP. Theoretical investigation of the systematics in the Knight shifts at nonmagnetic sites in rare-earth-, transition- and actinideGroup V A elements.

42. SCATTERING STUDIES

M. H. Mueller, G. H. Lander

$\$ 673,000$

$01-1$

Magnetic, electronic and structural properties of actinide materials using neutron and x-ray scattering. Particular emphasis on measurements on single crystals using both elastic and inelastic neutron scattering techniques. Structural investigations of $\mathrm{Pd}$ and $\mathrm{Nb}$ hydrides and deuterides, and studies of storage metal hydrides of the type $\mathrm{LaNi}_{5} \mathrm{H}_{6}$. Programs at the ANL pulsed neutron source involving both structural and dynamical studies; e.g., application of high-resolution powder techniques to perovskites and complex hydrides, inelastic neutron experiments on $\mathrm{UO}_{2}$.

43. ACTINIDE MATERIALS

M. B. Brodsky, A. J. Arko

$\$ 252,000$

$01-1$

Electronic structure of actinide metals, alloys and compounds; low temperature specific heat; electrical resistivity; and magnetic susceptibility of metallic actinides to study spin fluctuations and band magnetism; de Hass van Alphen effect in actinide intermetallic compounds to determine electronic structure. 
ARGONNE NATIONAL LABORATORY

Materials Science Division -01- (Continued)

44. PROPERTIES OF HIGH-TEMPERATURE MHD MATERIALS

$\$ 198,000$

D. J. Lam, A. T. Aldred,

B. W. Veal, Jr., D. P. Karim

Experimental and theoretical studies of the lattice and electronic structure of ceramic materials for very high temperature applications; electrical conductivity, Seebeck coefficient, and magnetic susceptibility studies of strontium-doped lanthanfum chromite; systematic XPS studies of $\mathrm{LaXO}_{3}$-type compounds ( $X=3 \mathrm{~d}$ transition element); theoretical study of the final-state multiplet structure of $3 d$ electronic conflgurations in cubic crystal environment; relativistic molecular cluster model calculation of XPS spectra of $\mathrm{LaXO}_{3}$-type compounds.

45. CATALYSIS AND SURFACE STUDIES

$\$ 191,000$

$01-1$

M. B. Brodsky, S. D. Bader,

T. W. Orent

Use of intermetallic compounds as catalysts; electronic and atomic structure of intermetallic compound and transition metal surfaces; effects of gases on surface properties, low energy electron diffraction; $x$-ray photoelectron spectroscopy; electron loss spectroscopy; and Auger electron spectroscopy.

46. CORROSION STUDIES

M. B. Brodsky, R. S. Averback,

O. K. Chopra, T. F. Kassner,

K. Natesan, P. R. Okamoto,

R. L. Lyles, Jr., L. E. Retin

In-situ studies of alloy corrosion in the High Voltage. Electron Microscope; studies of corrosion by low energy electron diffraction, Auger electron spectroscopy, x-ray photoelectron spectroscopy, electron loss spectroscopy, kinetic studies and ion-beam analysis; alloy modification by ion beam implantation for corrosion studies; effects of stress on oxidation and sulfidation. To start in FY 1979.

47. CONSTITUTIVE RELATIONS

U. F. Kocks, J. L. Routbort,

A. P. L. Turner, T. Hasegawa

$\$ 264,000$

$01-2$

Theoretical and experimental search for unifying constitutive relations describing the kinetics of flow and strain hardening, recovery and stress relaxation, creep and fatigue, over a wide range of strain rates, especially at high temperatures. Characterization of the dislocation structure of deformed specimens by TEM and $x$-ray scattering techniques. Materials currently investigated: stainless steels, nickel alloys, aluminum, copper, MgO. Application of results to theory of plastic instabilities. 
ARGONNE NATIONAL LABORATORY

Materials Science Division -01- (Continued)

48. STRENGTH OF ALLOYS

U. F. Kocks, R. A. Mulford,

R. 0. Scattergood, R. B. Schwarz

Theoretical and experimental investigation of strengthening mechanisms, especially solution hardening at high temperatures, using mechanical tests, internal friction techniques, and computer simulation. Dislocation theory, including dynamics and statistics. Materials currently. investigated: various nickel, aluminum, and copper base alloys.

49. METAL PHYSICS :

R. W. Siegel, A. S. Berger,

$\$ 880,000$

$01-3$

E. S. Fisher, M. J. Fluss,

N. Q. Lam, J. N. Mundy,

S. J. Rothman, L. C. Smedskjaer,

D. J. Westlake, J. F. Miller

R. P. Gupta

The nature and physical properties of atomic defects and their interactions in solids; the atomic mechanisms of diffusion in solids; the nature and properties of metal-hydrogen systems; investigations of atomic and defect diffusivities, equilibrium defect concentrations, atomic defect interactions with one-another, with solute atoms, and with surfaces and interfaces, hydrogen solubility limits and the properties of metal-hydrogen systems; studies of metals, including bcc refractory metals, alloys and intermetallic compounds using positron annihilation spectroscopy, tracer diffusion, resistometry, transmission-electronand field-ion-microscopy, neutron and X-ray diffraction, and ultrasonicwave propagation.

50. SUPERCONDUCTIVITY

F. Y. Fradin, G. S. Knapp,

$\$ 243,000$

$07-3$

$P$. Jena, $H$. Chen

Theoretical and experimental research on the electron-phonon interaction with changes in the electron and phonon spectra in various classes of high Tc intermetallic compounds; NMR and Mossbauer effect studies of the interaction of magnetic ions and the superconducting electrons in ternary rhodium-borides and ternary molybdenum-chalcogenides; EXAFS investigation of anharmonic behavior and the effects of defects on the superconducting properties of the $A-15$ compound $V_{3} G a$; heat capacity and magnetic susceptibility studies of the electron-phonon coupling in $\mathrm{C}-15$ compounds. Theoretical investigation of isotope effect in $\mathrm{PdH}(\mathrm{D})$ superconductors. 
ARGONNE NATIONAL LABORATORY

Materials Science Division -01-(Continued)

51. BASIC CERAMIC STUDIES

N. L. Peterson, W. K. Chen

$\$ 399,000$

$01-3$

J. Faber, Jr., M. D. Rechtin,

D. Wolf, and K. K. Kim

Diffusion mechanisms and point defect studies in metal oxides as a function of oxygen pressure at high temperature using tracer diffusion, NMR, Mossbauer, and differential dilatometry techniques; ionic transport mechanisms in sodium beta-alumina; defect-solute interactions in oxides; grain-boundary diffusion in oxides; theoretical studies of kinetic processes in metal oxides and solid electrolytes; neutron and $x$-ray scattering studies of order-disorder transition in superionic conductors and defect clustering in metal oxides, amorphous alloys and glasses including effects of helium using electron microscopy; oxidation processes in nonstoichiometric oxides using the environmental cell in the HVEM.

52. SOLAR MATERIALS

$01-3$

D. J. Lam, P. P. Pronko,

M. D. Rechtin, B. W. Veal, Jr.

Fundamental studies of structural and electronic properties of semiconducting materials for possible photovoltaic applications: transmission electron microscopy and nuclear backscattering study of kinetics of regrowth of ion-implanted silicon; ultra-violet and x-ray photoemission spectroscopy study of the electronic band structure of silicon-hydrogen ailloys; extended x-ray absorption fine structure study of near neighbor environment of germanium-hydrogen alloys; and the theoretical study of electronic band structure of silicon-hydrogen alloys. To start in FY 1979.
53. NEUTRON IRRADIATION STUDIES
$\$ 564,000$
$01-4$
T. H. Blewitt, R. C. Birtcher,
B. S. Brown, M. A. Kirk, Jr.
B. A. Loomis, H. Lefakis

Defect cascade production at liquid helium temperature and subsequent annihilation and clustering; flux pinning in superconductors by defect cascades; resistance and critical temperature changes in irradiated A-15 superconductors; characterization of neutron spectrum and damage energy distributions; neutron sputtering, replacement collision sequences; effect of defect saturation on length and resistivity changes; mechanical properties and swelling due to voids in $\mathrm{Nb}$ as a function of ion dose, temperature and oxygen content; void nucleation in nickel; radiation enhanced creep; target and irradiation facility. design for the Intense Pulsed Neutron Source (IPNS); radiation sources include the CP-5 low temperature facility and the $4 \mathrm{MeV}$ Dynamitron. 
ARGONNE NATIONAL LABORATORY

Materials Science Division -01- (continued)

54. CHARGED-PARTICLE IRRADIATION STUDIES

K. L. Merkle, R. S. Averback,

$\$ 632,000 \quad 01-4$

R. Benedek, R. L. Lyles, Jr.

W. B. Jager

Damage function studies by ion irradiation, HVEM, and field ion microscopy; correlations of $14 \mathrm{MeV}$ and fission neutron damage with heavy ion damage in metals; properties of self-interstitial atoms; studies of energy density effects in displacement cascades and sputtering; TEM and HVEM investigations of displacement cascades in binary alloys; interatomic potential calculations; diffusion of implanted hydrogen and helium in metals; defect cluster formation by HVEM. Major experimental facilities: $300 \mathrm{keV}$ heavy ion accelerator and High Voltage Electron Microscope with ion interface for future $2 \mathrm{MeV}$ ion accelerator and low energy ion injector.

55. KINETIC STUDIES
H. Wiedersich, B. H. Hall
F. V. Nolfi, Jr., P. R. Okamoto,
D. I. Potter, A. Taylor
L. E. Rehn, A. A. Sagues

$\$ 729,000$

$01-4$

Investigations into forces and mechanisms that lead to the formation of defect aggregates and precipitates and other inhomogeneous distributions of atoms in solids without and with displacement-producing irradiation; agglomeration of gaseous compounds, e.g., $\mathrm{CH}_{4}$ which can lead to hydrogen attack in pressure vessels used in coal gasification; solute segregation to voids and free surfaces during irradiation; defect-solute complexes; effects of irradiation on the microstructure of two-phase alloys dynamic dissolution and reprecipitation; the effect of fine precipitate dispersions, solute additions, and helium on void and dislocation loop formation during ion bombardment; irradiation creep; radiation sources include $300 \mathrm{KeV}$ heavy-ion accelerator, $4 \mathrm{MeV}$ Dynamitron -- $2 \mathrm{MeV}$ Van De Graaff Dual-ion-beam Facility, high-voltage electron microscope, and $2 \mathrm{MeV}$ ion accelerator (being procured) for in-situ HVEM studies and ion beam analysis.

56. HIGH VOLTAGE ELECTRON MICROSCOPE-

$01-4$

TANDEM FACILITY

R. L. Lyles, Jr., A. Taylor,

P. P. Pronko

Operations and development of $1.2 \mathrm{MeV}$ High Voltage Electron Microscope Facility with ion beam interface; specimen stages for heating $\left(1000^{\circ} \mathrm{C}\right)$, cooling $\left(9^{\circ} \mathrm{K}\right)$, straining, specific gaseous environments, in situ ion irradiations with $300 \mathrm{keV}$ ion injector and a $2 \mathrm{MeV}$ Tandem Ion Accelerator which will be operational in 1981; establishment of an external HVEM User Program. Operation to begin in FY 1979. 
ARGONNE NATIONAL LABORATORY

Materials Science Division -01- (continued)

57. NONDESTRUCTIVE EVALUATION

$\$ 65,000$

$01-5$

M. H. Mueller, E. S. Fisher

K. J. Reimann

Examination of voids, precipitates, and strain fields from impurities in materials by neutron small-angle scattering. Design responsibility for small angle instrument at IPNS. Use of bulk-wave ultrasonics. to provide quantitative description of size, shape, and orientation of flaws. Detection of near-surface defects using precise measurements of high frequency ultrasonic surface wave velocities.

58. EROSION AND WEAR

A. P. L. Turner, J. L. Routbort

$\$ 90,000$

$01-5$

R. 0. Scattergood, T. H. Kosel

Experimental investigation of erosion mechanisms by controlled particle impacting and SEM/TEM. Characterization of damage as it accumulates during creep and fatigue. Materials currently investigated: nickel alloys, high-strength steel, Mg0, silicon-carbide ceramics. 
ARGONNE NATIONAL LABORATORY

Solid State Science Division -02-

D. L. Price - Phone (FTS) 972-5493 or 312-972-5493

59. PULLSED NEUTRON SOURCE DEVELOPMENT

$\$ 350,000$

$02-1$

J. Carpenter, R. K. Crawford,

R. Kleb, R. Kustom,

J. Simpson, N. Swanson

The design and operation of prototypes of the proposed Intense Pulsed Neutron Source (IPNS) and their use for development and testing IPNS instrumentation. The unique pulse source advantages of a large epithermal flux and short pulse width will be exploited for elastic scattering studies of large momentum transfers (up to $80 \mathrm{~A})$ and for inelastic scattering at large energy transfers. Studies also include research and development activity in support of rapid-cycling high-intensity synchrotrons as pulsed-source.

drivers. Materials and phenomena to be investigated include superconductors, hydrogen-storage materials, candidate MHD electrode materials, solid electrolytes, one-dimensional conductors and amorphous materials, and magnetic processes such as Stoner excitations.

60. NEUTRON SCATTERING STUDIES

$\$ 1,243,000$

$02-1$
T. Brun, G. Felcher,
R. Kleb, C. Pelizzari,
S. Sinha, J. Jorgensen,
T. Postol, K. Skold,
P. Vora

Neutron inelastic scattering and neutron diffraction are used to study the dynamics and structure of dense fluids and amorphous solids, lattice excitations in crystals, magnetic systems, phase transitions and mechanical properties at high pressures, ferroelectrics, dynamics of hydrogen in snlid and liquid metals, and molecules adsorbed on surfaces. Steady-state and time-of-flight techniques are employed at the CP-5 research reactor, while increasing use is being made of the prototype pulsed source based on proton spallation reactions. A major effort is devoted to development of instrumentation for use with pulsed neutron sources such as IPNS. Facilities include a thermal neutron time-of-flight spectrometer, triple-axis spectrometer, timeof-flight diffractometer, a two-axis diffractometer, as well as highpressure and high-magnetic-field facilities. Current areas of interest include the structure and lattice dynamiccs of hydrides; the dynamics of amorphous As and liquids including $\mathrm{He}^{3}$ and $\mathrm{Ar}^{36}$; meiting of crystalline solids; the structure of dense molecular gases including $\mathrm{N}_{2} \mathrm{O}_{2}, \mathrm{CO}_{2}$ and $\mathrm{C}_{2} \mathrm{H}_{2}$; phase transitions in ferromagnetics; dynamics of superconductors and solid electrolytes; crystal-field interactions and magnetic properties of transition metals and alloys and of rare-earth intermetallics; magnetic. scattering in magnetically ordered systems and spin glasses; high-pressure diffraction and compressibility measurements of metals, ionic crystals, ice and high-temperature ceramics. 
ARGONNE NATIONAL LABORATORY

Solid State Science Division -02-

61. MATERIALS PREPARATION AND

CHARACTERIZATION

$\$ 170,000$

$02-2$

S. Susman, D. Hinks

Preparation of research samples of metal, insulator and semiconductor single crystals with documented physical and chemical properties; investigation of mechanisms involved in purification and the development of clean-room facilities and crystal growth techniques, including crystal growth of high-temperature materials and purification with halogen and hydrohalogen gases. Materials of current interest include rare-earth compounds with the $\mathrm{CsCl}$ structure for neution scattering and magnetic studies, refractory oxides such as $\mathrm{Y}_{2} \mathrm{O}_{3}$ for high-temperature materials research, rare-earth salts such as yttrium ethylsulfate: ytterbium for nuclear polarization experiments, and the alkali halides and cyanides in the orthorhombic phase.
62. DEFECTS IN NONMETALLIC SYSTEMS
$\$ 195,000$
$02-2$
P. Yuster, C. Delbecq,
S. Marshall

Study of defects and impurities in nonmetallic crystais and the processes caused by exposure of insulators to ionizing radiation. Major areas of activity include: the excitation, tunneling recombination and luminescence processes in heavy-metal impurities in insulators; structure and reorientation dynamics of covalently bonded molecular-ion centers ( $\left.\mathrm{F}_{\overline{2}}, \mathrm{Cl}^{-}, \mathrm{FCl}_{\overline{2}}, \mathrm{BrCl}^{-}\right)$in alkali halldes; ESR studies of $F z$ centers in alkali flyorides, and manganese in calcite; and production and motion of interstitial molecular-ion species ( $\mathrm{FCl}^{-}, \mathrm{BrCl}^{-}$and $\left.\mathrm{ICl}^{-}\right)$in alkali halides.

63. LOW TEMPERATURE STUDIES

P. Roach, R. Webb

$\$ 209,000 \quad 02-2$

Studies of properties of quantum liquids and solids at very lnw temperature. Current activities and areas of interest include: properties of superfluid phases of $\mathrm{He}^{3}$; sound propagation, ion mobility and "texture" in new $\mathrm{He}^{3}$ phases; adiabatic cooling by nuclear demagnetization; development of SQUID NMR techniques for susceptibility measurements in the low millikelvin range; static and dynamic susceptibility of $\mathrm{He}^{3}$ phases; and the search for triplet or P-wave superconductivity in metals. 
ARGONNE NATIONAL LABORATORY

Solid State Science Division -02-

64. SUPERCONDUCTIVITY STUDIES

K. Gray, C. Falco,

H. Willemsen

$\$ 308,000 \quad 02-2$

Research in nonequilibrium processes in superconductors and the relation between metallurgical and superconducting properties in type II materials. Current activities include: studies of quantum interference effects; magnetic structures and transport properties of superconductors using tunnel junctions; superconducting energy gap enhancement by microwaves; thermoelectric transport coefficients in the superconducting state; the preparation of high $\mathrm{T}_{C}$ materials such as $\mathrm{Nb}_{3} \mathrm{Sn}$ by high-rate sputtering and studies of flux pinning, critical current density and radiation damage in these new materials; the development of high-temperature SQUIDS and superconducting switches; and studies of superconducting transistor analogues.
65. CATALYSIS AND SURFACE STUDIES
$\$ 274,000$
$02-2$
D. O'Reilly, G. Crabtree,
L. Iton, G. Felcher,
R. Webb

The dynamics and properties of atoms and molecules adsorbed on surfaces as studied with NMR, ESR and ENDOR spectroscopy; studies of adsorbed species and catalysis in the zeolites, silica gel, the zinc and copper "chromite" systems, and supported metal catalysts; use of benzene and transition metal ions as a probe of active catalytic surfaces; atomicbeam scattering from surfaces; magnetic field effects on surface reactions; and SQUID susceptibility and NMR measurements.
66. ELECTRONIC, MAGNETIC AND LATTICE PROPERTIES
G. Crabtree, B. Dunlap,
H. Kierstead, G. Shenoy,
D. Dye, J. Friedt

$\$ 341,000$

$02-2$

Studies of the Fermi surface in metals, alloys and intermetallic compounds via the de Haas-van Alphen effect; measurement of conduction-clectron effective masses and g-factors; studies of the scattering of electrons by impurities, lattice defects and local moments. Materials of interest include $\mathrm{Nb}, \mathrm{Pt}$, and $\mathrm{Pd}$, actinide materials such as $U_{3} A_{4}, U G_{3}, U I r_{3}$ and $\alpha-U$ and rare-earths and superconducting $\mathrm{A} 75$ compounds such as $\mathrm{Nb}_{3} \mathrm{Sb}$. Mossbauer effect studies of high-field ternary superconductors such as $\mathrm{SnMo}_{6} \mathrm{~S}_{8}$ and related materials; crystal field and spin-relaxation effects in lanthanide and actinide compounds including $\mathrm{Yb}_{2} \mathrm{Ti}_{2} \mathrm{O}_{7}, \mathrm{Dy}(\mathrm{OH})_{3}$; defect pinning in Eu-Mg alloys and quadrupole interactions in $\mathrm{Hf}-\mathrm{Zr}$ alloys. Structural and electronic properties studies of the rare-earth hydrogen-bearing materials $\mathrm{ZrH}_{x}, \mathrm{HoH}_{2}, \mathrm{HoD}_{2}, \mathrm{ErH}_{2}, \mathrm{DyH}_{2}$ and $\mathrm{DyD}_{2}$ and rare-earth dtransition metal al Toys including $\mathrm{Th}_{7} \mathrm{Fe}_{3}$ and $\mathrm{Th}_{7} \mathrm{Fe}_{3} \mathrm{H}_{30}$. EXAFS studies of small metal molecules isolcated in inert gas matrices. 
ARGONNE NATIONAL LABORATORY

Solid State Science Division -02- (continued)

67. LIGHT SCATTERING AND ACOUSTICS

$\$ 53,000$

$02-2$

P. Roach, C. Falco,

K. Miyano

A program to study low-frequency mechanical and molecular statistical properties of liquids and solids employing light scattering, sound and surface waves. Research areas include ultrasonic propagation and Brillouin scattering studies of shear wave propagation in liquid crystals; wave propagation in monomoleçular films on fluids; and development of a tunable Josephson junction source of submillimeter radiation. Materials of interest include P-azoxyanisole and films of alkylalcohols and lecithins.

68. SOLAR MATERIALS

L. Guttman, J. McMillian

D. Y. Smith

$\$ 236,000 \quad 02-2$

A multi-disciplinary study of the properties of materials with solar applications. Topics include: study of crystallization and annealing processes in amorphous thin-film semiconductors for optically selective surfaces; properties of heat mirrors; investigation of the random network model of amorphous materials; electronic structure of pure and hydrogenated amorphous silicon; theory of bulk and surface optical properties; and sum-rule constraints on attainable optical properties.

69. ELECTRONIC AND TRANSPORT PROCESSES

IN REFRACTORY OXIDES

$\$ 211,000$

$02-2$

C. Delbecq, D. Hinks,

J. Jackson, S. Marshall,

W. Primak, S. Susman,

P. H. Yuster

Studies of refractory materials including the preparation and characterization of research samples of high-temperature oxides including $\mathrm{Y}_{2} \mathrm{O}_{3}$; optical and ESR studies of the motion and trapping of electrons and holes and glow-tube studies of ionic transport in conducting oxides and silicates; high-temperature transport measurements. Materials of interest include $\mathrm{Y}_{2} \mathrm{O}_{3}, \mathrm{Al}_{2} \mathrm{O}_{3}$, yttrium aluminum garnet, $\mathrm{A}_{2} \mathrm{O}_{3}: \mathrm{Cr}_{2} \mathrm{O}_{3}$ and silicate glasses. 
ARGONNE NATIONAL LABORATORY

Solid State Science Division -02- (continued)

70. SOLID STATE THEORY

$\$ 470,000$

$02-3$

T. Arai, T. Gilbert,

D. Koelling, A. Rahman,

J. Robinson, P. Vashishta,

C. Hsu, K. Lau

Molecular dynamics and the computer simulation of solids and liquids; electronic structure and properties of metals and intermetallic compounds; electron-hole plasmas in semiconductors; structure and interaction of atoms in condensed matter; the electron-phonon interaction; superconductivity in transition metals and alloys; theory of magnetism and metal-nonmetal transitions; surface phenomena including surface structure, physisorption, chemisorption and catalysis; electronic structure of perovskites; and theoretical studies of superionic conductors including $\mathrm{CaF}_{2}$ and $\alpha-\mathrm{AgI}$.

\section{PARTICLE SOLID INTERACTIONS}

J. Jackson, W. Primak

$$
\$ 260,000 \quad 02-4
$$

Production and recovery of radiation damage by ions, electrons and neutrons in metals and insulators; elementary defects and their interactions; defect production and trapping rates; properties of divacancies and self-interstitial atom clusters and associated strain fields. Metals under study include nickel and the soft superconductor indium. Studies of electromigration at high temperatures in glasses and nonmetal MHD electrodes; studies of surface radiation damage in insulators including work on $\mathrm{Al}_{2} \mathrm{O}_{3}, \mathrm{Si}_{3} \mathrm{~N}_{4}, \mathrm{SiC}, \mathrm{B}_{4} \mathrm{C}, \mathrm{ZrO}_{2}$, stabilized zirconia, vitreous silica, and glasses; studies of optical and electrical effects and dimensional changes; stress formation and relief migration of implanted ions to surfaces and voids; and blister formation and spallation.

72. ENGINEERING PHYSICS

$$
\text { C. Falco }
$$

Studies of the feasibility of using SQUID magnetometers for geological prospecting for hydrocarbon deposites; high-temperature SQUIDS. To be started in FY 1979. 
ARGONNE NATIONAL LABORATORY

Chemistry Division -03-

P. R. Fields - Phone (FTS) $972-3570$ or $312-972-3570$

73. NEUTRON SCATTERING, X-RAY AND EXAFS

$\$ 640,000$

03-1

STRUCTURAL STUDIES OF MATERIALS

S. W. Peterson, M. Atoji,

J. M. Williams, A. H. Reis, Jr.,

E: G. Sherry, A. J. Schultz,

J. Roziere, P. Johnson,

R. W. Broach, R. K. Brown,

M. Depp, D. Gerrity;

J. Kelber, T. Lynch,

T. Morrison, K. Stearley

The major goals are to develop new materials with important energyrelated properties and to develop property-structure correlations. Utilizing neutron and $x$-ray diffraction techniques, emphas is is on inorganic and organic compounds with high anisotropic conductivity, on hydrogenation and methanation catalysts, and on magnetic-moment structural studies of rare-earth metals, alloys, and compounds, plutonium and uranium carbides and oxycarbides, and sodium-tungsten bronzes. Extended $x$-ray absorption fine structure (EXAFS) analysis is being used to investigate graphite intercalates and Fischer-Trophsch catalysts. A single-crystal, pulsed-neutron diffractometer using white-beam Laue techniques and time-of-flight analysis is being developed.

74. CALORIMETRY AND THERMODYNAMICS
H. E. Flotow, D. W. Osborne

Heat capacity measurements and determination of entropies, enthalpies and Gibbs energies from 0.1 to $350 \mathrm{~K}$ for use in thermodynamic calculations at higher temperatures; emphasis is placed on inorganic compounds of importance in energy systems; compounds currently being studies are: has recentiy been completed, and measurements on $\mathrm{LaNi}_{5} \mathrm{Ha}_{\mathrm{x}}, \mathrm{Cs}_{3} \mathrm{CrO}_{4}$ and 3.75 $\mathrm{LaCrO}_{3}$ are also planned for : $\mathrm{FY} 1979$. 
ARGONNE NATIONAL LABORATORY

Chemistry Division -03- (continued)

75. PHYSICAL AND SURFACE CHEMISTRY

D. M. Gruen, A. Krauss,

$\$ 400,000$

$03-3$

R. L. McBeth, M. Mendeisohn,

D. Steinbruchel, R. B. Wright,

M. -B. Liu

Experimental and theoretical studies of charge transfer processes at surfaces; excitation and deexcitation mechanisms of sputtered atoms, ions and molecules; effects on secondary ion fractions of monolayer coverages of oxygen on metals as monitored by simultaneous Auger analysis, energy and analyzed secondary ion mass spectroscopy and in situ XPS. Secondary photon and ion emission; determination of ionization coefficients at surfaces from measured energy distributions of secondary ions and neutrals; development of new techniques for measuring energy distributions of sputtered neutrals via Doppler shifted laser fluorescence spectroscopy; structural, compositional and other factors determining the thermodynamic stabilities of intermetallic hydrides; effects of the cubic to hexagonal transformation on the hydrogen sorption properties of $\mathrm{AB}_{5}$ compounds; preparative methods for matrix isolated "naked" metal clusters and their cryochemistry; photochemistry of matrix isolated metal atoms and molecules of interest for catalysis.

76. HIGH-TEMPERATURE MATERIALS CHEMISTRY

$$
\$ 436,000
$$

R. J. Thorn, R. J. Ackermann,

G. E. Murch, E. G. Rauh,

W. - Y. Howng, G. H. Winslow,

J. Ziomek

High-temperature thermodynamic, transport and $x$-ray and electronic structural properties of innrganic, ceramic and metallic materials with special emphasis on the behavior of materials in energy systems such as LMFBR, HTGR, GCTBR, MHD and CTR; fundamental concepts of high-temperature chemistry in terms of lattice defects, phonon-electron interactions, and altered valent or aliovalent cations in nonstoichiometric phases; measurements of partial molar enthalpies and entropies of sublimation, phase equilibria, electronic structures with photoelectron spectroscopy, high-temperature x-ray diffraction and diffusion in uranium carbides and oxides; investigations of chemistry of condensation, especially of metastable phases and in relation to processes in energy systems; calculations related to defects and valence states through lattice potentials and ionic character of bonding. Monte Carlo evaluation of partition functions and computer simulation of diffusion in nonstoichiometric phases; studies of molecular ions present in thermal excursions in reactors; evaluation of thermochemical systematics and data of lanthandie and actinide phases; materials studied: oxides and carbides of uranium, rare-earth and actinide fluorides, $\mathrm{\beta}$-aluminas, $\mathrm{ZrO}_{2}$, $\mathrm{Y}_{2} \mathrm{O}_{3}, \mathrm{ThO}_{2}, \mathrm{LaCrO}_{2}$ with $\mathrm{Mg}$ and $\mathrm{Sr}, \mathrm{Cs}_{2} \mathrm{O} . \times \mathrm{SiO}_{2}, \mathrm{gl}$ asses and slags. 
ARGONNE NATIONAL LABORATORY

Chemical Engineering Division -03-

L. Burris - Phone: (FTS) $972-4314$ or 312-972-4314

F. Cafasso - Phone: (FTS) $972-4542$ or $312-972-4542$

\section{LIQUID METALS CHEMISTRY}

$\$ 245,000$

03-2

V. A. Maroni, E. Veleckis,

W. Calaway

Measurement of thermodynamic and transport properties of liquid alkali metals and their solutions; phase diagrams and solution thermodynamics of $\mathrm{Li}-\mathrm{Al}-\mathrm{H}, \mathrm{Li}-\mathrm{Pb}-\mathrm{H}, \mathrm{Li}-\mathrm{Si}-\mathrm{H}$, and $\mathrm{Ca}-\mathrm{Ni}-\mathrm{H}$ systems by a tensimetrictitration method; solubilities of $\mathrm{Li}_{2} \mathrm{O}$ and $\mathrm{Li}_{2} \mathrm{C}_{2}$ in liquid lithium; analysis of the chemical interactions in the Tithium-carbon-nitrogen system; distribution of oxygen, nitrogen, and carbon between liquid lithium and selected austenitic and refractory alloys by resistivity techniques; surface interactions of lithium with refractory metals and alloys; corrosion mechanisms of refractory metals and alloys in liquid metals.

78. CHEMISTRY OF MATERIALS

$\$ 350,000$

$03-2$

R. Kumar, B. Holt,

B. Hubble, H. R. Isaacson,

S. Johnson

Research on chemistry of sulfate and nitrate airborne particles and their formation mechanisms using stable isotope-ratio analysis; development of methodology and instrumentation for aerosol characterization as functions of size, time, and spatial variations by GC-FID methods and by Fourier-Transform infrared spectroscopy; study of kinetics of sulfur fixation by minerals (e.g.; dolomite) and of the regeneration of active material from sulfated product with emphasis on mechanism of the reactions.

79. PHYSICAL CHEMISTRY OF ELECTRO- $\quad \$ 750,000 \quad 03-2$

7. Nagy, C. Melendres,

M. Blander, M. Saboungi

Electrochemical studies of processes occurring at cell electrodes and in electrolytes with emphasis on kinetics and mechanisms in the lithium aluminum/ $\mathrm{LiCl}-\mathrm{KCl} / \mathrm{metal}$ sulfide cells and other electrochemical systems; study of metal ( $\mathrm{Fe}, \mathrm{Co}, \mathrm{Ni}$ ) and sulfide (FeS, NiS) dissolution/deposition reactions in molten salts by galvanostatic double-pulse and rotating-disc electrode techniques, respectively; thermodynamic measurements on lithium and sodium alloys emphasizing systems that show promise as battery electrodes (e.g., LiAlMg, LiMgCa); prediction of thermodynamic properties of ternary alloys and their phase diagrams using fundamental solution theories; extension of theories and experimental tests of extensions. 
ARGONNE NATIONAL LABORATORY

Chemical Engineering Division -03- (continued)

80. CALORIMETRIC STUDIES OF ENERGY RELATED MATERIALS

$\$ 130,000$

03-2

C. E. Johnson, W. N. Hubbard

G. K. Johnson, K. Kim

Measurement of thermochemical properties of organic and inorganic materials; prediction of enthalpies of formation, bond energies and molecular stabilities; enthalpies of formation of (1) heteroatomic polyaromatic molecules (e.g., benzofuran, thioxanthone, acridene, etc.) that are "building block molecules" of coal, and (2) compounds formed between glass systems (e.g., pollucite, scheelfte) and actinides or fission products that are considered for storage of nuclear wastes; enthalpies of hydrogenation of $\mathrm{AB}_{5}$-rare earth-transition metal alloys e.g., LaNi 5 ) and related compounds with aluminum (e.g., LaAlNif) that are potential hydrogen-storage systems. Emphas is is on developing relationships between heats of formation (and/or hydrogenation) and bond type, or structure, or both for predictive purposes; measurement techniques include oxygen, fluorine, and hydrogen-bomb calorimetry, hypergolic and flow calorimetry, and drop calorimetry to $2000^{\circ} \mathrm{C}$.

81. CHEMISTRY OF MOLTEN SALTS AND $\$ 115,000 \quad 03-2$ METALLURGICAL PROCESSES

M. Blander, Z. Nagy,

M. Saboungi, J. Settle

Prediction of thermodynamic properties and phase diagrams of molten salts using fundamental solution theories; application of theories to silicates and to solutions containing acid salts; extension of theories and experimental tests of extensions; measurement of the solubilities of transition metal and heavy metal sulfides in molten salts; study of sulfide-polysulfide equilibria and complexing of cations by anionic species in molten salts. Research on fundamental chemistry of energy saving environmentally acceptable metallurgical processes; chemistry of aluminum electrowinning from cryolite and from chloride melts; interactions of $\mathrm{Al}^{+3}$ and $\mathrm{O}^{=}$ions in chloride melts; electro-dissolution of sulfide ores. 
ARGONNE NATIONAL LABORATORY

Chemical Engineering Division -03- (continued)

82. SURFACE, STRUCTURAL, AND MORPHO-

LOGICAL STUDIES ON ELECTROCHEMICAL

STUDIES

S. Siegel, C. Melendres,

F. Cafasso

Studies at the submicroscopic and molecular levels of the various surface, structural, and morphological changes occurring during the operation of selected electrochemical systems; investigation of phenomena of electrocatalysis, electrode degradation, electrode wetting and dewetting, and dendrite growth; in-situ spectroscopic (Mossbauer and optical spectroscopy) and electrochemical investigations of electrocatalys is on model electrode/ electrolyte systems; research on mechanisms of oxide/molten salt electrodes and of corrosion of metals in molten salts.

83. HEAT TRANSFER MATERIALS AND

$\$ 96,000$

$03-2$

SALT VAPORS

L. Curtiss, D. Frurip,

M. Blander

Experimental and quantum mechanical studies on materials that exhibit strong or unusual bonding in the vapor and that may either have potential as heat-transfer fluids or can enhance gas phase mass transport; emphasis on the nature of vapor species, their equilibrium constants, their relative bond strengths and their structure; systems under investigation include trifluoroethanol pyridine, acetic acid, trifluoraecetic acid (TFA), binary mixtures of these compounds with water and high-temperature associated species formed between acid halides (e.g:, $\mathrm{BCl}_{3}, \mathrm{AlCl}_{3}$ ) and bases (e.g., $\mathrm{NH}_{3}, \mathrm{Ch}_{3} \mathrm{CN}$ ).

84. SEPARATIONS AND CATALYTIC PROCESSES

$\$ 40,000$

$03-2$

G. Papatheodorou

Research on spectroscopic and thermodynamic properties of vapor and vapor complexes, some having potential in separation processes and other applications; study of high-temperature complexes of transition, lanthanlde, and actinide halides with acidic gases (e.g., $\mathrm{Al}_{2} \mathrm{Cl}_{6}, \mathrm{Fe}_{2} \mathrm{Cl}{ }_{6}$ ); identification and characterization of vapor species by Raman and resonance Raman spectroscopy coupled with systematization of the thermodynamics of formation of the complexes principally by electronic absorption spectroscopy; study of the mechanisms of hydrngenation of polycylic aromatic hydrocarbons in low melting acidic molten salts (e.g., $\mathrm{AlCl}_{3}$, $\mathrm{InCl}_{3}, \mathrm{SbCl}_{3}$ ) by Resonance Raman spectroscopy; investigation of nature of organic radical cations formed in solution and of the effects of acidbase nature of the solvent and temperature on species, solvent-solute interactions, overall mechanism, and products, as part of the catalytic studies. 
ARGONNE NATIONAL LABORATORY

Chemical Engineering Division -03- (continued)

85. MHD SEED RECOVERY CHEMISTRY

$\$ 25,000$

03-2

C. Johnson

Thermodynamic, kinetic, and computer modeling studies of reactions between potassium seed compounds and synthetic ceramic systems; effusion-mass spectrometric investigations of effects of additives on potassium activity in seed-slag systems and identification of species above the systems with emphasis on understanding interactions that may limit recovery of potassium seed from magnetohydrodynamic (MHD) systems.

86. MOLTEN SALT CHEMISTRY

M. Blander, M. Saboungi,

G. Papatheodorou

This program includes (1) the investigation on the applicability of fundamental solution theories in the calculation of phase diagrams and other thermodynamic properties of molten salts, and (2) the study of thermodynamics and structure of high-temperature associated species formed between acid halides $\left(\right.$ e.g., $\mathrm{BCl}_{3}$ ) and bases (e.g., $\mathrm{NH}_{3}$ ). To be phased out in FY 1979.

87. BONDING AND STABILITY OF SULFUR $\quad \$ 30,000 \quad 03-2$ DIOXIDE SORBENT MATERIALS

\section{S. Siege 1}

Research on the bonding factors that govern decrepitation of dolomite and calcite stones--a phenomenon found to occur in fluidized beds when these stones are used as sulfur dioxide sorbents. This program is now terminated. 
BROOKHAVEN NATIONAL LABORATORY

Upton, Long Island, New York 11973

Corrosion Science Group -01-

D. H. Gurinsky - Phone: (FTS) 664-3504 or 516-345-3504

W. Y. Kato - Phone: (FTS) $664-2444$ or $516-345-2444$

J. R. Weeks - Phone: (FTS) $664-4617$ or 516-345-2617

88. INTERGRANULAR STRESS CORROSION

$\$ 190,000$

$01-2$

J. R. Weeks, Brihesh Vyas,

M. W. Kendig, Y. S. Park,

M. Suenaga, A. H. Winter

Electrochemistry of surfaces of iron and nickel base alloys under stress as revealed by scanning reference electrode and ac polarization techniques. Determination of sensitization of stainless steel using these techniques. Measurements of chromium depletion and grain boundary segregation in stainless steels and Inconel 600 using energy dispersive $x$-ray analysis attached to a transmission electron microscope. Measurements of the strain rate dependence of the stress corrosion of sensitized stainless steels and Inconel 600 in high temperature water.

Materials Science Division -01D. H. Gurinsky - Phone: (FTS) 664-3504 or 516-345-3504

M. Suenaga - Phone: (FTS) $664-4518$ or $516-345-3518$

89. RELATIONSHIP BETWEEN PROPERTIES

$\$ 650,000$

$01-3$ AND STRUCTURES

R. Caton, D. Dew-Hughes,

0 . F. Kamerer, K. Lee,

C. Pande, M. Suenaga, D. 0. Welch

Fundamental properties of high critical temperature superconductors; order parameter, phase stability, stoichiometry, heat capacity measurements, neutron irradiation, $x$-ray and neutron diffraction, and normal state resistivity: Preparation of high critical field, high critical current and critical temperature superconductors: Kinetics and mechanism of Al5 superconductor formation in solid state diffusion process: Mechanical deformation process in A15 superconductors:Hydrogen embrittlement and hydrogen attack in $\mathrm{Fe}$ and steels: Use of small angle neutron scattering for examination of materials. 
BROOKHAVEN NATIONAL LABORATORY

Materials Science Division -01- (Continued)

90. BASIC PROCESSES AND STRUCTURAL

PROPERTIES OF AMORPHOUS SEMI-

CONDUCTOR THIN FILMS FOR SOLAR

ENERGY CONVERSION

R. W. Griffith, F. Kampas,

P. Vanier

Fundamental materials investigations on the electrical, optical, and microstructural properties of amorphous semiconductor thin films that are tailored for efficient solar energy conversion. The basic. nature of localized states contained in the mobility gap of amorphous semiconductors will be explored within the dual context of: i) optoelectronic processes, and $i i)$ microstructural manifestations. Basic processes will be investigated that underlie plasma deposition and hydrogenation of semiconductor films .

91. PHYSICAL METALLURGY OF METAL HYDRIDE SYSTEMS

D. Dew-Hughes, M. Pick,

D. 0 . Welch

Studies of the metallurgical factors which influence the hydriding behavior of certain metal systems of hydrogen in metals and alloys: Potential metal hydrogen systems as hydrogen storage media such as $\mathrm{FeTi}, \mathrm{NiTi}$, CoTi, etc: Influence of substitutional atoms in $\mathrm{Nb}$ on hydriding behavior and of crystalline structures on hysteresis: Effects of surface contamination of hydriding process: Techniques of EXAF, TEM, neutron diffraction are used.

92. RADIATION DAMAGE

$$
\text { C. L. Snead, Jr. }
$$

$\$ 200,000$

$01-4$

Effects of different types of irradiation on critical properties of type II superconductors; electron, reactor neutron, $14 \mathrm{MeV}$ neutron, $17 \mathrm{MeV}, 800 \mathrm{MeV}$, and $30 \mathrm{GeV}$ proton irradiations: $\mathrm{Nb}-\mathrm{Ti}$, and $\mathrm{A} 15$ superconductors; defect and microstructure changes in irradiated materials; enhanced diffusion applied to A15 superconductors by solid-state process; application of positron annihilation to defect studics: voids and gases in metals. 
BROOKHAVEN NATIONAL LABORATORY Materials Science Division -01- (Continued)

93. EFFECT OF MICROSTRUCTURE AND

$\$ 100,000$

012 ENVIRONMENT UPON FRACTURE TOUGHNESS

A. Arbe 1, D. Dew-Hughes

Fundamental study on the relationship between microstructures and fracture toughness of structural materials: Microstructure changes due to fatigue and creep and various environmental atmospheres:

$\mathrm{Ni}$, solid solution superalloy and commercial alloys: TEM and small angle neutron scattering will be employed.

Physics Department -02-

M. Blume - Phone: (FTS) 664-3745 or 516-345-3735

94. NEUTRON SCATTERING - MAGNETIC SYSTEMS

$\$ 571,000$

$02-1$

S. M. Shapiro, J. D. Axe,

L. Passell, G. Shirane,

J. A. Tarvin, W. Thomlinson

Neutron scattering studies of the structure and dynamics of magnetic materials. Spin dynamics of low-dimensional antiferromagnets and amorphous ferromagnets; excitations of itinerant ferromagnets; magnetic ordering in superconductors.

95. NEUTRON SCATTERING - PHASE

$\$ 61 \%, 000$

$02-1$ TRANSITIONS

G. Shirane, J. D. Axe, J. Eckert,

W. D. Ellenson, Y. Noda, S. M. Shapiro,

R. Youngblood, R. Currat

Neutron scattering studies of structural phase transitions and their dynamics; low-dimensional charge density waves; phase transitions and dynamics of mercury chain compounds; soft modes in solids.

96. NEUTRON SCATTERING - ELEMENTARY

$\$ 548,000$

EXCITATIONS IN SOI.IDS

J. D. Axe, J. Eckert, W. D. Ellenson,

L. Passell, S. M. Shapiro, G. Shirane,

W. Thomlinson

Neutron spectrosocpy of low-lying excited states in solids; electronphonon interactions in metals; dynamics of mixed valence systems; lattice dynamics of high pressure phases of solid $4 \mathrm{He}$; anharmonic phonon effects in perovskites. 
BROOKHAVEN NATIONAL LABORATORY

Physics Department -02- (Continued)

97. NEUTRON SCATTERING - PARTIALLY ORDERED SYSTEMS

L. Passell, S. M. Shapiro,

J. Eckert, W. D. Ellenson,

J. A. Tarvin, W. Thomlinson

Neutron scattering studies of short-range order and excitations in partially ordered systems: radiation damage to the structures of high temperature superconductors; dynamics of solid electrolytes; dynamics of thin superfluid 4 He films adsorbed on graphite.

98. EXPERIMENTAL RESEARCH - SPECTROSCOPY
OF SOLIDS

B. C. Frazer and J. B. Hastings

$X$-ray and neutron studies of structural, dynamic and electronic properties of solids. Diffuse scattering in ferroelectric phase transitions. Central peak enhancement due to defects in $\mathrm{SrTiO}_{3}$. EXAFS studies with synchrotron radiation: dilute alloys with Fe in $\mathrm{Cu}$ and $\mathrm{V}$, and $\mathrm{Ti}$ in $\mathrm{Fe}$; structural changes in the $\mathrm{KH}_{2} \mathrm{AsO}_{4}$ phase transition.

99. EXPERIMENTAL RESEARCH - NATIONAL SYNCHROTRON LIGHT SOURCE

$\$ 622,000$ $02-2$

A. van Steenbergen, B. C. Frazer,

J. Godel, M. Perlman, K. Batchelor,

J. Bittner, L. Blumberg, B. Culwick,

J. Galayda, J. B. Hastings, R. Heese,

M. Howells, H. Hsieh, S. Krinsky,

J. Sheehan, J. Schuchman, R. Watson

R\&D in support of the NSLS project. This facility is the first in this country designed expressly for use of synchrotron radiation and the performance objectives for the electron storage rings are quite different from those of importance in high energy physics applications. Program involves design studies, model work, experimental testing and computer analyses to optimize performance characteristics and to develop new beam line instrumentation which permit users to take full advantage of the capabilities of this new research facility. 
BROOKHAVEN NATIONAL LABORATORY

Physics Department -02- (Continued)

100. THEORETICAL PHYSICS

$\$ 505,000$

$02-2$

V. J. Emery, J. Black,

M. Blume, G. J. Dienes,

J. Fields, R. H. Swendsen,

R. E. Watson, S. Aubry

(C.E.N., Saclay), B. L. Gyorffy

Phase transitions and critical phenomena, magnetism, liquid helium. (He-3, He-4, and their mixtures), ferroelectricity, electronic structure of metals and alloys, and crystal defect physics; properties of one- and two-dimensional materials, crystal growth and adsorbed films on surfaces; computer studies of one- and two-dimensional systems and random magnetic systems; commensurate-incommensurate phase transitions, analysis of soft $x$-ray photoemission data from alloys; properties of disordered materials; defect-defect interactions; molecular dynamical calculations of equations of state and shock waves; studies of valence electron distributions in crystals.

101. PARTICLE-SOLID INTERACTIONS -

$\$ 373,000$

$02-4$ RADIATION EFFECTS RESEARCH

A. N. Goland, P. W. Levy, K. G. Lynn,

Y. Plat.ov

Studies of neutron- and electron-irradiated metals and alloys employing positron-annihilation lifetime and Doppler-broadening measurements as well as electrical resistivity studies; simultaneous optical absorption and luminescence measurements during electrón irradiation of ceramics, glasses, alkali halides and minerals, diagnostic calculations of high-energy neutron damage with emphasis on fusion reactor materials including nonmetals.

102. PARTICLE-SOLID INTERACTIONS $\$ 426,000$ $02-4$ PROPERTIES OF REAL. SOLIDS

K. G. Lynn, P. W. Levy,

J. E. Dickman, A. N. Goland

Utilization of particle-solid interactions as diagnostic probes in solid-state physics investigations; electron states in solids by positron-annihilation measurements, development of slow-positron beam for surface studies; investigation of point defects and dislocations in annealed and deformed metals by positron-annihilation lifetime and Doppler broadening measurements; applications of $\mu+S R$ to defect problems in solids; geophysics of mineral thermoluminescence. 
BROOKHAVEN NATIONAL LABORATORY

Physics Department -02- (Continued)

103. PARTICLE-SOLID INTERACTIONS ADVANCED MATERIALS SYNTHESIS

AND CHARACTERIZATION

D. E. Cox, A. Moodenbaugh,

B. C. Frazer

Solid electrolytes, electrode materials for MHD power generation, structural disorder and other defects in superconductors. Preparation and characterization of high temperature oxide systems based upon $\mathrm{La}_{2} \mathrm{O}_{3}$; defect fluorite structure analysis, high- $\mathrm{T}_{\mathrm{C}}$ superconductor studies.

104. PARTICLE-SOLID INTERACTIONS ALTERATION AND ANALYSIS OF SOLIDS

BY ION BEAMS

A. N. Goland, J. S. Rosner,

M. Strongin

High resolution Rutherford backscattering for materials analysis, materials modification by ion implantation, channeling phenomena in thin single crystals, charge-states of channeled heavy ions, ion-induced lattice damage and studies of the relationship between defect structure and superconducting properties of thin-film A-15 superconductors.

105. ENGINEERING PHYSICS -

$\$ 398,000$

$02-5$ SUPERCONDUCTIVITY
A. Ghosh, H. Lutz,
M. Strongin

Superconductivity and transport properties in A-15 films; studies of "saturation" of resistance at high temperatures and anomalous temperature dependence of the resistivity of low temperatures; studies of the density of states in disordered A-15's; investigations of resistivity, density of states, and $T_{C}$ changes with disorder in low $T_{C} A-15$ 's such as $\mathrm{Mo}_{3} \mathrm{Ge}$. Transport measurements in highly disordered and amorphous materials. Photoconductivity and electrical conductivity measurements on hydrogenated amorphous silicon; new techniques for making hydrogenated a-șilicon. 
BROOKHAVEN NATIONAL LABORATORY

Physics Department -02- (Continued

106. ENGINEERING PHYSICS -

SURFACE STUDIES

R. J. Smith, M. Strongin,

J. Strozier, M. Yu.

Use of photoemission with polarized radiation to determine orientation and geometry of adsorbates chemisorbed on transition metals; studies of electronic properties of clean surfaces. The physics of secondary, ion mass spectroscopy and applications to chemisorption; correlation with chemisorption bands and surface phases. Use of a.c. pulsing techniques under ultra-high vacuum conditions to study chemical reactions at surfaces. 
IDAHO NATIONAL ENGINEERING LABORATORY 550 2nd Street

Idaho Falls, Idaho 83401

D. D. Keiser - Phone: (FTS) 583-1770 or commercial (208) 526-1770

107. WELDING RESEARCH

$$
\text { J. F. Key, G. R. Smolik }
$$

$\$ 180,000$

$01-5$

Heat source/molten pool interaction studies utilizing high-speed cinematography, emission spectroscopy and infrared thermography. Post weld embrittling mechanisms; cracking tendency determinations; age hardenable nickel base alloys; grain boundary characterization influence of oxygen and trace elements. in the embrittlement process.

108. GEOTHERMAL SCALING AND

$\$ 130,000$

03-3 CORROSION RESEARCH
L. A. Casper, W. F. Downs

Chemical mechanisms of scaling and corrosion; dissolution kinetics and thermodynamics of calcium carbonate polymorphs in synthetic geothermal solutions; rotated ring disk electrode apparatus to determine the chemical kinetics of mass transfer at a heat exchanger surface; mapping of the chemistry of metal surfaces to determine sites which promote nucleation of scale components or the initiation of corrosion. 
ILLINOIS, UNIVERSITY OF

Urbana, I11inois 61801

$\therefore$ Materials Research Laboratory -01-

C. P. Flynn - Phone: 217-333-1370

109. LOCALIZED CORROSION OF PASSIVE

METALS

$\$ 40,000 \quad 01-3$

R. C. Alkire

Corrosion of metals owing to fluid flow. Erosion by particle impaction and cavitation. Transport models of crevice corrosion and differential aeration systems.

110. MECHANISMS OF STRESS-CORROSION $\$ 84,000 \quad 01-2$ CRACKING:

E. N. Pugh

Investigation of intergranular and transgranular crack propagation in engineering materials using fractographic (SEM, TEM) metallographic and acoustic-emission measurements. Role of hydrogen in cracking process.

171. CHARACTERIZATION OF COMPOUNDS $\$ 126,000 \quad 1$ AND ALLOYS

H. L. Fraser, C. A. Wert

Developmerit of microchemical and analytical methods on $20 \AA$ scale using electron energy loss and energy dispersive spectroscopies. Application to hydride and carbide precipitate formation in bcc metals, to oxide and semiconducting compounds, and to microcharacterization of coai.

112. HYOROGEN BEHAVIOR IN BCC METALS $\$ 1740,000 \quad 01-3$ H. K. Birnbaum

Hydrogen, deuterium, tritium and helium mobility in niobium, tantalum, vanadium and palladium through classical and quantum mobility regillics. Properties and phase transitions of group $V b$ metal hydrides; neutron and anelastic techniques. Mechanisms of hydrogen transfer across solid interfaces.

113. DYNAMICAL STRUCTURE OF MATERIALS UNDER $\$ 125,000$ 1 EXTREME CONDITIONS OF TEMPERATURE

AND PRESSURE

J. Jonas

Dynamical structure of water and electrolytes at high temperature and pressure. Phase transformations in disordered inorganic solids; structureproperty relationships in polymeric materials. Laser Raman scattering and nuclear magnetic resonance at high temperatures and pressures. 
ILLINOIS, UNIVERSITY

Materials Research Laboratory -02- (Continued)

114. THEORY OF POLYMERS

R. J. Gaylord

$\$ 15,000$

$01-1$

Morphology of chain confinement in semicrystalline polymers, block copolymers and filled elastomers; effect on deformation and anelasticity.

115. SOLID DIELECTRICS

D. A. Payne,..W. Petusky

$\$ 49,000$

$01-3$

Fabrication, characterization and physical property measurements on new and improved piezo, ferro and pyroelectric ceramics for dielectric and energy conversion applications. Microstructure and compensation in diphasic mixtures. Mechanisms of electrode and insulator deterioration under severe electrochemical environments in MHD generation.

116. PHYSICAL PROPERTIES OF OXIDE

$\$ 36,000$

$01-3$ CERAMICS

G. P. Wirtz

Electrical conduction and oxygen mobility in non-stoichiometric oxides for solar energy collection, for oxygen permeable conductors in fuel cells, and for water electrolys is applications. Catalysis by mixed lanthanum-cobalt oxides.

117. SITE LOCATIONS IN CERAMIC MATERIALS

$\$ 63,000$ $01-3$

H. J. Stapleton

Investigations of mobile cation distribution in solid electrolytes and of active sites on rare earth oxide catalysts, using electronspin resonance methods.
118. MECHANICAL PROPERTIES OF MATERIALS
$\$ 43,000$
$01-2$

J. Holder

Inter and intragranular microfracture, grain boundary sliding, twinning and plastic flow during triaxial deformation of sandstone, limestone and marble. Plasticity and dislocation motion in ice.
119. ELECTRONIC PROPERTIES OF ORGANIC SEMICONDUCTORS
$\$ 49,000$
$01-3$
T. J. Rowland

Electrical, magnetic and magnetic resonance investigation of doped one-dimensional organic semiconductors. 
ILLINOIS, UNIVERSITY OF

Materials Research Laboratory -02- (Continued)

120. LOW TEMPERATURE STUDIES OF

$\$ 100,000$

$02-2$

DEFECT STRUCTURE IN SOLIDS

A. C. Anderson

Effect of interfaces and lattice defects on thermal transport at low temperature. Disordercd interstilial solutions: solid electrolytes and hydrogen in metals. Development of low-temperature thermometry.

121. RESPONSE OF SOLIDS TO ELECTROMAGNETIC \$31,000;:02-2 RADIATION

J. D. Dow

Optical semiconductor response to intense light; deep trap efficiencies in model photovoltaic and electroluminescent materials. LEED and photoelectron spectra of layered dichalcogenides. Theory of synchrotron radiation spectra of deep cores in metals.

122. USE OF VERY HIGH PRESSURES TO INVESTIGATE THE, STRUCTURE OF, MATTER

$\$ 118,000$ $02-2$

H. G. Drickamer

Use of very high pressures to investigate phosphor efficiency, energy transfer and photochemistry of inorganic and organic solids and polymers, and to study viscosity and related properties of polymer solulions.

123. IMPURITIES IN SUPERCONDUCTORS

$\$ 43,000$

$02-2$

D. M. Ginsberg

Use of tunneling measurements to investigate the effect of hydrogen and magnetic impurities on the electronic and dynamical pruperties of superconductors.

124. ULTRASONIC INVESTIGATIONS OF THE $\quad \$ 125,000 \quad 02-2$ STRUCTURE OF MATTER

A. V. Granato

Investigation by ultrasonic methods of impurity - self interstitial interactions in irradiated metals, of hydrogen in bcc metals and of non-linear mechanical properties of solids.

125. PROPERTIES OF CRYSTALLINE $\quad \$ 95,000 \quad 02-2$ CONDENSED GASES

R. 0. Simmons

Phase transitions in solid hydrogen and methane crystals; thermal and isotopic defects in helium crystals; quantum effects in diffusion. Thermodynamics of highly anharmonic insulators from low temperature to melting. 
LABORATORIES - 39 -

ILLINOIS, UNIVERSITY

Materials Research Laboratory -02- (Continued)

126. DEFECT PROPERTIES OF SOLIDS

D. Lazarus

$\$ 161,000 \cdot 02-2$

Atomic mobility in bcc transition metals and in solid electrolytes. Spin-glass and mictomagnet properties at high pressure.

127. NUCLEAR MAGNETIC RESONANCE

$\$ 130,000$

$02-2$

IN SOLIDS

C. P. STichter

Investigations of magnetic impurities in nonmagnetic metals, of layered materials with charge density waves and of platinum-silica reforming. hydrocarbon catalysts, using nuclear magnetic resonance methods.

128. PHYSICAL PROPERTIES OF TRANSITION METAL CARBIDES

$\$ 77,000$

$02-2$

W. S. Williams

Investigation of ceramic properties including catalytic behavior of tungsten carbide, effect of order on superconductivity in niobium carbide, hardness and potential use in photovoltaic conversion of transition metal carbides.

129. RADIATION DAMAGE IN SOLIDS

$\$ 140,000$

$02-4$

J. S. Koehler

Mechanisms of generation and annealing of radiation damage in metals and semiconductors. Structure of point defects; effect of defects on physical properties. 
LAWRENCE BERKELEY LABORATORY

University of California

Berkeley, California 94720

Materials and Molecular Research Division

D. A. Shirley - Phone: (FTS) 451-5619 or 415-843-2740

130. MICROSTRUCTURE, PROPERTIES AND

$. \$ 350,000$

$01-1$

AI IOYY DESIGN - ELLCTRON DIFFRACTIIUN

AND MICROSCOPY

G. Thomas

Relationships between microstructure and properties; control of properties through characterization and control of structure; application of principles of strengthening and phase transformations to alloy design for mechanical and magnetic property improvements energy conservation; systems under investigation include ferrous alloys, steels, alloys undergoing spinodal and ordering transformations, and ceramics. Quantitative analyses of structure by high resolution electron microscopy and diffraction and high voltage electron microscopy.

131. 1.5 MeV ELECTRON MICROSCOPE K. H. Wes tmacott

$\$ 100,000$

Crystal lattice defect-impurity interactions, structural transitions. High voltage electron microscopes equipped with environmental cells are used to conduct dynamic in-situ studies of gas-solid interactions. The object of this research is to understand in detail the changes in microstructure and properties of materials exposed to contaminating or hostile environments.

132. POWDER METALLURGY

$\$ 100,000$

$01-1$

M. Fickus

Application of fundamental principles of materials science and high temperature chemistry to the design of ncw materials required in. advanced technologies, and to the development of special proccssing lechniques for ubtalning them in useful forms. Multiphase composites of brittle intermetallic compounds in metallic matrices for application in severe environments, and rare-earth containing intermetallic compounds with useful magnetic properties. Use of a low melting additive which provides a transient liquid during the sintering cycle; inicrostructure control of liquid phase sintered iron-carbon alloys;... preparation of powders with metastable structures. 
LAWRENCE BERKELEY LABORATORY

Materials and Molecular Research Division (Continued)

133. ATOMIC RESOLUTION MICROSCOPY

R. Gronsky, G. Thomas

Development and use of the most sophisticated electron imaging techniques to photograph atoms in crystalline or amorphous arrangements and provide for real-space structural analysis. Localized atomic configurations responsible for solid state reactions, bulk as well as surface properties, and material failure in new energy technologies. To be initiated in FY 1979.

134. THEORETICAL PROBLEMS IN

$\$ 345,000$

$01-2$ ALLOY DESIGN

J. W. Morris, Jr.

Mechanical properties of alloys: quantitative characterization of microstructure. Use of analytic, computer simulation, and experimental techniques. Alloy design: design of new engineering alloys to meet advanced requirements in the energy area.

135. RELATIONS BETWEEN DISLOCATIONS, POINT DEFECTS, AND PROPERTIES OF METALS

J. Washburn

Structural characterization and measurement of properties of materials potentially useful to collection, conversion and storage of solar energy. Point defect clustering, properties of grain boundaries and mechanisms of mass transport in amorphous silicon; high resolution transmission electron microscopy. Transport properties of mixed cadmium-zinc sulfide single-crystal layers. Growth of zinc diphosphide as a possible new material fur solar ccll use. Size distribution of particles in spectraliy selective electroplated black chrome surface layers for high absorption in the visible and low emissivity in the far infrared.

136. HIGH TEMPERATURE OXIDATION $\$ 160,000$ $01-2$ $\$ 225,000$ AND CORROSION OF MATERIALS D. P. Whittle

Determination of the effects of metallurgical and environmental variables on the surface degradation of materials in complex gaseous atmospheres and the influence of sulphatic deposits. Mechanisms of degradation, and their relation to diffusional, structural and compositional parameters of the metal oxides, sulfides and carbides involved. Development of resistant materials and coatings: rare earth metal additions to promote improved scale/alloy adherence by modification to the scale/alloy interface; the nature of the alloy/ scale interface and optimization of addition elements. Multicomponent diffusion studies in coating/alloy substrate systems and quantitative relationship to the fundamental thermodynamic and transport properties involved. 
LAWRENCE BERKELEY LABORATORY

Materials and Molecular Research Division (Continued)

137. SUPERCONDUCTIVITY EFFECTS -

HIGH FIELD SUPERCONDUCTIVITY

$\$ 220,000$

$01-3$

M. Pickus

Application of the principles of materials science to the design of special processing systems that will yield multifilamentary superconducting tape or wire. The filaments are composed of A-15 compounds such as $\mathrm{Nb}_{3} \mathrm{Sn}, \mathrm{Nb}_{3} \mathrm{Al}, \mathrm{Nb}_{3}(\mathrm{Al}, \mathrm{Ge})$ and $\mathrm{Nb}_{3} \mathrm{Ge}$. All of these compounds are extremely brittle and therefore difficult to obtain in the required form of tape or wire. The technical approach emphasizes the use of powder metallurgy. Other approaches are used when circumstances favor doing so. Examples are the use of high temperature solid solubilities and preferential precipitation sites such as regions of high strain energy.

138. MICROSTRUCTURE AND MECHANICAL BEHAVIOR OF CERAMIC MATERIALS;

GLASS AND CERAMIC-METAL SYSTEMS J. A. Pask

Kinetics and mechanisms of solid state reactions, nucleation and growth phenomena, and distribution of phases in multiphase ceramic systems; applications to microstructure design of materials whose principal constituents are within the $\mathrm{Al}_{2} \mathrm{O}_{3}-\mathrm{SiO}_{2}$ system.

Thermodynamic considerations of sintering with and without a liquid phase. Relationship of the character (particularly grain boundaries) of ceramic materials to their mechanical behavior at elevated temperatures. Mechanisms of corrosion of ceramic materials. Thermodynamics and kinetics of electrochemical reactions at glass-metal and ceramicmetal interfaces.

139. HIGH TEMPERATURE REACTIONS

$\$ 235,000$

$01-3$ A. W. Searcy

Transport kinetics of vapor mixtures through porous solids. Kinetics of decomposilion of struntium carbonate. Catalysis of the decomposition of strontium sulfate. The effects of temperature, $\mathrm{CO}_{2}$ pressure, and particle size on the surface area of calcium oxide formed by decomposition of calcite. Variation of thermodynamic stability and surface area of magnesium hydroxide. Catalysis of the sintering of calcium oxide by carbon dioxide. Solution thermodynamics of solid calcium carbonate. Theoretical studies on the kinetics of decomposition reactions and on surface thermodynamics. 
LAWRENCE BERKELEY LABORATORY

Materials and Molecular Research Division (Continued)

140. RELATION OF MICROSTRUCTURE TO

PROPERTIES IN CERAMICS

$\$ 195,000$

$01-3$

J. A. Pask, A. W. Searcy

Microstructure and properties of ceramic materials. Densification of powder compacts with and without a liquid phase; use of a hot stage scanning electron microscope facility developed for this purpose. Densification and grain growth kinetics; effect of ambient atmosphere. Piezoelectric and ferroelectric properties in ceramic materials. Thick film conducting systems on ceramic substrates. Bonding microstructure in the metallic phase, reduce precious metal contents.

141. STRUCTURE AND ELECTRICAL

$\$ 105,000$

$01-3$

PROPERTIES OF COMPOSITE

MATERIALS

R. H. Bragg

Carbon Materials: Structure, electrical and thermophysical properties of carbon materials heat treated in the range $1000^{\circ} \mathrm{C}-3000^{\circ} \mathrm{C}$. Characterization using $x$-ray and electron diffraction, small angle scattering, conductivity, Hall Effect and magnetoresistance in magnetic fields to 5.0 Tesla. Measurements in the range $4.20 \mathrm{~K}-3000 \mathrm{~K}$. Mechanism of graphitization and point defect annealing in Glassy Carbon and Pyrolytic Graphite. Composites: Aligned two phase microstructures obtained by directional solidification of eutectic alloys. Effect of microstructure on electrical, thermophysical and mechanical properties. Usefulness of rule of mixtures as a predictor.

142. MECHANICAL PROPERTIES

$\$ 0$

$01-3$

OF CERAMICS

A. G. Evans

Study of concurrent deformation and fracture processes in ceramics polycrystals at elevated temperatures to evolve schemes for characterizing and predicting high temperature failure. Microstructural causes of toughening, investigation of crack tip process zones at high resolution. Development of a quantitative framework for the design of microstructures for ceraliics. Erosion-Corrosion phenomena in ceramics, toughness and hardness properties of corrosion layers. To be initiated in FY 1979. 
LAWRENCE BERKELEY LABORATORY

Materials and Molecular Research Division (Continued)

143. EROSION-CORROSION-WEAR PROGRAM

$\$ 430,000$

$01-5$

A. V. Levy

Determination of solid particle erosion and combined erosion-corrosion mechanisms. Surface chemistry of hot combined, reactive, flowing gases and char particle in contact with metals and ceramics of different compositions. Mechanisms of formation, composition, nurphology and behavior of surface scales; protective barriers.

144. IN-SITU INVESTIGATION OF

GAS-SOLID REACTIONS BY

ELECTRON MICROSCOPY

J. W. Evans

Use of environmental cells in the existing $650 \mathrm{kV}$ electron microscope and the new $1.5 \mathrm{MeV}$ electron microscope for an investigation of the effect of microstructure on reactions between gases and solids. Nickel oxide reduction by hydrogen, which shows evidence of being strongly influenced by microstructure will be studied first; subsequently, oxidation, sulfidation and other reactions of significance to materials performance in energy conversion systems will be investigated. To be initiated in FY 1979.

145. EXPERIMENTAL SOLID STATE PHYSICS AND QUANTUM ELECTRONICS $Y$. Shen

Modern optical techniques are used to study linear and nonlinear optical properties of materials. The materials under investigation include gases, liquids, liquid crystals, metals, semiconductors, and magnetic crystals. Newly-developed optical techniques are applied to current problems of interest, such as laser isotope separation, photochemistry, and surface phenomena.

140. FAR INFRARED SPECTROSCOPY P. L. Richards

$\$ 170,000$ $02-2$

Development of improved types of far infrared detectors, mixers and spectrometers. Use of advanced infrared techniques for measurement of: the infrared radiation left over from the creation of the universe, radiation from dust clouds in our galaxy, infrared spectra of impurities in semiconductors, far infrared spectra of electrons trapped on the surface of liquid helium and near infrared absorption spectra of molecules chamically adsorbed on metal surfaces. 
LAWRENCE BERKELEY LABORATORY

Materials and Molecular Research Division (Continued)

147. EXCITED QUANTUM FLUIDS

IN SOLIDS

C. Jeffries

Study of phenomena arising when light strikes matter, in particular semiconductors like germanium, at low temperatures: electrons are excited into higher states leaving vacant states, or holes. At sufficient densities, excitons condense into a metallic electron-hole liquid, a novel state of matter. Being studied are: droplet nucleation; surface tension effects; gas-liquid coexistence curves and phase diagram; kinetics of formation and decay; motion and spatiaj. distribution of free excitons and drops under pulsed and steady excitation; unusual explosive formation kinetics at high excitation; unusual optical hysteresis and optical nonlinearities of the gasliquid system, and the possible transient existence of biexcitons and higher excitonic molecules during the nucleation of the liquid.

148. SUPERCONDUCTIVITY, SUPER$\$ 200,000$ $02-2$ CONDUCTING DEVICES, AND $1 / f$ NOISE

J. Clarke

Development of Superconducting Quantum Interference Devices (SQUIDS) for measuring small fluctuations in magnetic fields and magnetic field gradients--highly reliable and easily operated devices using integrated thin-film technology. Use of SQUIDS in magnetotelluric measurements of the apparent resistivity of the earth's crust; acquisition and analys is of magnetotelluric data. Nonequilibrium superconductivity: enhancement of the superconducting energy gap and transition temperature by microwaves; enhancement of the energy gap by tunnel injection; response of superconducting films to pulsed perturbations; measurement of the electron-phonon relaxation times in aluminum, tin, and lead.

149. THEORETICAL SOLID STATE

$\$ 60,000$

$02-3$

PHYSICS

M. L. Cohen

A variety of theoretical approaches aided by computer calculations are used to explain measured properties and to predict new properties of solids: surface energy states on clean semiconductors and transition metals; adsorbates on solids; electrons at interfaces (Schottky barriers and heterojunctions); bulk electronic properties of semiconductors and transition metals; phonon and non-phonon mechanisms for superconductivity and properties of high transition temperature A15 superconductors; development of pseudopotential theory. 
LAWRENCE BERKELEY LABORATORY

Materials and Molecular Research Division (Continued)

1.50. LOW TEMPERATURE PROPERTIES

OF MATERIALS

$\$ 115,000$

03-1

N. E. Phillips

General objectives: Obtain low-temperature heat-capacity data that contribute to an understanding of the relations between atumic properties and the macroscopir propertics of materials. The materials investlgated include normal and superconducting metals, super-fluids, dielectric solids, and magnetic llaterlals. Heat capacity measurements are confined to temperatures below $25 \mathrm{~K}$ because usually only in that region can various contributions be reliably separated. Establishment of a temperature scale for the region from 0.06 to $25 \mathrm{~K}$ based on germanium resistance thermometers. For temperatures from $0.06 \mathrm{~K}$ to below $1 \mathrm{mK}$ nuclear susceptibility and $\gamma$-ray anisotropy thermometers will be used as primary thermometers.

151. HIGH PRESSURE CHEMISTRY

$\$ 40,000$

$03-1$

G. Jura

Objectives: Determination of the heat capacities of metals and alloys as a function of temperature and pressure; determination of heat conductivities of nonmetals as a function of temperature and pressure; heats of polymorphic transitions. Use of lhe heat capacities as means of deducing the equation of state of the metal or alloy under consideration; and for the characterization of the thermodynamic properties. Development of pulse methods on the microsecond scale.

152. ELECTROCHEMICAL PROCEESSES

$\$ 115,000$

$03-1$ C. W. Tobias

This program is designed to advance the scientific foundations of electrochemical engineering, and to widen the range of useful applications of electrochemical transformations. Mass and charge transport. in cell processes: combined influences of electrode geometry, surface potential, and ionic transport on the distribution of current on electrode macro-profiles. Gas-electrolyte-electrode interfaces: supersaturation, coalescence, and bubble separation phenomena. Nonaqueous ionizing media: thermodynamic and kinetic properties of electrode reactions which are not feasible in aqueous media. 
LAWRENCE BERKELEY LABORATORY

Materials and Molecular Research Division (Continued)

153. HIGH TEMPERATURE THERMODYNAMICS

L. Brewer

Characterization of the high-temperature chemical behavior of materials, particularly refractory ceramic materials, metals and gases. The high temperature thermodynamic properties are being determined through use of solid-electrochemical cells, solid-gas equilibria, and by $X$-ray characterization of phase boundaries. The data are being used to test and improve chemical models capable of predicting the thermodynamic properties of high-temperature materials.

154. CHEMISTRY AND MATERIALS

$$
\$ 145,000
$$

PROBLEMS IN ENERGY PRO-

DUCTION TECHNOLOGIES
D. Olander

Chemical and physical behavior of materials in environments characteristic of energy production devices, with major emphasis on fission and fusion reactors. Experiments are designed to develop insight into the mechanisms of the phenomena involved: the high temperature behavior of uranium dioxide, including transient vaporization, oxygen self-diffusion, thermal gradient migration of inclusion, and hydrogen solubility; molecular beam studies of gas-solid reactions, including hydrogen atom reaction with ceramic oxides and refractory carbides and the silane cracking reaction, and radiation-enhanced stress corrosion cracking of zircaloy.

155. ELECTROCHEMICAL PHASE BOUNDARIES

$$
\$ 135,000
$$

R. H. Muller

Investigation of new means to accelerate electrochemical mass transport in order to increase the space-time yield and energy efficiency of electrochemical processes. Formation of boundary layers and thin films at electrochemical interfaces. Development and use of new optical techniques in combination with simultaneous electrical measurements and selected methods of contemporary surface science. 
LAWRENCE BERKELEY LABORATORY

Materials and Molecular Research Division (Continued)

156. SOLID STATE AND SURFACE

$\$ 280,000$

$03-3$

REACTION

G. Somorjai

Studies of the structure, chemical composition and oxidation state of surfaces and of adsorbed gases using low-energy electron diffraction and various techniques of electron spectroscopy. Invëstigations of chemical surface reactions and catalysis on crystal surfaces at low and al high pressures by jointly using several techniques: molecular beam scattering, gas chromatography and mass spectrometry.

157. NUCLEAR MAGNETIC

$\$ 120,000$

03-3 RESONANCE

$$
\text { A. Pines }
$$

Nuclear spin interactions and their use in developing new NMR techniques. Molecular properties of ordered condensed phases and effect of nuclear spin on chemical processes. Development of the concept of coherent multiple quantum NMR and its use for the analys is of oriented materials. Molecular behavior of organized matter; this includes fuel material, liquid crystals, molecules adsorbed on surfaces and molecules excited by light.

158. PLASMA ENHANCED DEPOSITION OF THIN FILMS

D. W. Hess

This program is designed to establish scientific foundations for the rf plasma-enhanced deposition of thin films; control of chemical, magnetic, optical and electrical properties by variation of deposition parameters. Kinetic models of deposition processes as they affect solar cell fabrication, integrated circuit processing, and structureproperty relationships in catalyst support materials. To be initiated in FY 1979. 
LAWRENCE LIVERMORE LABORATORY

P. O. Box 808

Livermore, California 94550

G. Dorough - Phone: (FTS) $532-4892$ or $415-422-4892$

159. HOT CORROSION STUDIES

$\$ 180,000$

$01-1$

RELATED TO FOSSIL FUELS

D. W. Short, J. Truhan

Mechanisms and kinetics of hot corrosion; quantitative model to relate the susceptibility of nickel and iron base alloys to corrosive media at elevated temperatures $\left(800^{\circ}\right.$ to $\left.1000^{\circ} \mathrm{C}\right)$; early stages of corrosion; kinetics sutdied by weight change and scale growth; salt-substrate interactions; molten salt electrochemical reactions; effects of oxide additions to a given salt.

160. RAPIDLY QUENCHED AMORPHOUS

$\$ 100,000$ $01-3$ MATERIALS RESEARCH

C. Cline

Selection, preparation and preliminary screening of amorphous alloys based on quenching by ejecting molten metal in a continuous stream from a nozzle against a spinning cylinder; sputtering technique also used for preparation of alloys; X-ray diffraction and differential scanning calorimetry.

161. LOW INDEX OPTICAL

$\$ 216,000$

$02-2$

MATERIALS RESEARCH

J. J. Weber, C. Cline,

W. L. Smith, D. Milam

Nonlinear optical properties of materials subjected to intense light." beams; intensity-dependent refractive index change and multiphoton absorption; optical materials studies include: glasses (BeF2), crystals (alkali halides, fluorides, oxides), and polymers; timeresolved interferometry used to measure nonlinear refractive index.

162. OPTICALLY-INDUCED DAMAGE

$\$ 88,000$

$02-2$ IN TRANSPARENT DIELECTRIC MATERIALS

D. Milam, W. L. Smith,

M. J. Weber

Laser damage in transparent dielectric materials as a function of pulse duration (100 ps - $30 \mathrm{~ns}$ ) and wavelength at (1064 nm, $532 \mathrm{~nm}$, $355 \mathrm{~nm}$, and $266 \mathrm{~nm}$ ); materials include optical glasses, alkali halide and fluoride crystals; and thin films; studies of electron avalanche, multiphoton absorption, bulk absorption, surface properties, and nonlinear absorption. 
LAWRENCE LIVERMORE LABORATORY (Continued)

163. LASER-EXCITED FLUORESCENCE

$\$ 90,000$

$02-2$

IN AMORPHOUS SOLIDS

M. J. Weber, S. Brawer

Laser-induced fluorescence line narrowing to probe variations in local fields and ion-phonon interactions of paramagnetic ions in disordered solids. Simple and multicomponent oxide and fluoride glasses. Computer simulations of glass configurations us ing Monte Carlo methods. Modeling of local iull coordination and structure.

1.64. THIN FILM MATERIALS STUDIES

$\$ 216,000$

$02-2$

FOR LASER OPTICAI. COATINGS

J. Khan

To develop a quantitative understanding of the factors that influence. the properties of thin films; clarification of the relationship between deposition process variables and atomic scale structure employing scanning high energy electron diffraction; effects of stress, diffusion, annealing and recrystallization; $\mathrm{TiO}_{\mathrm{x}}$.

165. D2-DT-T2

PHASE DIAGRAM

$\$ 140,000$

$03-2$

C. Souers

To measure deviations from Raoult's Law of D-T mixtures-solid and liquid: to determine the exterit of fractionation in large frozen sainples; to determine the kinetics of chemical and ortho-para reactions. Infra-red spectroscopy will be developed as new quantitative tool for the study of liquid and solid D-T. Methods for separating pure molecular DT will be investigated. 
LOS ALAMOS SCIENTIFIC LABORATORY

University of California

P. 0. Box 1663

Los Alamos, New Mexico 87545

Chemistry - Materials Science Division

R. D. Baker - Phone: (FTS) 843-4563 or 505-667-4563

M. G. Bowman - Phone: (FTS) 843-6014 or 505-667-6014

166. HIGH TEMPERATURE MATERIALS FOR ENERGY APPLICATIONS

$\$ 210,000 \quad 01-2$

E. K. Storms, B. A. Mueller,

D. L. Rohr

Knudsen and Langmuir vaporization of various compositions near $\mathrm{LaB}_{6}$; boron and lathanum activities determined by high temperature mass spectrometry; data used to obtain vapor composition, surface composition, mass loss rate, phase relationship, thermodynamic properties and a general model of vaporization for similar materials; data is being applied to give a proper interpretation to the electron emission. behavior when the hexaborides are used as electrodes in thermionic diodes.

167. HIGH TEMPERATURE IRRADIATION

$\$ 300,000$

$.01-4$

DAMAGE STUDIES

J. R. Cost, W. V. Green,

L. S. Levinson, D. M. Parkin,

W. F. Sommer

Proton irradiation with LAMPF beam; concurrent cyclic stressing; dislocation vibration; void growth; numerical analysis of point defecl diffusion during pulsed irradiation; dislocation damping measurements of interstitial escaping cascades, during electron, neutron and proton irradiation; search for point defects in irradiated amorphus metals.

168. MATERIAL DEFORMATION UNDER MULTIAXIAL LOADING

$$
\$ 70,000 \quad 01-5
$$

S. S. Hecker, J. J. Petrovic

Multiaxial deformation of aluminum, copper and stainless steel; small deformations by biaxial sheet stretching; study of the evolution of microstructure with plastic deformation. 
LOS ALAMOS SCIENTIFIC LABORATORY

Chemistry - Materials Science Division

169. CTR RELATED CHEMICAL RESEARCH TRITIUM

$\$ 170,000$

$03-2$

CHEMISTRY ASSOCIATED WITH THE LITHIUM

BLANKET AND CONTAINER MATERIALS

D. H. W. Carstens, W. A. Stark,

J. L. Anderson

Siriultaneous measurement of diffusion coefficient and solubility of hydrogen isotopes (including tritium) in liquid $1 i$ thium and container materials $\mathrm{Nb}, \mathrm{Nb}-1 \% \mathrm{Zr}, \mathrm{Ni}, \mathrm{Fe}-21 / 4 \% \mathrm{Cr}-1 \%$ Mo over the temperature range $1000-1400 \mathrm{~K}$, and a pressure range $10^{2} \cdot-10^{4} \mathrm{~Pa}$; incorporation of the results into theurtes of diffusion in liquids; development of an infusion technique which allows for Sieverts' law behavior of hydrogen isotopes in metals; determination of the effect of impurities and radiation damage on transport properties; measurements of phase diagrams and isotope effects in appropriate metal-tritium and alloy-tritium systems; removal of tritium from helium streams using eutectic alloys.

Energy/Q Division

W. E. Keller

170. ULTRAHIGH PRESSURF. STUDIES OF HYDRUGEN

$\$ 120,000$

$02-2$

R. L. Miller

Adaptation of diamond-dnvil cells for experiments on cryogenic gases to $200 \mathrm{k}$ bar; measurements of pressure, volume, temperature, and ultrasonic velocity; work on a two stage system combining the pistoncylinder and diamond"anvil techniques to pressurize hydrogen to 1 M bar.

Thenretical Division

P. Carruthers

171. LOS ALAMOS EQUATION OF STATE $\$ 200,000 \quad 02-3$

B. I. Bennett

Maintain file of materials properties which can be accessed by computer codes in a variety of applications; used for realistic hydrodynamics calculations; continuing effort to develop and improve theoretical models. 
LOS ALAMOS SCIENTIFIC LABORATORY Theoretical Division (continued)

172. ELASTIC WAVE SCATTERING AND

Development of an analytical scientific reference data base for flaw identification; calculations of scattering phenomena selected as representative of applications; study will use principally an integral equation to describe the scattering permitting a systematic development of approximations; scattering will be calculated for special geometries by various approximations and compared with exact results from a sphere. 
MOUND LABORATORY

P. 0. Box 32

Miamisburg, Ohio 45342

W. H. Smith - Phone:

(FTS) $774-7296$ or $513-866-7296$

173. HIGH TEMPERATURE FLUIDS FOR

$\$ 220,000$

$01-3$

ENERGY SYSTEMS

L. J. Wittenberg

Characterization at elevated temperatures of potentially useful liquid systems for advanced energy concepts; fluids for solar phntnthermal absorption processes and electrotransport of tritium in liquid lithium; identification of soluble chromophoric materials dissolved in fluids which are liquids at ambient temperatures; absorptivities, emissivities, long-term thermal stability. 
OAK RIDGE NATIONAL LABORATORY

P. 0 . Box $X$

Oak Ridge, Tennessee 37830

Metals and Ceramics Division -01-

J. R. Weir, Jr. - Phone: (FTS) 850-1554 or 615-483-1554

C. J. McHargue - Phone: (FTS) 850-1277 or 615-483-1277

174. THEORETICAL STUDIES OF METALS

$\$ 380,000$

$07-1$

AND ALLOYS

J. S. Faulkner, W. H. Butler

G. S. Painter, G. M. Stocks,

M. H. Yoo

Interstitial dislocation loop nucleation and growth during charged particle irradiation, role of self-ion deposition, cascades, and solute trapping; CPA treatment of electronic states in random alloys ( $\mathrm{Cu}-\mathrm{Ni}$, $\mathrm{Cu}-\mathrm{Zn}, \mathrm{Cu}-\mathrm{Al}, \mathrm{Nb}-\mathrm{Mo}$ ); layer and cluster calculations for surfaces, 0 and $\mathrm{CO}$ chemisorbed on $\mathrm{Cu}, \mathrm{O}$ on $\mathrm{A} 7$; superconducting transition temperature and phonon linewidth in $\mathrm{Nb}$; contribution of lattice conduction to thermal conductivity in metals and alloys; calculation of binding energies, in solids.

175. X-RAY SCATTERING RESEARCH

$\$ 235,000$

$01-1$

H. L. Yakel, B. S. Borie,

R. W. Hendricks, J. S. Lin,

C. J. Sparks

Small angle $x$-ray scattering sutides of voids and loops in irradiated metals, porosity in coals, poisoning of catalysts, and structure of polymers; crystallography of modulated structures and defect structure of FeS; theoretical and experimental studies of extinction phenomena; inelastic resonance scattering.

176. PREPARATION AND SYNTHESIS OF HIGH $\$ 310,000 \quad 01-7$

TEMPERATURE MATERIALS
G. W. Clark, S. L. Bennett,
C. B. Finch, J. D. Holder,
C. F. Yen

Directional solidification of binary and ternary metal-non-metal systems (oxides, carbides, borides, nitrides); evaluation of directionally solidified $W C-C O$, $\mathrm{TiB}_{2}-\mathrm{TiC}, \mathrm{ZrO}_{2}\left(\mathrm{Y}_{2} \mathrm{O}_{3}\right)-\mathrm{Al}_{2} \mathrm{O}_{3}\left(\mathrm{Cr}_{2} \mathrm{O}_{3}\right)$-Mo, and Tiquid phase sintered $\mathrm{TiB}_{2}-\mathrm{Fe}(\mathrm{Ni})$ for tool applications; theoretical treatment of coupled solidification and the IZG (internal zone growth) and EFG (edge-defined film-fed growth) processes; actinide-doped halide crystals; hydrothermal growth of quartz and II-IV compounds. 
OAK RIDGE NATIONAL LABORATORY

Metals and Ceramics Division -01- (continued)

177. EROSION AND WEAR OF CERAMICS

C. S. Yust, C. F. Yen

$\$ 300,000 \quad 01-1$

TEM and SEM studies of damage by multi-particle impact on polycrystalline mullite and alumina to $470^{\circ} \mathrm{C}$; subsurface structure of single particle damage in single crystal alumina, friction and microstructural changes caused by sliding wear, effect of temperature, atmosphere, crystal orientation; strength and deformation mechanisms in ceramics.

178. STRUCTURE OF COAL

I. A. Harris, C. S. Yust

$\$ 85,000$

$01-1$

TEM, SEM, microprobe, optical and infrared petrography studies of microporosity and microminerology of specific maccrals in coajls.

179. X-RAY RESEARCH USING SYNCHROTRON $\quad \$ 80,000 \quad 01-1$

C. J. Sparks, H. L. Yakel

Development and application of techniques using the $x$-rays at Stanford Synchrotron Radiation Laboratory; fluorescence experiments for trace elements and low concentrations of defects and surface layers; search for short- or long-range chemical order in $\mathrm{Fe}-\mathrm{Ni}-\mathrm{Cr}$ steels, sigma phase and mixed oxide phases.

180. HIGH VOLTAGE AND ANALYTICAL ELECTRON $\$ 300,000$ 01-1

R. W. Carpenter, J. Bentley,

E. A, Kenik, N. Zaluzec

Development and application of analytical transmission electron microscopy and high voltage electron microscopy to determine the microstructure and microchemistry of solids; weak-beam dark field studies of precipitates in neutron irradiated alloys; SAES of internally oxidized Ta-W-Hf alloys; in-situ studies in the $1 \mathrm{MeV}$ microscope using an environmental stage with heating and strain capabilities.

181. DEFORMATION AND MECHANICAL BEHAVIOR $\$ 450,000 \quad 01-2$ OF STRUCTUPAL MATERTAIS

R. A. Vandermeer, J. C. Ogle,

T. C. Reiley, C. L. White

Relationships between structure, deformation mechanisms, and mechanical properties; rolling and recrystallization textures in Ta single crystals; annealing of voids; deformation modes, transformation and the shapememory effects; grain boundary segregation and fracture in $\mathrm{Fe}-3 \% \mathrm{Si}$ bicrystals; segregation to surfaces of creep voids; creep studies at strain rates of $5 \times 10^{-10} \mathrm{sec}^{-1}$. 
OAK RIDGE NATIONAL LABORATORY

Metals and Ceramics Division -01- (continued)

182. KINETICS AND MECHANISMS OF SURFACE

$\$ 600,000$

$01-3$

AND SOLID STATE REACTIONS

J., V. Cathcart, P. T. Carison,

R. E. Druischel, R. A. Mckee,

R. E.' Pawè l, G. F. Petersen

Defect interaction during diffusion and during growth of surface layers; kinetics of sulfur reactions with Fe-base alloys, definition of the electronic-ionic defect structure of $\mathrm{FeS}, \mathrm{Hall}$ effect determination of mobile species; diffusion mechanisms and solute-lattice interactions for interstitial diffusion in oxides ( $\mathrm{T}$ in $\mathrm{TiO}_{2}, \mathrm{Al}_{2} \mathrm{O}_{3}, \mathrm{Cr}_{2} \mathrm{O}_{3}, \mathrm{CoO}$ ); aliovalent impurity diffusion in oxides; fast diffusion in lead allays; theoretical model for oxidation of zirconium alloys.

183. PHYSICAL PROPERTIES RESEARCH

$\$ 300,000$

$01-3$

D. L. MCElTroy, J. P. Moore,

R. K. Williams, R. 0. A. Hall

Development and application of measurement methods for physical property studies from 4.2 to $2600 \mathrm{~K}$; lattice conduction and Lorenz function in $\mathrm{Ni}$ and $\mathrm{Cr}$ alloys; electron-phonon scattering in transition metals; Ettingshausen-Nernst effect in $\mathrm{Ni}$ alloys; thermal conduction in insulators; absorptivity and emissivity in thin films.

184. METALLURGY OF SUPERCONDUCTING MATERIALS $\$ 300,000 \quad 01-3$

C. C. Koch, A. DasGupta,

D. S. Easton, D. M. Kroeger,

W. Specking

Flux pinning in $\mathrm{Nb}$ bicrystals, calculations of pinning force in $\mathrm{Hf}-\mathrm{Nb}$ and $\mathrm{Ta}-\mathrm{Nb}$ alloys; stress effects on superconducting parameters in $\mathrm{Nb}_{3} \mathrm{Sn}$ and $\mathrm{V}_{3} \mathrm{Ga}$; ac. 1nss mechanism; preparation and properties of PbMo6S8; amorphous, microcrystalline and metastable phases.

185. RADIATION EFFECTS

J. 0. Stiegler, K. Farrell,

$\$ 1,100,000$

$01-4$

J. Bentley, R. W. Carpenter,

W. A. Coghlan, E. A. Kenik,

M. B. Lewis, L. K. Mansur,

N. H. Packan, T. C. Reiley,

H. Schroeder

Analysis of neutron damage in aluminum-base binary alloys with respect to effect on void nuicleation and growth; neutron damage in $\mathrm{Zr}, \mathrm{Ni}$, and $\mathrm{Fe}-\mathrm{Cr}-\mathrm{Ni}$ alloys; damage simulation studies using multiple ion beams from two accelerators, relationships between neutron and ion damage, role of gases in nucleation and growth of voids and interstitial 1nops; irradiation creep simulation using ORIC and neutron pre-irradiated specimens; phase stability during irradiation; theoretical analysis of void and loop growth, solute-defect interactions, and irradiation creep; HVEM irradiations. 
OAK RIDGE NATIONAL LABORATORY

Metals and Ceramics Division -01-(continued)

186. FUNDAMENTAL STUDIES IN WELDING

$\$ 250,000$

$01-5$

G. M. Goodwin, S. David,

J. M. Leitnaker

Control of weld microstructure; effect of process parameters; heat and mass transport during solidification; composition, distribution, and stabilities of microphases; austenitic and ferritic steels.

187. STUDIES IN NONDESTRUCTIVE EVALUATION $\$ 0$ 01-5

R. W. McClung

Theoretical and experimental study of wave system resulting from interaction of an ultrasound wave with various kinds of internal boundaries. in metals; effect of acoustic properties of the solid. To start in FY 1979. 
OAK RIDGE NATIONAL LABORATORY

Solid State Division -02-

M. K. Wilkinson - Phone (FTS) 850-6713 or 615-483-6713

F. W. Young, Jr. - Phone (FTS) 850-1704 or 615-483-6713

\section{ELEMENTARY EXCITATIONS IN CONDENSED}

MATTER
R. M.i Nicklow, B. Alefeld
R. L. Cappelletti, W. P. Crummett;
W. C. Koehier, N. Kunitomi,
W. Lovesey, H. Miwa,
H. A. Mook, Y. Nakai,
H. G. Smith, Y. Tsunoda
L. Van Bodegom, N. Wakabayashi

Inelastic neutron scattering studies of phonons, magons, and single particle excitations in solids and liquids; lattice dynamics and molecular reorientation in $\mathrm{NaO}_{2}$, lattice dynamics and crystal field excitations in $\gamma-\mathrm{Ce}$, SmS and $\mathrm{Sm}_{x} \mathrm{Y}_{1-x} \mathrm{~S}$, phonons and magnons in $\mathrm{Ni}-\mathrm{Pt}$, $\mathrm{Fe}-\mathrm{Pt}$, and $\mathrm{Fe}-\mathrm{V}$ alloys, spin wave spectra in $\mathrm{Pd}(5 \% \mathrm{Fe})$, spin waves in amorphous $\mathrm{Fe}$ and $\mathrm{Co}$, phonon measurements and phase transitions in TTF-TCNQ, MEM(TCNQ $)_{2}, \mathrm{TiSe}_{2}$, and Pd $1-x \mathrm{Ge}_{x} \mathrm{Te}$.

189. MAGNETIC PROPERTIES OF SOLIDS

$$
\$ 530,000
$$
R. M. Moon, J. W. Cable,
H. R. Child, W. C. Koehier,
H. A. Mook, R. M. Nicklow,
R. Parra, N. Wakabayashi

Elastic and inelastic scattering of polarized and unpolarized neutrons by magnetic systems; magnetic moment distributions in alloy systems $\mathrm{Ni}-\mathrm{Pt}, \mathrm{Pd}-\mathrm{Gd}$; magnetic structure of TmS; magnetic form factor and magnetic moment density in valence fluctuation systems SmS, Sm $.76^{\mathrm{Y}} \cdot 24^{\mathrm{S}}$, $\mathrm{SmB}_{6}$, and $\mathrm{Ce}{ }_{74} \mathrm{Th}_{2} 26$; induced moment form factor and moment density of $\mathrm{Zr}$, diluté $\mathrm{Fe}$ - $\mathrm{Cu}$ alloys (Kondo systems), CeSn 3 ; magnon spectra and magnetic exchange in rare earth-Y alloys and Laves phase intermetallic compounds; magnetic short range order in Gd. 
OAK RIDGE NATIONAL LABORATORY

Solid State Division -02-

190. PROPERTIES OF DEFECTS, SUPERCONDUCTORS, AND HYDRIDES

$\$ 525,000$ $02-1$

W. C. Koehler, H. R. Child,

D. K. Christen, H. A. Mook,

R. M. Moon, F. Mueller

R. M. Nicklow, H. G. Smith,

S. Spooner, N. Wakabayashi

Elastic, inelastic, and small angle scattering of neutrons by superconductors, superionic conductors, metal hydrides, and by elements and compounds containing defects; high resolution neutron spectrometry of $\mathrm{KCl}(\mathrm{CN})$; phonon spectra of superconductors, $\alpha-U$, Mo-Re, A1-15 type compounds; dynamic properties of tritium in metal systems; electronphonon interactions in $\mathrm{Nb}$ and Mo; phase transitions in $7 \mathrm{LiD}$; phonon densities of states, magnetic structures, and crystal field excitations in reentrant superconductors; localized modes in $\mathrm{Th}(.06 \mathrm{C})$; lattice dynamics and diffusive motion in silver halides; small-angle neutron scattering studies of void sizes and shapes in irradiated steel, $\mathrm{Al}, \mathrm{Nb}$; high resolution small-angle diffraction studies of fluxoid lattice morphology and anisotropy in high $\mathrm{T}_{C}$ superconductors.

191. PHYSICAL PROPERTIES OF SUPERCONDUCTORS $\$ 405,000$ 02-2

S. T. Sekula, B. R. Appleton,

D. K. Christen, H. R. Kerchner,

R. H. Kernohan, O. A. Pringle

H. G. Smith, J. R. Thompson

Studies of fluxoid arrays, flux flow, flux creep, fluxoid-defect interactions, and anisotropy in $\mathrm{Nb}-, \mathrm{V}-$, and Ta-base alloys and superconducting compounds ( $A 75$ and $B 1$ ); dc magnetization, ac magnetic permeability, critical currents, and normal-state electrical transport; small-angle neutron scattering by fluxoid lattices in superconductors; low-temperature ion damage, ion implantation, and ion backscattering in superconductors; inelastic neutron-scattering studies of high-transition-temperature superconductors. 
OAK RIDGE NATIONAL LABORATORY

Solid State Division -02- (continued)

192. PHYSICAL PROPERTIES OF CERAMICS

$\$ 640,000$

$02-2$

J. B. Bates, E. Sonder,

M. M. Abraham, Y. Chen

H. L. Engstrom, T. Kaneda,

F. A. Modine, J. C. Wang,

R. A. Weeks, C. Wood

Solid state reactions at high temperatures involving charge and mass transport and valence changes of defects and impurities in materials such as $\mathrm{MgO}, \mathrm{Al}_{2} \mathrm{O}_{3}, \mathrm{TiO}_{2}$, and $\mathrm{MgAl}_{2} \mathrm{O}_{3}$; determination of the mechanisms involved in electric breakdown at high temperatures; mechanisms of . hydrogen diffusion; techniques include measurements of electrical conductivity, thermoelectric power, and diffusivities, Raman scattering; polarization modulation and Fourier transform infrared spectroscopy, optical absorption and emission, electron paramagnetic resonance, and. electron-nuclear double resonance.

193. RESEARCH AND DEVELOPMENT ON PURE MATERIALS

L. A. Boatner, M. M. Abraham,

G. C. Battle, W. E. Brundage,

Y. Chen, Y. K. Chang,

T. F. Connolly, C. C. Robinson

Growth and characterization of high-quality single crystals of research materials; preparation of high-purity metals and alloys in rod and foil form; information regarding the physical properties and worldwide avai1ability of research materials provided by the Research Materials Information Center; arc-fusion growth of pure and doped $\mathrm{Y}_{2} \mathrm{O}_{3}, \mathrm{MgO}, \mathrm{CaO}, \mathrm{SrO}^{\circ}$ and other refractory oxides; growth of single crystals of perovskite-structure oxides $\left(\mathrm{KTaO}_{3}, \mathrm{KTa}-\mathrm{Nb}_{\times} \mathrm{O}_{3}, \mathrm{~K}-\mathrm{Na} \mathrm{NaO}_{3}\right)$; electron-beam float-zone growth of refractory metals (Tî, V, Zr, NB, Ta, W, Ir, Re), alloys and some A-15 compounds ( $\mathrm{Ti}_{3} \mathrm{Au}, \mathrm{Ti}_{3} \mathrm{Pt}$ ); float zone growth of high-purity $\mathrm{Fe}-\mathrm{Cr}-\mathrm{Ni}$ alloys, flux growth of tungsten carbide single crystals, preparation and growth of spinel ferrites, special fabrication techniques for thin silicon single crystals; general exploratory crystal growth. 
OAK RIDGE NATIONAL LABORATORY

Solid State Division -02- (continued)

194. PHOTOPHYSICAL PROCESSES OF SOLAR

ENERGY CONVERSION

$\$ 455,000 \quad 02-2$

R. F. Wood, M. M. Abraham,

B. R. Appleton, J. B. Bates,

J. W. Cleland, H. L. Engstrom,

B. C. Larson, J. Narayan,

T. F. Polgreen, P. P. Pronko,

J. C. Wang, R. D. Westbrook,

C. W. White, R. T. Young

Initial characterization of single and polycrystalline Si to determine the effects of point defects, defect clusters, dislocation, twin boundaries, stacking faults, grain boundaries, chemical impurities and defect-impurity interactions on electrical and optical properties; thermal neutron transmutation, diffusion, and ion implantation doping experiments for fabrication of $p-n$ or $n-p$ junctions; thermal or laser annealing of lattice damage in reactor irradiated, diffused or ion implanted Si; electrical, optical (including infrared, laser-based infrared and Raman spectroscopy), transmission electron microscopy, $x$-ray diffuse scattering, electron paramagnetic resonance, surface photovoltage, secondary ion mass spectrometry and Rutherford ion back scattering property measurements; grain boundary compensation in polycrystalline Si by neutron transmutation doping and diffusion; fabrication of test solar cells; study of factors known to degrade solar cell conversion efficiency under single sun and concentrator conditions, junction depth concentration profile and absolute quantum efficiency spectral response measurements.

195. FUNDAMENTAL ASPECTS OF METAL FRACTURE $\$ 220,000$ S. M. Onr, S. J. Chang

J. Narayan, T. S. Noggle

Theoretical and experimental investigations to relate phenomena of continuum fracture mechanics to microscopic physical phenomena occurring at a crack tip; in situ transmission electron micrnscope observation crack propagation in stainless steel, molybdenum and magnesium oxide; distribution of dislocations in the plastic zone ahead of the crack tip in metals and ceramics; high resolution electron microscope studies of crack nucleation.

196. JOLID ELECTROLYTES : ANO SUPERIONIC CONDUCTIVITY

J. B. Bates, T. Kaneda,

H. Sato, J. C. Wang

Mechanisms of high ionic conductivity in solid electrolytes such as the beta- and beta'-aluminas and $\mathrm{Li}_{3} \mathrm{~N}$; preparation and characterization of new materials based on modification of the beta-alumina structure; techniques include measurements of electrical conductivity and dielectric constant, Raman scattering and infrared absorption, reflection, and emission spectroscopy; experimental results interpreted and correlated by means of model calculations. To be initiated in FY 1979. 
OAK RIDGE NATIONAL LABORATORY

Solid State Division -02- (continued)

197. THEORY OF CONDENSED MATTER
R. F. Wood, J. H. Barrett,
J. F. Cooke, H. L. Davis,
D. K. Holmes, T. Kaplan,
M. E. Mostoller, 0. S. Oen,
M. Rasolt, M. T. Robinson,
M. Ulehra

Electronic structure and optical properties of defects in insulators; superionic conductivity and solid electrolytes; high temperature oxides and carbides; reflection of light atoms from surfaces; near surface diffraction of Auger electrons; interpretation of LEED data; surface studies with back-scattered ions; lattice vibrations in disordered alloys; the coherent potential approximation; vibrational properties around substitutional impurities in insulators; neutron scattering from molecular-like impurities in crystals; band structure calculations in metals and insulators; electronic properties of rare-earth and actinide compounds; electron screening and phonon spectra; lattice dynamics of high $\mathrm{T}_{C}$ superconductors; ferromagnetism in transition metals; spin wave calculations in $\mathrm{Ni}$ and $\mathrm{Fe}$; Brillouin zone integration; Heisenberg spin systems; computer simulation of radiation damage and sputtering; radiation damage analys is procedures; correlation of neutron damage with ion bombardment; theory of laser annealing and laser-induced diffusion in semiconductors.

198. LOW-TEMPERATURE RADIATION EFFECTS

R. R. Coltman, Jr., C. E. Klabunde,

J. K. Redman, J. M. Williams

$\$ 515,000 \quad 02-4$

Fission-neutron damage rates in metals and alloys at $4.7^{\circ} \mathrm{K}$; dose-dependent recovery studies of stainless steel and pure and doped $V$ irradiated at $4^{\circ} \mathrm{K}$; defect-production studies of alloys and pure and doped metals fastneutron irradiated near room temperature; normalization of ion and fission-neutron damage in Al irradiated near $4^{\circ} \mathrm{K}$; correlated studies of resistivity and density changes in Cu fast-neutron irradiated near room temperature; effects on insulators for superconducting magnets irradiated at $4.7^{\circ} \mathrm{K}$.

199. X-RAY DIFFRACTION AND EI.ECTRON MICROSCOPY

$\$ 325,000$

$02-4$

T. S. Noggle, J. F. Barhorst,

B. C. Larson, J. Narayan,

S. M. Ohr, J. B. Roberto

Radiation damage resulting from reactor neutrons, $14 \mathrm{MeV}$ neutron and ion irradiations of $\mathrm{Au}, \mathrm{Cu}, \mathrm{Ni}, \mathrm{Si}, \mathrm{Nb}$ and stainless steel; transmission electron microscopy; x-ray diffuse scattering; single crystal films; laser annealing; defects in $\mathrm{MgO}$; anisotropic elasticity theory of dislocation loops; computer simulation of electron microscopy images; theory of interactions of electrons and $x$-rays with defects in solids. 
OAK RIDGE NATIONAL LABORATORY

Solid State Division -02- (continued)

200. ION BOMBARDMENT

B. R. Appleton, J. H. Barrett,

$\$ 260,000$

$02-4$

P. P. Pronko, O. E. Schow III,

C. W. White, S. R. Wilson,

S. P. Withrow, R. A. Zuhr

Development of Positive Ion Crystallography of Surfaces (PICS) technique for surface studies; application of PICS to studies of reordered, relaxed and oxygen covered single crystal surfaces; exploitation of the channeling effect in the narrow and wide (111) planar subchannels in Si to.study impact parameter dependent stopping powers of He, $C$, and $B$ ions; investigations of uni- and bi-directional double alignment channeling for. defect studies; determination of the lattice sites of B; As, Sb, Cu, Fe, $\mathrm{Zn}$ and $\mathrm{Al}$ in ion-implanted, laser-annealed Si single crystals; measurements of one-dimensional lattice contraction in B-implanted, laserannealed $\mathrm{Si}$ by ion channeling and $x$-ray scattering; development of nuclear resonance techniques for detecting $\mathrm{Al}, \mathrm{H}_{2}$ and $\mathrm{D}_{2}$ in solids; investigations of laser annealing mechanisms of defects in $\mathrm{Si}, \mathrm{Nb}$ and $\mathrm{Al}$ by ion scatteringchanneling techniques.
201. NORMALIZATION OF ION AND NEUTRON DAMAGE
$\$ 170,000$
$02-4$
T. S. Noggle, B. R. Appleton,
J. Narayăn, O. S. Oen,
J. M. Williams

Normalization of damage production rates using fission neutrons and MeV self ion irradiation of thin films of $\mathrm{Al}$ and $\mathrm{Ni}$; damage production rates as a function of ion penetration depth for $\mathrm{H}, \mathrm{He}, \mathrm{Mg}, \mathrm{AT}, \mathrm{Si}, \mathrm{P}$, $\mathrm{S}, \mathrm{Cl}$ and $\mathrm{Ar}$ ions in $\mathrm{Al}$ and $\mathrm{Ni}$ ions in $\mathrm{Ni}$; damage theory computations.

202. SURFACE STUDIES AND CATALYSIS

L. H. Jenkins, B: R. Appleton,

$\$ 500,000$

$02-5$

J. H. Barrett, H. L. Davts,

J. R. Noonái, M. Rasolt,

M. UTehla, J. F. Wendelken,

D. M. Zehner

Studies of the crystallographic and electronic structure of clean and adsorbate-covered metal surfaces with emphas is on surfaces which either reordered or have interplanar spacings different from those of the bulk; combined techniques of low energy electron diffraction (LEED) and positive ion crystallography of surfaces (PICS) for surface crystallography studies; LEED and Auger electron spectroscopy (AES) from "d" ind " $f$ " electron band solids; AES of quasi-atomic nature, angular emission dependence and line shape analysis of Auger spectra; vibronic structure of adsorbates examined by high resolution electron energy loss spectroscopy; examination of surface electronic and geometric structures with respect to solid state aspects of heterogeneous catalysis. 
OAK RIDGE NATIONAL LABORATORY

Solid State Division -02- (continued)

203. ION IMPLANTATION

B. R. Appleton, P. P. Pronko,

$\$ 180,000 \quad 02-5$

O. E. Schow III, N. Thompson,

C. W. White, S. R. Wilson

Capability for in situ ultra high vacuum ion implantation, ion scatteringchanneling and surface analyses, and laser annealing; investigations of laser annealing mechanisms and implanted impurity mobility in ion implanted silicon; fabrication of improved efficiency solar cells from boron-implanted laser-annealed silicon; studies of surface alloy formation by laser processing of ion implanted metals; effects of ion implantation on corrosion mechanisms; alteration of superconducting properties by ion implantation doping of superconducting materials; investigations of metastable materials prepared by ion implantation doping and laser processing. 
OAK RIDGE NATIONAL LABORATORY

Chemistry Division -03-

0. L. Keller - Phone: (FTS) 850-6444 or 615-483-8611, Ext. 3-6444

204. CHEMICAL STRUCTURE OF ENERGY

$\$ 730,000$

$03-1$

RELATED MATERIALS

W. R. Busing, G. M. Brown,

C. K. Johnson, E. Johnson,

H. A. Levy, A. H. Narten,

W. E. Thiessen

Atomic and molecular arrangements in crystais and in liquids determined by neutron and $x$-ray diffraction studies; location of light atoms, especially hydrogen: identification of isotopic substituents such as deuterium; development of new computational methods for solving and refining crystal structures; graphic displays for interpreting structure of materials use of intermolecular potentials to compute and extrapolate physical properties. Materials studied include molten salt catalysts for clean fuel synthesis, salt hydrates for thermal energy storage, catalysts for hydrogen production, sterically hindered hydrocarbons, compounds derived from the coal research program, and ionic and organic conductors.

205. MATERIALS CHEMISTRY RELATED TO

$\$ 470,000$

$03-2$

FUSION REACTOR SYSTEMS

J. T. Bell, H. F. Bittner,

J. D. Redman, G. M. Bègun

High temperature chemical interactions are being defined and characterized in order to determine their advantageous or detrimental effects on materials in energy producing systems. Tritium management in reactor systems will require permeation barriers. Tritium permeation rates through clean metals and alloys and through construction alloys whose surfaces have been oxidized with steam are measured. The chemistry of the steam oxidation of alloys to form effective permeation barriers, and the high temperature chemistry of the oxides are determined. Basic chemical and thermodynamic information is obtained on the tritium fuel cycle; systematic studies are done on the solubilities and on the extraction of hydrogen isotopes in and from breeding blanket materials.
206. PHYSICAL CHEMISTRY OF MOLTEN SALTS
$\$ 215,000$
$03 n 3$
IN ENERGY UTILIZATION
J. Braunstein, C. E. Vallet

Electrochemical measurements, thermodynamics of irreversible processes, and nuclear magnetic resonance are used to investigate diffusion, migration, electrical conductance, and relaxation in ionic systems such as molten salts, hydrous melts, vitreous and solid electrolytes; modelling and measurement of polarization and mass transport in electrolytes used in high temperature battery and fuel cell applications. 
OAK RIDGE NATIONAL LABORATORY

Chemistry Division -03- (continued)

207. LOCALIZED CORROSION AND STRESS

CRACKING PHENOMENA RELATED TO

$\$ 325,000$

$03-3$

ENERGY TECHNOLOGIES

F. A. Posey, A. L. Bacarella,

E. J. Kelly, A. A. Palko

Basic electrochemical investigations of mechanisms of corrosion reactions applicable to localized attack of metals (e.g., titanium, stainless steel) needed for understanding corrosion in active and passive states and effects of restrictive geometries (pitting, crevice corrosion, stress corrosion cracking); kinetics of coupled active-passive electrode systems; kinetics of corrosion reactions in concentrated aqueous electroTytes; effect of strain on dissolution kinetics; development of rapid electrochemical methods for testing susceptibility to localized attack.
208. PREPARATION AND PROPERTIES OF
$\$ 190,000$
$03-2$
ACTINIDE CARBIDES/NITRIDES
T. B. Lindemer, E. C. Beahm,
T. M. Besmann

Fundamental studies associated with advanced fast breeder reactor fuels. Basic chemical compatibility of uranium carbides, thorium carbides, and plutonium carbides with $\mathrm{Cr}-\mathrm{Fe}-\mathrm{Ni}$ alloys. Thermodynamics properties and compounds in the systems $\mathrm{U}-\mathrm{C}-\mathrm{Cr}-\mathrm{Fe}-\mathrm{Ni}, \mathrm{Th}-\mathrm{C}-\mathrm{Cr}-\mathrm{Fe}-\mathrm{Ni}$, and $\mathrm{Pu}-\mathrm{Cr}-\mathrm{C}$. Carbothermic conversion of actinide oxides to acinide carbides. Phase equilibria and thermodynamic properties of the systems $U(C, 0)] .9-C$;



209. CHEMICAL ENGINEERING RESEARCH $\$$ 03-2

J. S. Watson, S. D. Clinton

R. E. Barker, J. B. Talbot

The measurement and evaluation of materials properties important to chemical processes; the development and evaluation of separation techniques including the study of hydraulic cyclones for removing solid particles from viscous fluids (e.g. coal-derived liquids), and a study of deep-bed filters for removing very small (submicron) particles from organic and aqueous streams. 
PACIFIC NORTHWEST LABORATORY

P.0. Box 999

Richland, Washington 99352

R. Ne1son - Phone (FTS) 444-0120 or 509-942-0120

210. METAL-INSULATOR-SEMICONDUCTOR PHOTOVOLTAICS

$\$ 80,000 \quad 01-7$

R. P. Turcotte, L. C. Orsen

Photoelectric and physical/chemical structure evaluation of MIS photovoltaic cells. Correlation of performance to thin film structure/ fabrication parameters. Thin film properties--optical transmission, ellipsometry, Auger profile analyses, electron microscopy. Systems of major interest based on single crystal silicon--Au/SiO $2 / \mathrm{n}-\mathrm{Si}$ and $\mathrm{Al} / \mathrm{SiO}_{2} / \mathrm{p}-\mathrm{Si}$.
211. SPUTTER-DEPOSITED SOLAR MATERIALS
R. Wang, W. T. Pawlewicz,
C. H. Henager, Jr.
$\$ 150,000 \quad 01-1$

Structure-property relationships for thin film photovoltaics, photochemical electrodes and selective photothermal absorbers; electrical, optical and photoelectronic properties of sputter-deposited amorphous Si film; photochemical reactions on semiconductor-electrolyte interface; band-gap, photo-response and electrical properties of sputterdeposited fine-grained and amorphous $\mathrm{SrTiO}_{3}$ and $\mathrm{FeTiO}_{3}$ semiconductors, impurity effects of plasma-sprayed $\mathrm{TiO}_{2}$ for photoelectrolysis of water; sputter-deposited photothermal absorbers.
212. FUNDAMENTAL STUDIES OF STRESS CORROSION AND CORROSION FATIGUE MECHANISMS
R. H. Jones, M. T. Thomas,
S. M. Bruemmer
$\$ 150,000 \quad 01-2$

Investigations of the mechanisms controlling stress corrosion cracking and corrosion fatigue cracking of iron, iron-chromium-nickel and nickelbased alloys in gaseous and aqueous environments. Computer modeling and experimental measurement of surface and grain boundary segregation of $\mathrm{S}, \mathrm{P}, \mathrm{Sb}$ and $\mathrm{C}$ in $\mathrm{Fe}$ and $\mathrm{Ni}$. Relationships between grain boundary chemistry, electrochemical potential and fracture in aqueous solutions. Effect of plastic strain and various gaseous environments on the quantity and distribution of surface segregants will be studied in an Auger electron spectrometer using an in-situ straining stage. 
PACIFIC NORTHWEST LABORATORY (continued)

213. OXIDATION, CORROSION AND WEAR RESISTANT $\$ 130,000$ 01-3 FINE-GRAINED MATERIALS

M. D. Merz

Mechanisms of oxidation, corrosion and wear in fine-grained and amorphous materials; relation of properties to structure and microstructure, high temperature oxidation of sputter-deposited stainless steels, Inconels and Inconel with oxide dispersants; diffusion of protective oxide forming elements; activation energies and rate controlling steps for oxide formation; stress in oxide films; sulfidation resistance; aqueous corrosion of amorphous stainless steel; wear behavior of fine- : grained and amorphous materials: $\mathrm{Cu}, \mathrm{Ni}, \mathrm{W}_{50} \mathrm{Fe}_{50}$ and $\mathrm{Fe}_{80} \mathrm{~B} 20$; extremely hard alloys and intermetallic components; diskrider method of wear evaluation in vacuum and controlled atmosphere; coefficient of friction.
214. SPUTTER-DEPOSITED SUPERCONDUCTORS
S. D. Dahlgren, R. Wang
$\$ 130,000$
$01-3$
M. T. Thomas

Study of sputter-deposited superconductors; cathodic sputtering; synthes is of new superconducting materials; relation of sputter-deposition parameters to properties; structure and stability of sputter deposits; effect - of heat treatment under high pressure; atomic volume; heats of transformation; relation of critical current and flux pinning force to grain size; role of additives such as oxygen; high-field A-15 compounds; $\mathrm{Nb}_{3} \mathrm{Al}, \mathrm{Nb}_{3}(\mathrm{Al}-\mathrm{Ge}), \mathrm{Nb}_{3} \mathrm{Ge}, \mathrm{Nb}_{3} \mathrm{Sn}, \mathrm{Nb}_{3} \mathrm{Si}$; effect of substrate on sputterdeposited superconductor properties.

215. RADIATION EFFECTS ON METALS

J. L. Brimhall, E. P. Simonen,

H. E. Kissinger, P. L. Hendrick,

L. A. Charlot, E. R. Bradley

$\$ 400,000 \quad 01-4$

Study of the production, migration and interaction of radiation produced defects; effect of helium on void formation and other damage microstructures; dual beam (heavy ion + helium) irradiations; comparison of ion and neutron irradiated metals; pure refractory metals, refractory alloys, nickel alloys, amorphous metals; use of transmission electron microscopy, resistivity, $x$-ray diffraction; theoretical analys is of nucleation and growth of defect structure; testing of theoretical models by experiment; simulation of neutron enhanced creep by light ions; stress dependence of irradiation creep in nickel; creep of reactor pre-conditioned specimens; modelling of creep behavior; transmission electron microscopy of specimen crept during ion irradiation. 
PACIFIC NORTHWEST LABORATORY - (continued)

216. RADIATION DAMAGE IN CERAMICS

$\$ 80,000$

$01-4$

R. P. Turcotte, W. J. Weber,

T. D. Chikalla

Particle induced radiation damage in cubic oxides (fluorite and spinel structures), $\mathrm{SiO}_{2}$ and complex silicates. Alpha bombardment using actinide sources and preparation of actinide compounds. Structura? changes by X-ray diffraction, density, scanning electron microscopydamage ingrowth and annealing kinetics. Inert gas diffusion/defect interactions in glass.

217. SPUTTERING PARAMETER INFLUENCES ON

$\$ 150,000 \cdots 01-5$

MATFRTAI STRIIC.TIIRE AND BEHAVIOR.

R. Busch, J. W. Pattern,

E. D. McClanahan'

Effect of sputtering parameters on structure and behavior of deposited materials; columnar growth, types of boundaries, diffusion properties and character of substrate-deposit interface in metallic deposits ( $\mathrm{Cr}$, $\mathrm{Ni}, \mathrm{Co})$. Effect of deposition rate, substrate temperature and bias, and oxygen partial pressure on stoichiometry and structure of oxide deposits; effect of material parameters, e.g., free energy of formation, cation/anion mass ratio, etc.; oxides of $\mathrm{Al}, \mathrm{Cr}, \mathrm{Ni}$, and others; study of physical/chemical factors in adherence of oxide deposits to metallic substrates.

218. OPTICAL AND LASER MATERIAL STUDY

$\$ 110,000$

$02-2$

J. S. Hartman, D. L. Lessor,

R. L. Gordon

Examine validity of theory describing scattering of light from metal surfaces by using visible wavelengths and controllably roughed single crystal copper surfaces; optical scattering; et.r.h pits in copper surfaces; chemical crystal polishing; independent sample topography using modified Normarski reflection microscopy; quantitative surface topography analysis; non-contact and non-destructive topography evaluation; fractional wavelength vertical resolution; examine radiation effects on the optical properties of metal reflectors with in-site measurements; copper ion irradtation of single crystal copper reflectors; copper reflectors; laser fusion reflectors; ellipsometry evaluation of optical properties during irradiation. 
PACIFIC NORTHWEST LABORATORY - (continued)

219. SPUTTER-DEPOSITED COATINGS FOR

$\$ 90,000$

$02-2$

OPTICAL APPLICATIONS

N. Laegreid, W. T. Pawlewicz,

R. Busch, J. S. Hartman

Development of sputter-deposited materials for optical applications; oxides of $\mathrm{Ti}, \mathrm{Si}, \mathrm{Zr}, \mathrm{Hf}$ and $\mathrm{Ta}$; fluorides of $\mathrm{Mg}$ and $\mathrm{Th}$; $\mathrm{SiC}, \mathrm{Bn}$ and GaAs; range of refractive indexes; visible or infrared spectral region; property characterization related to stoichiometry and structure, manipulation and control of properties by adjustment of sputtering conditions; refractive index, absorption coefficient and optical band edge by normal incidence transmission/reflection and ellipsometry, $X$-ray energy spectrometry, $X$-ray diffraction, scanning electron microscopy and transmission electron microscopy.

220. NANOMETRE MACHINING AND GRINDING DEVELOPMENT - MATERIALS PROPERTIES

$$
\$ 165,000
$$

$02-5$ RESEARCH

D. M. Miller, N. Laegreid,

R. Busch

Development of machining and grinding technology permitting achievement of surface roughness less than 1.5 nanometre $r m s$, and total contour accuracy of 100 nanometre for flat, concave and conves spherical and aspherical surfaces up to one metre diameter. Determine relationship between microstructure and physical/chemical properties of materials and machining/grinding parameters necessary to achieve desired result. 
SANDIA LABORATORIES

P. 0. Box 5800

Albuquerque, New Mexico 87115

John Galt - Phone: (FTS) $475-4669$ or 505-264-4669

221. STRESS CORROSION CRACKING $\$ 160,000 \quad 01-2$ W. H. Smyr1

Crack propagation behavior of austenitic and ferritic stainless steels in molten salt environments; low melting mixtures of $\mathrm{AlCl}_{3}-\mathrm{NaCl}-\mathrm{KCl}-\mathrm{LiCl}$, chosen to provide data at same temperature as boiling $\mathrm{MgCl}_{2}$ tests. Determination of hydrogen effects on cracking; measurement of hydrogen permeation and diffusion in the austenitic stainless steels. Electrochemical measurements are conducted in parallel with the stress

corrosion tests. New alternating current impedance corrosion techniques have been developed to generate fast, accurate data.

222. ION IMPLANTATION AND DEFECTS $\$ 300,000 \quad 01-3$

IN MATERIALS

G. W. Arnold, K. L. Brower,

D. M. Follstaedt, G. B. Krefft,

S. M. Myers, P. S. Peercy,

S. T. Picraux, F. L. Vook

Ion beam modification and analysis of near surface regions of solids. Laser annealing of implanted and amorphous solids, $H$ concentration measurements and bonding observations in crystalline and amorphous Si, EPR and optical investigation of radiation-induced defects and $H$ in $\mathrm{SiO}_{2}$ glasses, surface recrystallization of glasses and fused $\mathrm{SiO}_{2}$. Ion implantation metallurgy: formation of equilibrium and nonequilibrium alloys, measurement of diffusion coefficients, solubility, enthalpy and entropy of reaction, phase diagram determinations. Observations of solute trapping. TEM diffraction and microscopy, temper embrittlement of $\mathrm{Fe}$ alloys.

223. EROSION AND WEAR IN A FLUID $\quad \$ 100,000 \quad 01-5$ ENVIRONMENT

R. E. Cuthre11, H. 0. Pierson,

D. M. Mattox, E. Randich

Basic studies on the erosion and wear of surfaces by abrasion and particulate impact in varying thermal and chemical environments. Effect of chemical environment on the fracture of brittle materials (Rebinder effect) under well controlled conditions, as delermined using acoustlc emission techniques. Substrate-coating interactions in the formation of adherent wear- and erosion-resistant coatings for energy applications. Failure analysis of eroded surfaces and modeling of the erosion mechanisms. 
SANDIA LABORATORIES (continued)

224. SURFACE PHYSICS RESEARCH

J. E. Houston, J. A. Panitz

$\$ 200,000$

$02-2$

R. R. Rye, P. J. Feibelman,

D. R. Jénnison, F. L. Vook

Field-desorption microscopic imaging of the structures of molecules adsorbed on metal surfaces. Mass and site specific, two-dimensional images are recorded with Angstrom spatial resolution. Auger electron spectroscopy has been demonstrated both experimentally and theoretically to be a unique probe of local chemical environment using the correlated spectral resulits from selected series of gas-phase molecules.

225. DEVELOPMENT OF FIELD-DESORPTION

MICROSCOPE FOR BIOMOLECULE IMAGING

J. A. Panitz, J. E. Houston,

F. L. Vook

An instrument is being developed utilizing field-desorption and TEM techniques to obtain structural images of biological molecules with approximately 1 A resolution. This apparatus will include the capabilities of time-of-flight mass analysis on desorbed species and surface sample dosing wi thout breaking vacuum. To start in FY 1979.

226. HYDROGEN PRODUCTION BY SOLAR PHOTO- $\$ 130,000 \quad 02-2$ ASSISTED ELECTROLYTIC DECOMPOSITION OF WATER

M. A. Butler, D. S. Ginley,

M. L. Knotek, B. Morosin,

J. E. Schirber

Investigation of the feasibility of $H$ production by photoassisted electrolys is of $\mathrm{H}_{2} \mathrm{O}$ at chemically inert semiconductor electrodes. Electrochemical behavior of aqueous and related systems including electrospectroscopy of reaction intermediates; variation of semiconductor electrode material properties, including surface film passivation as well as activation. Surface studies on a microscopic bas is to understand basic reaction steps; theoretical studies to model the behavior of material property characteristics of electrodes. 
SANDIA LABORATORIES (continued)

227. STUDIES OF THE VAPOR PHASE OF THE CHEMICAL-VAPOR-DEPOSITION PROCESS

$\$ 60,000$ $02-5$

G. H. Miller, A. W. Johnson,

A. J. Mulac, P. J. Hargis

Studies of important vapor-phase reactions and condensation process during CVD processing of thin-film photovoltaic cells; measurements of major and trace species densities and gas temperature using Raman scattering, laser-induced fluorescence and stimulated two-photon spectroscopy. Efforts to develop predictive model and improved CVD processilly leclini iques. 
SANDIA LABORATORIES

Livermore, California 94550

228. GASES IN METALS

W. D. Wilson, G. J. Thomas,

W. A. Swansiger, M. I. Baskes,

J. H. Holbrook, C. F. Melius

A joint theoretical and experimental program to increase fundamental understanding of the behavior of hel ium and hydrogen in metals and their influence on the mechanical properties of metals. Measurements and calculations of diffusion, trapping and clustering of helium in metals and alloys. Hydrogen phenomena are being examined utilizing transport measurements, autoradiography, electron microscopy and mechanical tests. Quantum theoretical calculations are performed in direct support of the experimental program. 
SECTION B

Universities

The information was taken from current 200-Word Summaries provided by the contractor. There is considerable (about 10\%) turnover in the University program and some of the projects will not be continued beyond the current contract period. 
ARIZONA STATE UNIVERSITY

-301. IMAGING SURFACES AND DEFECTS

IN CRYSTALS

J. M. Cowley - Dept. of Physics

Phone: (602)-965-6459

New techniques for the study of the surface structure of crystalline solids by diffraction and imaging with electrons have been evolved. A new type of instrument has been built using an ultra-high vacuum system and allowing a combination of medium energy (1-10 keV), electron diffraction and scanning electron microscopy with a novel procedure for forming images by the use of diffracted beams. Near atomic resolution is being achieved on surface imaging by transmission.

UNIVERSITY OF ARIZONA

302. STUDY OF GAS EVOLUTION

$\$ 72,720$

$02-2$

THRESHOLDS AT SEMICONDUCTOR-

ELECTROLYTE INTERFACES USING

DIFFERENTIAL REFLECTANCE

SPECTROSCOPY

S. Sari - Optical Sciences Center

Phone: (602)-884-3025

This study examines a number of aspects of gas evolution, properties of adsorbed layers and reaction processes at semi-conductor-electrolyte interfaces. Optical spectroscopic methods utilizing sensitive differential reflectance techniques will be emphasized. Electronic and molecular processes at solid-liquid interfaces, in particular the metal-liquid boundary under electrolytic action, will be studied.

BROWN UNIVERSITY

303. A COMBINED MACROSCOPIC AND

$\$ 121,000$

$01-2$

MICROSCOPIC APPROACH TO THE

FRACTURE OF METALS

J. Gurland - Division of Engineering

Phone: (401)-863-2628

$\mathrm{J}$. R. Rice - Division of Engineering

Phone: (401)-863-2866

Evaluation of deformation and fracture of metal alloys -- primarily steels; plasticity considerations in ductile crack growth; relation of microscale fracture mechanisms to macroscopic fracture mechanics; shear localization; embrittlement due to hydrogen or grain boundary segregation. 


\section{CALIFORNIA INSTITUTE OF TECHNOLOGY}

304. STUDIES OF ALLOY STRUCTURES AND PROPERTIES

$\$ 140,000 \quad 01-1$

W. L. Johnson - Division of Engineering

Phone: (213)-795-6811, X1435

Research on the properties and structure of amorphous magnetic or superconducting alloys; ternary amorphous alloys covering the range from ferromagnetism to superconductivity; flux pinning by crystalline phase precipitates embedded in an amorphous superconducting matrix; Fe-P-B amorphous alloys; high temperature amorphous superconductors based on $\mathrm{Zr}$, Mo or $\mathrm{Nb}$; amorphous Gd-La-Au alloys; low temperature specific heat measurements; superconducting tunneling experiments.

305. A STUDY OF METAL HYDRIDES AND IONIC CONDUCTORS WITH NUCLEAR MAGNETIC RESONANCE TECHNIQUES

R. W. Vaughan - Chemistry and Chemical Engineering Dept.

Phone: (213)-795-6811, X1183

Muitiple pulsed nuclear magnetic techniques to investigate chemical and electronic bonding in binary metal hydrides. Materials to be studied include the alkaline-earth hydrides and a group of "cluster" covalent hydrides of Ru and Os containing covalently linked CO. Additional systems to be studied will include polycrystalline $\beta$ and $\beta^{\prime \prime}$-alumina, alkali-doped $\mathrm{BPbF}_{2}$ and $\mathrm{CdF}_{2}$. A widely-based effort will be made to employ NMR techniques in the study of ionic mobility.

306. THE PRESSURE DEPENDENCE OF THE MECHANICAL PROPERTIES OF POLYMERS

$\$ 96,000$

$01-2$

N. W. Tschoegl - Dept. of Chemistry and Chemical Engineering

Phone: (213)-795-6811, X1676

Evaluation of time-temperature-pressure superposition in elastomers; measurement of time-dependent Poisson ratio, shear relaxation modulus, thermal expansivity and compressibility up to 10 kbars; analysis of behavior near glass-transition pressure. 


\section{UNIVERSITY OF CALIFORNIA/LOS ANGELES}

307. IRRADIATION INDUCED PRECIPITATION

$\$ 75,000$

$01-4$

IN PALLADIUM-BASE ALLOYS

A. J. Ardell - Materials Department

Phone: (213)-825-5135

Experimental study of irradiation-induced precipitation in binary Pd-base alloys; 400 to $1000^{\circ} \mathrm{C}$; proton, electron, and heavy-ion irradiations; TEM and auger spectroscopy; alloys of Pd with $V$, $\mathrm{Cr}, \mathrm{Mn}, \mathrm{Ce}, \mathrm{Zn}, \mathrm{Cd}, \mathrm{Nb}, \mathrm{Mo}, \mathrm{Ta}, \mathrm{W}, \mathrm{Ag}, \mathrm{Ni}$, and $\mathrm{Cu}$; effect of solutesolvent atomic-size misfit; effect of dose rate; stability of the precipitate; relationship between irradiation-induced precipitate and void swelling.

308. SEMI CONDUCTOR EUTECTICS FOR ENERGY CONVERSION

A. S. Yue - Materials Department

Phone: (213)-825-4166

This research involves the preparation of SnSe (p-type) and $\mathrm{SnSe}_{2}$ (n-type) compounds and a lamellar SnSe-SnSe2 eutectic, and the investigation of semiconductor behavior of these compounds and the eutectic. Because of the extremely high $p-n$ junction density of the SnSe-SnSe2 eutectic, it will be an ideal material for efficient conversion of solar energy into electricity. Liquid phase epitaxy will also be attempted. In addition the GaAs-Ge eutectic system will be studied.

\section{UNIVERSITY OF CALIFORNIA/RIVERSIDE}

309. THEORETICAL ASPECTS OF SUPERCONDUCTOR BEHAVIOR

E. Simanek - Physics Department

Phone: (714)-187-5640

Theoretical study of the properties of inhomogeneous superconducting films and aggregates of ultrafine metallic particles; temperature dependence of the order parameter to be calculated from the model of random superconductivity to interpret tunneling studies of $A l$ films; effects of Josephson coupling between particles in aggregates. 
UNIVERSITY OF CALIFORNIA/SAN DIEGO

310. THE RESPONSE OF SUPERCONDUCTORS

TO VARIATIONS IN IMPURITY

CONTENT AND APPLIED PRESSURE

M. B. Maple - Dept. of Physics

Phone: (714)-452-3969

This is an experimental research program to investigate the response of superconductivity to variations in impurity content, throughout the entire range of solute magnetic character, and applied pressure. The primary interest is in A-15's, ternary molybdenum chalcogenides, and other high $T_{C}$ superconductors. Properties of new rare earth compounds such as $\mathrm{ErRh}_{4} \mathrm{~B}_{4}$ and $\mathrm{ErMo}_{6} \mathrm{Se}_{8}$ will be studied in order to understand re-entrant and coexistence phenomena.

311. RESEARCH ON THERMOPHYSICAL

$\$ 225,393$

$02-2$

PROPERTIES OF MATERIALS

J. C. Wheatley - Dept. of Physics

Phone: (714)-452-2490

The orbital properties of superfluid $3 \mathrm{He}-\mathrm{A}$ are some of the most novel of this superfluid. Using ultrasonic attenuation as a probe both $A$ and $B$ phases of 7 iquid 3 He will be investigated. In addition to this low temperature work, a new effort on liquid engines will be inaugurated.

UNIVERSITY OF CALIFORNIA/SANTA BARBARA

312. RESONANCE STUDIES OF SUPERIONIC CONDUCTORS

V. Jaccarino - Dept. of Physics

Phone: (805)-961-2121

NMR and EPR study of superionic and related compounds; study of phase transition in $\mathrm{PbF}_{2}$ at $310^{\circ} \mathrm{C}$; use of EPR to study electrodeelectrolyte interfaces; Fl9 NMR in $\mathrm{KMn}_{x} \mathrm{Mg} 1-\mathrm{x}$ and in Mn-doped

$\mathrm{PbF}_{3}$; EPR of ion interchange in rutile structure crystals.

\section{CARNEGIE-MELLON UNIVERSITY}

313. KINETICS, MORPHOLOGY AND $\$ 44,740$ 02-2

$\$ 58,995$

02-2

$\$ 154,356$

\section{-2-2}


CASE WESTERN RESERVE UNIVERSITY

314. STUDY OF COUPLED DIFFUSION PHENOMENA

IN MULTICOMPONENT GLASSES AND

GLASS FORMING LIQUIDS
A. R. Cooper - Dept. of Metallurgical and Materials Sciences
Phone: (216)-368-4224

Multicomponent diffusional mass transport in both temperature and concentration gradients; theoretical and experimental; chemical potentials and activities; intrinsic and chemical diffusion coefficients; glasses and glass forming liquids; $\mathrm{K}_{2} \mathrm{O} \cdot \mathrm{SrO} \cdot \mathrm{SiO}_{2}$ system; microprobe analysis; theory of continuous glassmaking.

315. PLASTIC DEFORMATION IN OXIDE $\quad \$ 66,500 \quad 01-2$ CERAMICS

A. H. Heuer - Dept. of Metallurgical and Materials Sciences

Phone: (216)-368-4224

Transmission electron microscopy of dislocation structures and interactions during high temperature deformation of single crystal oxides; effects of stoichiometry; interactions between vacancies, interstitials, clusters and moving dislocations; loop annihilation kinetics and diffusion coefficients.

316. EXPERIMENTS IN HIGH VOLTAGE $\quad \$ 100,087 \quad 01-4$ ELECTRON MICROSCOPY

T. E. Mitchell and L. W. Hobbs - Dept. of Metallurgy. and Materials Science

Phone: (216)-368-4210

High voltage electron microscopy of in-situ radiation damage and kinetic process enhancement; threshold displacement determinations in metals and ceramics; radiation effects in metallic alloys with particular reference to the role of defects; radiation defect stabilization in ceramics; defect aggregation, loop growth kinetics, vacancy condensation and void formation, swelling, and radiationinduced phase decomposition in caramics.

317. ELASTIC AND PLASTIC STRAINS AND $\$ 46,000 \quad 01-2$

THE STRESS CORROSION CRACKING OF AUSTENITIC STAINLESS STEELS

A. R. Troiano - Dept. of Metällurgy and Materials Science

Phone: (216)-368-4234

Stress corrosion cracking in austenitic stainless steels in aqueous chloride solutions; electrochemical potentials of steels with various martensite contents and after cold rolling; passive film structure and stability. 
CASE WESTERN RESERVE UNIVERSITY (Continued).

318. ENVIRONMENTAL REACTIONS AND THEIR EFFECTS ON MECHANICAL BEHAVIOR OF METALLIC MATERIALS

R. Gibala - Department of Metallurgy and Materials Science

Phone: (216) $-368-4210$

Interactions among bulk and near-surface defect structures in metals and influence on mechanical behavior; softening of $\mathrm{Nb}$ and Ta coated with oxide below $77^{\circ} \mathrm{K}$; stress differential effect; dislocation nucleation in stress gradients; effect of 0 on deformation in $\mathrm{Nb}-\mathrm{H}$ alloys and hydride coherency; $\mathrm{H}$ embrittlement of low alloy steels; techniques used -- HVEM and TEM, electrical resistivity, mechanical testing.

CATHOLIC UNIVERSITY OF AMERICA

319. IONIC TRANSPORT AND ELECTRICAL $\$ 47,800$ $01-3$ RELAXATION IN GLASS

C. T. Moynihan, Vitreous State Laboratory

Phone: (202) $-635-5328$

Ionic transport and electrical relaxation in glass; molecular dynamics computer simulation; dielectric relaxation as a function of alkali content; mixed alkali effect.

\section{UNIVERSITY OF CHICAGO}

320. THE STUDY OF PHONONS AND ELECTRONIC . \$64,929. 02-2 PROCESSES IN ORDERED AND DISORDERED SOLIDS

S. A. Solin - Dept. of Physic.s

Phone: (312)-7.53-8224

Raman, infrared and $x$-ray techniques used to investigate dis-. ordered, partially ordered and ordered solids. Specifically, amorphous diamond films, chalcogenide glasses and alloys, graphite intercalates, sodium tungsten bronzes, graphite and tungsten tri-; oxide arc being studied. 


\section{UNIVERSITY OF CINCINNATI}

321. FLUX PINNING AND FLUX FLOW STUDIES IN SUPERCONDUCTORS USING FLUX FLOW NOISE TECHNIQUES

W. C. H. Joiner - Dept. of Physics

Phone: (513)-475-2232

The objective of this work is to study flux pinning and the dynamics of flux flow in type II superconductors. Superconducting alloy samples will be prepared containing various metallurgical defects and exhibiting different critical current characteristics resulting from the defect structure and the flux flow noise power spectrum will be studied. This gives information on flux bundle size, transit time, pinning forces and other flux flow parameters. Magnetic field dependence of flux pinning sites, pinning force curve, surface pinning effects, surface grooving effect are examples of particular phenomena to be studied.

\section{CLARKSON COLLEGE OF TECHNOLOGY}

322. CONDENSATION PROCESSES IN COAL

$$
\$ 39,000
$$

COMBUSTION PRODUCTS

J. L. Katz - Dept. of Chemical Engineering

Phone: (315)-268-6652

M. C. Donohue - Dept. of Chemical Engineering

Phone: (315)-268-6663

Theoretical and experimental study of complex condensation processes occurring in coal-fired energy systems; study of materials problems arising from condensation of slag.

\section{COLORADO ENERGY RESEARCH INSTITUTE}

(COLORADO SCHOOL OF MINES AND COLORADO STATE UNIVERSITY)

323. HYDROGEN AND METHANE SYNTHESES

THROUGH RADIATION CATALYSIS

$\$ 161,990$

$02-2$

J. G. Morse, Colorado School of Mines

Phone: (303)-279-0300

J. DuBow, Colorado State University

Phone: (303)-491-8235

Ionizing radiation has been shown to increase reaction rates by up to two orders of magnitude. The radiation generates electron-hole pairs through optical or radioactive stimulus and subsequent excitation via sub-damage threshold radiation enables the continuous generation of metastable high energy carrier pairs. This research is involved with a study of radiation-induced catalysis examining mechanisms of energy transfer from the catalyst to its adsorbed reactant in an ionizing radiation environment. 
COLORADO SCHOOL OF MINES

324. FERROUS ALLOY METALLURGY -
LIQUID LITHIUM CORROSION
AND WELDING
D. L. Olson - Dept. of Metallurgical Engineering
Phone: (303)-279-0300, X787
D. K. Matlock, Dept. of Metallurgical Engineering
Phone: (303)-279-0300, X775

Weight loss measurements as a function of temperature and nitrogen. content of stainless steel in liquid lithium; grain boundary penetration of stainless steel by liquid lithium; mechanical testing system capable of a range of tensile, creep and fatigue tests in a liquid metal environment; role of alloying elements in controlling weld metal microstructure in dissimilar metal joints; welding of $2 \frac{1}{4} \mathrm{Cr}-1$ Mo to stainless steel; predictive diagrams for weld structure.

UNIVERSITY OF COLORADO

325. CRITICAL SCATTERING OF LASER $\$ 107,385$

$02-2$

LIGHT BY BULK FLUIDS AND THIN

R. Mockler - Dept. of Physics \& Astronomy

Phone: (303)-492-7777

W. O'Sullivan - Dept. of Physics \& Astronomy

Phone: (303)-492-7457

The dependence upon film thickness of the critical temperature of binary fluid films will be studied using index of refraction techniques. The recently discovered 2-d Ising model scaling behavior will be exploited. The cross-over from three-dimensional Ising model to two dimensional will be studied. In particular Brownian motion in critical fluid films will be observed as the film crosses over to two dimensions.

\section{COLUMBIA UNIVERSITY}

326. DEFECT INTERACTIONS AT HIGH CONCENTRATIONS IN SOLID-OXIDE ELECTROLYTES

A. S. Nowick - Krumb School of Mines

Phone: (212) $-280-2921$

Interactions of defects at high concentrations in oxides that are fast-ion conductors; $\mathrm{CeO}_{2}$ doped with trivalent elements ( $Y, \mathrm{Gd}$, $\mathrm{La}, \mathrm{SC}$ ) of different ionic radius; study of relationship between defect structure and electrical properties; relationship between simple defects that form at low concentrations and the ordering and microdomain formation observed at high concentrations; defect structure in $\mathrm{Bi}_{2} \mathrm{O}_{3}$-based solid solutions, with the fluorite structures, having high conductivity. 
COLUMBIA UNIVERSITY (Continued)

327. HIGH TEMPERATURE PROPERTIES

OF NUCLEAR REACTOR COOLANTS

$\$ .47,599$

$03-2$

AND THERMODYNAMIC POWER CYCLE

WORKING FLUIDS

C. F. Bonilla - Dept. of Chemical Engineering

Phone: (212) $-280-4441$

Determination of the isothermal compressibility of liquid sodium to $3000^{\circ} \mathrm{F}$ and to measure the vapor pressure of lithium in the critical regime. Surface tension properties' of lithium and PVT data for cesium near the critical point.

UNIVERSITY OF CONNECTICUT

328. ELECTRON-DISLOCATION INTERACTIONS

AT LOW TEMPERATURES

$\$ 51,218$

$01-2$

J. M. Galligan - Dept. of Metallurgy

Phone: (203)-486-3541

Electron and phonon drag on dislocations; use of superconductornormal transition to alter electronic state; dislocation-fluxoid interactions; flow stress-field interactions in normal metals; dislocation-interstitial interactions; orientation effects; $\mathrm{Pb}$, $\mathrm{Pb}-\mathrm{Sn}, \mathrm{Pb}-\mathrm{Ag}, \mathrm{Cu}$, and $\mathrm{Zn}$.

329. CLUSTER CAREURIZING

J. E. Morral - Dept. of Metallurgy

$\$ 32,500$

$01 \cdot 1$ and Inst. of Materials Sciences

Phone: (203)-486-2923

Carburization of Ta-Hf and $\mathrm{Nb}-\mathrm{Hf}$ alloys on pre-existing solute clusters or on dislocation network; theory of subscale:formation; $\mathrm{NbC}-\mathrm{HfC}$ phase diagram.

330. ELECTRODE POLARIZATION STUDIES

IN HOT CORROSION SYSTEMS

$\$ 42,200$

$01-1$

0 . F. Devereux - Dept. of Metallurgy

Phonie: (203)-486-4714

Elevated temperature corrosion of metals -- $\mathrm{Fe}, \mathrm{Ni}, \mathrm{Cr}$ and their alloys -- in gases and liquids with high $S$ contents; thermodynamic modelling of activities in multicomponent systems; measurement of . electrochemical behavior of $\mathrm{Fe}$ and $\mathrm{Ni}$ in molten $\mathrm{Na}_{2} \mathrm{CO}_{3}$; development of $\mathrm{Al}_{2} \mathrm{O}_{3}$ reference electrode. 
CORNELL UNIVERSITY

331. MECHANICAL PROPERTIES OF

$\$ 87,021$

$01-2$

CRYSTALLINE SOLIDS

Che-Yu Li - Dept. of Materials Science and Engineering

Phone: (607)-256-4349

E. W. Hart - Dept. of Materials Science and Engineering

Phone: (607)-256-4853

Development of concepts and methods for characterizing mechanical properties of solids based on the state variable approach; load relaxation of metallic glasses; load relaxation of Zircaloy-4; growth kinetics of grain boundary methane bubbles in $\mathrm{Ni}$; creep damage in the form of grain boundary cavities in Zircaloy-4; non-elastic deformation and recovery in $\mathrm{Al}$ and $\mathrm{Ni}$.

332. DEFECTS IN METAL CRYSTALS

$\$ 211,948$

$01-4$

D. N. Seidman - Dept. of Materials Science and Engineering

Phone: (607)-256-2365

Field ion microscopy and field ion atom probe techniques used to study vacancies, interstitials, solute atoms, aggregates of point defects such as voids and their interactions with one another; in-situ irradiation; point defect structure of depleted zones in ion-irradiated metals; transmission sputtering of gold thin films by low energy zenon ions; range of focussed collision replacement sequences; recovery behavior of proton irradiated tungsten; mobility and range of implanted low energy helium in tungsten.
333. MECHANICAL BEHAVIOR OF MATERIALS
$\$ 75,000$
$01-2$
AND STRUCTURAL ELEMENTS AT
ELEVATED TEMPERATURES
R. H. Lance - Dept. of Theoretical and Applied Mechanics
Phone: (607)-256-4326
E. W. Hart, Dept. of Theoretical and Applied Mechanics
Phone: (607)-256-1853

Analytical and experimental research on constitutive eqúation for mechanical deformation; deformation of thick walled spheres and. cylinders for all symmetrical loading methods; computer programs for the predicted deformation for a variety of loading conditions for spherical and cylindrical geometry; testing and comparison for beams under long and short time test conditions and under many loading sequences. 
CORNELL UNIVERSITY (Continued)

334. INFLUENCE OF GRAIN BOUNDARIES

ON THE ELECTRICAL TRANSPORT

$\$ 52,600$

$01-1$ PROPERTIES OF POLYCRYSTALLINE SI FILMS

D. G. Ast - Dept. of Materials Science and Engineering

Phone: (607)-256-4140

Evaluation of structure and electrical activity of defects in crystalline Si; tilt and twist boundaries in hot-pressed Si: twin boundaries in Si produced by edge-defined film-fed growth; techniques used: TEM, SEM, EBIC in SEM.

335. PROBABILISTIC MODELS OF THE STRESSRUPTURE OF COMPOSITE MATERIALS

$\$ 53,000$

$01-2$

S. L. Phoenix - Sibley School of Mechanical and Aerospace Engineering

Phone: (607)-256-3462

Development of probabilistic models of tensile strength and stressrupture of fiber reinforced polymer composites; local vs equal load sharing considerations; weakest link rule scaling of composite size effect.

336. ENVIRONMENT AND FRACTURE

H. H. Johnson - Dept. of Materials

$\$ 66,000$

$01-2$ Sciences and Engineering

Phone: (607)-256-2323

Transient effects and trapping sites associated with $H$ permeation in $\mathrm{Fe}$ and steels; trap densities and binding energies in steels; effect of aqueous sulfide environment on $\mathrm{H}$ permeation; $\mathrm{Nb}-\mathrm{H}$ alloy fracture and hydride formation during thermal cycling.

337. HIGH TEMPERATURE MECHANICAL BEHAVIOR OF SILICON NITRIDE

R. Raj - Dept. of Materials Science and. Engineering

Phone: (607)-256-4040

Crack initiation and crack growth leading to failure in silicon nitride ceramics at elevated temperatures; relation of microstructure to deformation and fracture; effects of grain size, porosity, composition, volume fraction and distribution of intergranular phases; grain boundaries; slow crack growth; internal friction, transmission electron microscopy. 
CORNELL UNIVERSITY (Continued)

338. INELASTIC DEFORMATION IN NONMETALLIC CRYSTALLINE SOLIDS

D. L. Kohlstedt - Dept. of Materials Science and Engineering

Phone: (607)-256-7144

Plastic deformation of germanium and transition metal carbides; load relaxation and constant strain rate experiments; transmission electron microscopy; dislocation etch pit studies on germanium; effects of charged impurities on dislocation dynamics in germanium; correlation of dislocation substructures to a mechanical equation of state.

DARTMOUTH COLLEGE

339. THEORY OF ELECTRON-PHONON SCATTERING EFFECTS IN METALS

W. E. Lawrence - Dept. of Physics and Astronomy

Phone: (603)-646-2963

It is proposed to continue studies of the quasi-particle scattering times of the noble and polyvalent metals. The transport problem will be studied by means of the diffusion model. Electron-electron scattering will be studied further in the noble metals, with regard to deviations from Matthiessen's rule when electron-phonon scattering is present. Nonequilibrium studies in general will be continued and new studies begun for superconductors. In the latter case variational methods will be used.

340. EXPERIMENTAL DETERMINATION OF THE $\$ 30,809 \quad 02-2$ TEMPERATURE DEPENDENCE OF METALLIC WORK FUNCTIONS AT LOW TEMPERATURES

P. B. Pipes - . Dept. of Physics and Astronomy

Phone: (603)-646-2962

The effect of the superconducting transition on the temperature dependence of the contact potential in niobium will be studied as a function of magnetic field and surface preparation to determine the relative importance of bulk and surface effects. The influence of adsorbed $4 \mathrm{He}$ will also be studicd. 
DREXEL UNIVERSITY

341. STRAIN HARDENING AND DUCTILITY

OF IRON: AXISYMMETRIC VS. PLANE

$\$ 40,900$

$01-2$

STRAIN ELONGATION

G. Langford - Dept. of Materials Engineering

Phone: (215)-895-2330

Correlation of strain hardening of iron and steel with dislocation structure developed during secondary fabrication; axisymmetric and plane strain deformation; technique used; high voltage electron microscopy, wire and strip drawing, tensile testing.

UNIVERSITY OF FLORIDA

342. SYNTHESIS AND CHARACTERIZATION \& $\$ 70,000 \quad 03-3$

UH NOVEL POLYMEKS FRUM. NON-

PETROLEUM SOURCES

G. B. Butler - Dept. of Chemistry

Phone: (904)-392-2012

T. E. Hogen-Esch - Dept. of Chemistry

Phone: (904)-392-2011

The synthesis and characterization of novel polymers for evaluation in the enhanced oil recovery program. "Tailor-made" polymers designed to overcome deficiencies of polymers presently being used, and made from non-petroleum sources such as naturally occurring carbohydrates, proteins, lignins, or polyisoprenes.

343. DEFORMATION PROCESSES IN REFRACTORY \$ $\$ 44,000$ 01.-2 METALS

R. E. Reed-Hill - Dept. or Materials Science and Engineering

Phone: (904)-392-1456

Effect of impurity interstitials $(\mathrm{O}, \mathrm{H})$ on dynamic strain aging of refractory metals ( $\mathrm{Nb}, \mathrm{V}$ ) and correlation: with slow strain rate embrittlement; effect of interstitial clustering; techniques used: internal friction, tensile testing.

344. QUANTITATIVE ANALYSIS OF SOLUTE SEGREGATION IN ALLOYS BY TRANSMISSION

$\$ 53,800$ $01-1$ ELECTRON MICROSCOPY

J. J. Hren - Dept. of Metallurical and Materials Engineering

Phone: (904)-392-1462

C..S.: Hartley - Dept. of Metallurgical

and Materials Engineering

Phone: (904)-392-1457

Experimental and analytical study of defect images in TEM; effects of local strain fields and elastic anisotropy; catalogue of simulated dislocation images for face-centered-cubic and body centered-cubic-metals; techniques used: computer simulation, HVEM. 
GEORGIA INSTITUTE OF TECHNOLOGY

346. THE STRUCTURE AND REACTIVITY OF HETEROGENEOUS SURFACES AND STUDIES

OF THE GEOMETRY OF SURFACE COMPLEXES

U. Landman - Dept. of Physics

Phone: (404)-894-3368

E. W. Montroll - Dept. of Physics \& Astronomy

Phone: (716) -275-4371

An investigation of methods for the study of the geometry and dynamics of adsorbates on surfaces. Using a newly developed cluster migration technique and surface molecular dynamics such problems as diffusion, annealing and bimolecular surface reactions are being studied. Also a vibrational-phonon coupling model to explain thermal desorption is being developed.

347. INVESTIGATIONS OF RELATIONSHIPS $\$ 82,000 \quad 01-1$ BETWEEN MICROSTRUCTURE, MAGNETIC PROPERTIES AND THE HYDRIDING PROCESSES

IN INTERMETALLIC COMPOUNDS OF RARE

EARTH AND TRANSITION METALS

B. R. Livesay - Applied Sciences Laboratory

Phone: (404)-894-3489

Studies of both thin and thick films of FeTi and certain RT5 alloy systems where $R$ represents a rare earth and $T$ a transition metal element; microstructure, magnetic properties, electronic structure, and pressure-composition relationships caused by modifications to the alloy system; surface coatings, ternary alloy additions and thermal mechanical effects; TEM, AES and SEM; hydride nucleation sites, growth mechanisms, hydride decomposition and hysteresis and stability.

UNIVERSITY OF HAWĀIII

347. PRESSURE DERIVATIVES OF ELASTIC MODULI IN B.C.C. TRANSITION METALS

AND THEIR SOLID SOLUTIONS

M. H. Manghnani - Dept. of Geology and Geophysics

Phone: (808)-948-8111

Investigation of the pressure dependence of the structure and elastic properties of bcc solid solutions alloys of the transition elements of groups IV B, V B, and VI B using u7trasonic interferometry to $5 \mathrm{Kbar}$, and $\mathrm{x}$-ray diffraction techniques up to $200 \mathrm{kbar}$. The relationship between the electronic band structure and the elastic properties of these materials will be studied. 
UNIVERSITY OF HOUSTON

34.9. MICROSTRUCTURAL STUDIES OF

HYDROGEN AND OTHER INTERSTITIAL

$\$ 65,800$

$02-2$

DEFECTS IN BCC REFRACTORY METALS

S. C. Moss - Dept. of Physics

Phone: (713)-749-2840

$X$-ray and neutron diffraction study of $H$ and $D$ occupancy in $\mathrm{V}, \mathrm{Ta}$, $\mathrm{Nb}$; symmetry of interstitial-induced strain field; short-range and long-range order; positron annihilation in $\mathrm{Ta}-\mathrm{H}$ alloys related to Fermi surface modifications.

\section{ILLINOIS INSTITUTE OF' TECHNOLOGY}

350: DIFFUSION MECHANISMS AND

DEGRADATION OF ENVIRONMENTALLY

$\$ 48,400 \quad 01-2$

SENSITIVE COMPOSITE MATERIALS

L. J. Broutman - Dept. of Metallurgy and Materials Engineering

Phone: (312)-567-3049

Investigation of moisture diffusion mechanisms and environmental degradation in graphite fiber reinforced epoxy composites; comparison with matrix behavior alone; influence of stress on permeation and fiber-matrix decohesion.

351. ELECTROCHEMISTRY OF ACETYLIDES, NITRIDES AND CARBON CATHODES IN MOLTEN HALIDES

J. R. Selman - Dept. of Chemical Engineering

Phone: (312)-567-3037

Investigation of the electrochemical properties of carbon as a cathode in molten halides, and of the stable acetylides and nitrides of lithium and calcium in molten-halide solutions. Chronopotentiometric and potentiodynamic techniques used for electrode-kinetic studies, and $x$-ray and ion microscopy techniques used for characterization of carbon substrates and deposits. 
LEHIGH UNIVERSITY

352. PRESSURE SINTERING AND CREEP DEFORMATION - A JOINT MODELLING

$\$ 48,707$

$01-1$ APPROACH

M. Notis - Dept. of Metallurgy and Materials Sciences

Phone: (215)-691-7000, X636

Correlation of the kinetics of later stages of densification by pressure sintering with creep deformation; determination of ratecontrolling mechanisms; effects of stress, temperature, microstructure, stoichiometry, and impurity content; quantitative relationships via. deformation maps; transmission electron microscopy of dislocation substructures; grain boundary segregation; grain boundary deformation; $\mathrm{COO}, \mathrm{NiO}$, and $\mathrm{MgAl}_{2} \mathrm{O}_{4}$.

UNIVERSITY OF MARYLAND

353. ALLOY STRENGTHENING DUE TO ATOMIC $\$ 53,600$ 01-2 ORDER

M. J. Marcinkowski - Dept. of Mechanical Engineering

Phone: (301)-454-2408

Mathematical modelling of cracks and interfaces in metals in terms of dislocation arrays; differential geometry description of elastic and plastic distortions and tearing; cyclic stress and tensile vs shear crack considerations; development of scaling methods.

MASSACHUSETTS INSTITUTE OF TECHNOLOGY

354. MICROMECHANICAL MODELLING OF MICRO-

$\$ 122,700$ $01-2$

STRUCTURAL DAMAGE AT ELEVATED

TEMPERATURE DURING CREEP OF SUPERALLOYS

FOR ENERGY APPLICATIONS

A. S. Argon - Dept. of Mechanical Engineering

Phone: (617) -253-2217

F. A. McClintock - Dept. of Mechanical Engineering

Phone: (617)-243-2217

Investigation of crack nucleation and growth during creep of metal alloys; analytical description of singularities such as particlematrix decohesion at grain boundaries; modelling boundary sliding and crack initiation and growth; materials --- stainless steel, nickel alloys. 
MASSACHUSETTS INSTITUTE OF TECHNOLOGY (Continued)

\author{
355. KINETIC PROCESSES AT GRAIN \\ BOUNDARIES \\ R. W. Balluffi - Dept. of Materials \\ Science and Engineering \\ Phone: (607)-256-4135
}

$\$ 94,000$

$07-1$.

Experimental investigation of kinetic processes in grain boundaries in metals; atomic transport along grain boundaries; interaction of lattice dislocations with grain boundaries; thin-film specimens containing boundaries of controlled geometry; modeling of the kinetics in terms of the dissociation and glide of appropriate grain boundary dislocation segments in the boundaries.

356. HIGH TEMPERATURE PROPERTIES AND $\$ 124,000$ $01-3$ PROCESSES IN CERAMICS

H. K. Bowen - Dept. of Ceramics

Phone: (617)-253-6892

B. J. Wuensch - Dept. of Ceramics

Phone: (617) $-253-6889$

Effects of large temperature gradients on atomic transport behavior in ceramics; theory of time dependent thermomigration; kinetic and thermodynamic effects in transport theory; ion microprobe analysis; . oxygen tracer diffusion; Seebeck effect; pore migration; $\mathrm{FeO}, \mathrm{FeAl}_{2} \mathrm{O}_{4}-$ $\mathrm{Fe}_{3} \mathrm{O}_{4}$ solid solutions, $\mathrm{KCl}, \mathrm{NaCl}, \mathrm{Al}_{2} \mathrm{O}_{3}$.

357. PROCESSING STUDIES OF POWDER METALLURGICALLY PRODUCED HIGH

$\$ 46,800$ $01-2$ TEMPERATURE ALLOYS

N. J. Grant - Dept. of Materials Science and Engineering

Phone: (617)-253-5637

Powder metallurgical fabrication of $\mathrm{Fe}-, \mathrm{Ni}-$, and $\mathrm{Co}$-base alloys; use of pulsed atomization process to modify composition and phase distribution from those of ingot stock; elevated temperature stress rupture behavior. 
MASSACHUSETTS INSTITUTE OF TECHNOLOGY (Continued)

358. BASIC RESEARCH IN CRYSTALLINE

$\$ 585,000$

$01-1$

AND NONCRYSTALLINE CERAMIC SYSTEMS

W. D. Kingery - Dept. of Materials Science and Engineering

Phone: (617)-253-3319

R. L. Coble - Dept. of Materials Science and Engineering

Phone: (617)-253-3318

Electrical conduction mechanism operating in $\mathrm{Al}_{2} \mathrm{O}_{3}$. at elevated temperatures; electronic and ionic conduction in $\mathrm{UO}_{2}$; dc conductivity and ionic transference in $\mathrm{MgO}$; sintering of $\mathrm{ZnO}$; sintering maps for $\mathrm{MgO}$ and $\mathrm{Al}_{2} \mathrm{O}_{3}$; activated sintering of $\mathrm{CaF}_{2}$; ion transport and diffusion in $\mathrm{KCl}$; oxidation kinetics of $\mathrm{Fe}$ in $\mathrm{MgO}$; calculations of defects and defect clustering in MgO; effect of dislocations in MgO on the modification of dielectric loss; sintering mechanisms in covalent materials; deformation and sintering mapping of $\mathrm{UO}_{2}$ low temperature microstructure development of cementitious materials; carbide ceramics survey; ionic thermocurrent of defect complexes in MgO; STEM analys is of grain boundary segregation in MgO.

359. LOW TEMPERATURE AND NEUTRON PHYSICS $\$ 166,322$ 02-1 STUDIES

C. G. Shul1 - Dept. of Physics

Phone: (617)-253-4521

The neutron spectrometers currently being modernized at the reconstructed MIT Research Reactor have been reinstalled and used for studies in materials characterization and fundamental neutron physics.: The high flux reactor at ORNL will also be used. These studies will:include further work on the diamagnetization structure of bismuth, de Haasvali Alphen scattering effects and on neutron interferometry. development and uses.

360. ELECTRONIC CONDUCTION IN SOLID

$\$ 60,000$ $03-3$ OXIDE ELECTROLYTES

H. L. Tuller - Dept. of Materials Science and Engineering

Phone: (617)-2.53-6890

Investigate electronic conduction in solid oxide electrolytes; a subgroup of fast ionic conductors in which oxygen diffuses rapidly at elevated temperatures. Parameters controlling nonstoichiometry, impurities and electronic mobility. Pure and doped $\mathrm{ThO}_{2}$ examined for electronic conductivity thermoelectric power, and ionic transference number. Microstructural studies of second phases, grain boundary effects and segregation. 
MASSACHUSETTS INSTITUTE OF TECHNOLOGY (Continued)

361. SPECTROSCOPIC INVESTIGATIONS OF

SMALL MOLECULE INTERACTIONS ON

METAL OXIDE SURFACES

E. I. Solomon - Dept. of Chemistry

Phone: (617)-253-4508

F. R. McFeely - Dept. of Chemistry

Phone: (617)-253-6106

The study of the surface chemistry of meldilic oxide systems of importance as catalysts in industrial processes such as hydrogenation, dehydrogenation and dehydration. Primary emphas is on the interaction of chemically relevant molecules (e.g. $\mathrm{H}_{2}, \mathrm{CO}$, $\mathrm{CO}_{2}, \mathrm{CH}_{4}$ ) with $\mathrm{ZnO}, \mathrm{Al}_{2} \mathrm{O}_{3}$, and $\mathrm{Cr}_{2} \mathrm{O}_{3}$ single crystals, using angleintegrated uv photoemission spectroscopy and high resolution energy loss spectroscopy.

362. A BASIC STUDY OF ELECTROSLAG

$\$ 60,000$

$01-5$ WELDING

J. Szekely - Dept. of Materials Science and Engineering

Phone: (617)-253-6885

T. Eagar - Dept. of Materials Science and Engineering

Phone: (617)-253-.3236

Study of electroslag welding of low alloy steels; two dimensional analysis of heat and fluid flows for orthogonal and radial weld geometries; evaluation of weldment macro- and microstructure and hardness profiles.

MICHIGAN TECHNOLOGICAL UNIVERSITY

363. A STUDY OF GRAIN BOUNDARY SEGREGATION $\$ 56,000 \quad 01-2$ IJSING THE NUGER ELECTRON EMISSION TECHNIQUE

D. F. Stein - Dept. of Metallurgical Engineering Phone: (906) $-487-2440$

L. A. Heldt - Dept. of Metallurigal Engineering

Phone: (906) $-48 /-2630$

Grain boundary segregation in metals and effect on properties; stress corrosion cracking, theory and experiment; Auger photoelectron spectroscopy; sulfur segregation in $\mathrm{Mo}, \mathrm{Bi}$ in $\mathrm{Fe}, \mathrm{S}$ in $\mathrm{Fe}$; stress corrosion cracking of aluminum bronzes; hydrogen embrittlement of copper alloys and pure iron; liquid and solid metal embrittlement as affected by grain boundary segregation; embrittlement of $\mathrm{Cu}$ by $\mathrm{Pb}$. 
UNIVERSITY OF MINNESOTA

364. EXPERIMENTAL INVESTIGATIONS IN

SOLID STATE AND LOW TEMPERATURE

PHYSICS

A. M. Goldman - Dept. of Physics

Phone: (612)-373-5480

W. V. Weyhmann - Dept. of Physics

Phone: (612)-373-5481

W. Zimmermann, Jr. - Dept. of Physics

Phone: (672)-373-9787

Measurements of pair-field susceptibility will be done as well as fluctuation phenomena, and the interaction of long-range magnetic order and superconductivity. The metal-nonmetal transition in $\mathrm{Hg}_{\mathrm{x}} \mathrm{Se} \mathrm{I}_{-\mathrm{x}}$ will be completed. The magnetic studies will be carried out at temperatures in the 1-100 mK range, and applied fields of $10 \mathrm{G}$ to $80 \mathrm{KG}$ wi 11 be used to study the static and dynamic properties of weak magnetic materials in the critical region. Paramagnetic materials for magnetic refrigerators above $1 \mathrm{~K}$ will be investigated in a series of promising compounds.

NEW MEXICO INSTITUTE OF MINING AND TECHNOLOGY

365. MICROSTRUCTURE AND MECHANICAL

PROPERTIES OF COATINGS FOR SOLAR

$\$ 65,000$

$01-1$

COLLECTORS

0 . T. Inal - Dept. of Metallurgical and Materials Engineering

Phone: (505)-835-5011

L. E. Murr - Dept. of Metallurgical and Materials Engineering

Phone: (505) -835-5011

Effect of plating geometry, bath compositions and current densities on the surface structure of electroplated black chrome; transmission electron microscopy, hardness, solar energy absorption studies; nucleation studies using field ion microscopy. 
CITY UNIVERSITY OF NEW YORK

366. NONADIABATIC APPROACH TO VIBRONICALLY ASSISTED RADIATION AND RADIATIONLESS TRANSITIONS

M. Lax - Dept. of Physics

Phone: (212) $-690-6864$

A relation will be developed between the vibronically assisted radiative cross-section and that for radiationless transitions. Calculations will be made of the cross section associated with a true multiphonon process. The method proposed will treat the nuclei classically but avold the adfabatfc appruxillaliun and will be patterned after a method due to Landau and Zener. A specific calculation is the rate of piezoelectric and deformation potential production of acoustic phonons during nonradiative capture in GaAs.

STATE UNIVERSITY OF NEW YORK/BINGHAMTON

367. ENERGIES AND BONDING IN MANGANESE PHOSPHIDES

C. E. Myers - Dept. of Chemistry

Phone: (607)-798-2269

Systematic interrelations among the atomization enthalpies, electron binding energies, bond energies in manganese phosphides in relationship with other transition metal phosphides. Dissociation pressure measurements of two-phase regions in the Mn-P system, as well as $X$-ray photoelectron spectra of manganese phosphides in comparison with phosphides of iron.

STATE UNIVERSITY OF NEW YORK/STONY BROOK

368. PREPARATION, CHARACTERIZATION AND $\$ 49,000 \quad 01-1$ USE OF METAL HYDRIDES FOR FUEL SYSTEMS P. J. Herley - Dept. of Materials Science Phone: (516)-246-6759

Effects of various pretreatments on the thermal decomposition kinetics of aluminum hydride powder; determination of kinetic parameters governing thermal decomposition; effects of gamma-ray pre-irradiation; photodecomposition with high intensity uv light; activation energies and chemical order of reactions; lithium aluminum hydride, magnesium aluminum hydride, and magnesium hydride; mechanisms underlying decomposition reactions, preparation and recrystallization of high purity hydrides; atomic hydrogen bombardment. 
STATE UNIVERSITY OF NEW YORK/STONY BROOK (Continued)

369. THEORETICAL STUDIES OF CHEMISORPTION

$\$ 72,968$

$02-3$

ON TRANSITION METAL SURFACES: INTER-

ACTION OF HYDROGEN WITH TITANIUM

J. L. Whitten - Dept. of Chemistry

Phone: (516)-246-6068

J. D. Do11 - Dept. of Chemistry

Phone: (516)-246-5014

This research is concerned with the theory of chemisorption of molecules on solid surfaces and is directed toward the development of a theoretical model for treating electronic interactions at an ab-initio level. Calculations on the hydrogen-titanium system are proposed: in which the objective is to obtain a detailed account of molecule-surface interactions including an adequate response of the lattice to the adsorbate. The removal of special surface atoms will replicate the formation of a step.

UNIVERSITY OF NORTH CAROLINA

370. THE STRUCTURE OF NEUTRON DAMAGE

IN IONIC REFRACTORY OXIDES

J. H. Crawford, Jr. - Dept. of Physics

Phone: (919)-933-2078

Structure of neutron damage in ionic refractory oxides; lattice expansion, lattice defects, and associated charge states; optical absorption; luminescent emission; electron spin resonance;

dimensional charge measurements; elastic constant measurements; $\mathrm{MgO}, \mathrm{Al}_{2} \mathrm{O}_{3}, \mathrm{MgAl}_{2} \mathrm{O}_{4}, \mathrm{Y}_{3} \mathrm{Al}_{5} \mathrm{O}_{2}$, and $\mathrm{TiO}_{2}$.

NORTHEASTERN UNIVERSITY

371. EQUILIBRIUM AND TRANSPORT PROPERTIES \$37,639 OF DISORDERED TRANSITION AND NOBLE METAL ALLOYS

A. Bansil - Dept. of Physics

Phone: (617)-437-2923

P. N. Argyres - Dept. of Physics

Phone: (617)-437-2924

Theoretical studies of equilibrium and transport properties using the average t-matrix approximation: (ATA) applied to a vartety of disordered:alloys with noble metal base and polyvalent solute. 
NORTHEASTERN UNIVERSITY (Continued)

372. STUDIES OF DISLOCATION MOTION AND SLIDING FRICTION

J. Sokoloff - Dept. of Physics

Phone: (617)-437-2931

The Frenkel-Kontorova model will be used to study the epitaxial growth of films and how they get pinned in place even when its periodicity is not commensurate with the substrate. In addition the damping of dislocation motion and friction between sliding crystal planes will be studied in a modified Frenkel-Kontorova model in which phonons are created. The method will also be applied to a model of superionic conduction.

NORTHWESTERN UNIVERSITY

373. INVESTIGATION OF DISPERSED IRON

ALLOY CATALYSTS IN THE CARBON

MONOXIDE-HYDROGEN SYNTHESIS.

REACTION

J. B. Butt - Dept. of Chemical Engineering and Materials Sciences

Phone: (372) $-492-7620$

L. H. Schwartz - Dept. of Chemical Engineering and Materials Sciences

Phone: (312) $-492-5370$

Study of highly dispersed bimetallic iron alloys and their carbides as formed in the $\mathrm{CO}_{-} \mathrm{H}_{2}$ synthesis reaction; iron-copper and iron-alkali systems; determination of particle sizes, shapes and size distribution using fourier analysis, $X$-ray line broadening, and transmission electron microscopy; precise determination of the caribde structure using temperature variation in Mossbauer experimental, experiments to characterize the magnetic saturation structure. Measurement of local temperature rise on the carbide as a consequence of the synthesis reaction.

374. STUDIES OF METAL-SEMICONDUCTOR

$\$ 60,000$

INTERFACES IN CATALYSIS AND

ENERGY CONVERSTON

$Y-W$. Chung - Dept. of Materials Science and Engineering

Phone: (3.12)-492-3584

The study of the properties of metal-semiconductor interfaces in nickel methanation and photochemical energy conversion. Emphasis will be on the electronic properties of the interface between nickel and its support (either $\mathrm{TiO}_{2}$ or $\mathrm{ThO}_{2}$ ) and the chemisorption of $\mathrm{H}_{2}, \mathrm{CO}$ and $\mathrm{H}_{2} \mathrm{~S}$ on supported $\mathrm{Ni}$ surfaces. 
NORTHWESTERN UNIVERSITY (Continued)

375. EFFECT OF POINT DEFECTS ON MECHANICAL PROPERTIES OF METALS

$\$ 58,400 \quad \therefore \quad 01-4$

M. Meshi i - Dept. of Materials Science

Phone: (312)-492-3213

Deformation of metals at low temperature, surface film softening of $\mathrm{Ni}$-coated $\mathrm{Fe}$; electron irradiation of $\mathrm{Nb}$ sheet, effects of crystal-. lographic orientation, temperature, strain rate and prestrain on strength, dislocation motion, and slip band formation.

376. BASIC RESEARCH ON CERAMIC MATERIALS FOR ENERGY STORAGE

$\$ 65,000$

$01-1$ AND CONVERSION SYSTEMS

D. H. Whitmore - Dept. of Materials Science

Phone: (312)-492-3533

Experimental determination of the factors affecting charge and mass transport in solid electrolyte and electrode materials; single crystal growth; electrical conductivity, tracer diffusion, nuclear magnetic resonance, dielectric loss, ionic thermal currents, and laser Raman spectroscopy; study of electrolyte polarization by complex admittance analysis in sodium doped $\beta^{\prime \prime}$ alumina; solid solution electrodes for lithium and sodium cells; growth of single crystal zirconium sulfide; zirconium selenide; layered compounds; fast ion conductors; various antimonates; mixed chlorides; lithium titanates, indium and thallium ternary iodides.

UNIVERSITY OF NOTRE DAME

377. PORE SHRINKAGE AND OSTWALD RIPENING IN METALLIC SYSTEMS

G. C. Kuc.zynski - Dept. of Metallurgy Engineering and Materials Science

Phone: (219)-283-6151

C. W. Allen - Dept. of Metallurgy Engineering and Materials Science

Phone: (219)-283-7456

Experimental study of the kinetics of pore shrinkage in porous structures; theoretical and experimental investigation of Ostwald ripening of pores, second phases, and supported catalysts; in-situ transmission electron microscopy; $\mathrm{Ni}-\mathrm{Al}$ and $\mathrm{Au}-\mathrm{Fe}$ alloys. 
OHIO STATE UNIVERSITY

378. FUNDAMENTAL STUDIES OF METAL

FLUORINATION REACTIONS

R. Rapp - Dept. of Metallurgical Engineering

Phone: (614)-422-6178

Study of structural, thermodynamic, and transport properties pertinent to solid state electrolytes and fluorination of $\mathrm{Cu}$ and $\mathrm{Ni}$; electrical conductivity, defect structures and transport mechanisms in $\mathrm{CaF}_{2}$, $\mathrm{NiF}_{3}$, and $\mathrm{PbF}_{2}$.

379. HYDROGEN ATTACK OF STEEL

P. G. Shewmon - Dept. of Metallurgical

$\$ 41,257$

$01-2$ Engineering

Phone: (614)-422-2491

Experimental investigation of the microscopic processes that 1 imit the nucleation and growth of methane bubbles during hydrogen attack of steel; effects of deoxidation practice, microstructure, and inclusions; mechanism and kinetics of hydrogen attack; metallography of fracture kinetics and volume-change kinetics.

380. CORROSION, STRESS CORROSION CRACKING

$\$ 61,400$ $01-1$ AND ELECTROCHEMISTRY OF THE IRON AND NICKEL BASE ALLOYS IN CAUSTIC ENVIRONMENTS

R. W. Staehle - Dept. of Metallurgical Engineering

Phone: (614)-422-6255

A. K. Agrawal - Dept. of Metallurgical Engineering

Phone: (614)-422-1634

Corrosion of $\mathrm{Fe}, \mathrm{Ni}$, and $\mathrm{Cu}$ and their alloys in caustic and sulfide aqueous environments between ambient and $150^{\circ} \mathrm{C}$; surface film formation and rupture and correlation with alloy composition in SCC of austenitic stainless steels; effectiveness of inhibitors, including chromate union, related to redox couples; techniques used: slow and fast straining electrode, potentiodynamic scans, controlled potential coulometry. 
OKLAHOMA STATE UNIVERSITY

381. ELECTRONIC STRUCTURE OF DEFECTS IN OXIDES

G. P. Summers - Dept. of Physics

Phone: (405)-624-5813

Photoconductivity and fluorescence measurements in oxides -- $\alpha-\mathrm{Al}_{2} \mathrm{O}_{3}$, $\mathrm{CaO}$, SrO, and spinels; determination of electronic structure of defects and changes produced by $\gamma$-ray, electron, neutron or proton irradiation; effect of $\mathrm{V}, \mathrm{Cr}$, and $\mathrm{Fe}$ impurities on charge transfer in $\alpha-\mathrm{Al}_{2} \mathrm{O}_{3}$.

PENNSYLVANIA STATE UNIVERSITY

382. CERAMIC RESEARCH

R. C. Bradt - Dept. of Materials Science

$\$ 40,000$

$01-2$

Phone: (814)-865-4700, X4631

J. H. Hoke - Dept. of Materials Science

Phone: (814)-865-4700, X2071

Transformational and isothermal superplasticity in two phase eutectoid systems such as $\mathrm{Bi}_{2} \mathrm{O}_{3}-\mathrm{Sm}_{2} \mathrm{O}_{3}$ and in single phase $\mathrm{Bi}_{2}$ WO6-type compounds; effects of stoichiometry on fracture and elastic properties of $\mathrm{TiO}_{2-x}, \mathrm{FeO}_{1+x}$ and $\mathrm{MgAl}_{2} \mathrm{O}_{4}$ spinel; $\mathrm{K}_{\text {Ic }}$ measurements; subcritical crack growth; fracture.
383. GRAIN BOUNDARY DIFFUSION AND
GRAIN BOUNDARY CHEMISTRY OF
$\$ 18,500$
$01-3$
CR-DOPED MAGNESIUM OXIDE
V. S. Stubican - Dept. of Materials Science
Phone: (814)-865-9921
J. W. Halloran - Dept. of Materials Science
Phone: (814)-865-2262

Grain boundary diffusion and characterization in ceramics, initially $\mathrm{Cr}$-doped $\mathrm{MgO}$; effect of boundary composition; techniques used:

radioactive tracers, autoradiography, TEM, ion beam spectrochemical analysis, electron microprobe.
384. STUDIES OF MECHANICAL PROPERTIES AND IRRADIATION DAMAGE NUCLEATION OF HTGR GRAPHITLS
P. A. Thrower - Dept. of Materials Science
Phone: (814)-865-1934

Degradation of graphite by water vapor, air, and mixtures of $\mathrm{CO}$ and $\mathrm{CO}_{2}$; effect of various filler: binder ratios and porosity characteristics; residual strength measurements; TEM examination of neutron irradiated pyrolytic graphite. 
PENNSYLVANIA STATE UNIVERSITY (Continued)

385. STRUCTURE OF GLASSES CONTAINING TRANSITION METAL IONS

$\$ 72,000 \quad 01-1$

W. B. White - Materials Research Laboratory

Phone: (814)-865-1152

Structure and stability of insulator glasses with transition metal oxide additions; degree of order, structure of modifier; transition metal sites; theory of crystal field effects and electronic transitions in glass environment; glass structure relative to crystals of same composition; phase separation; leaching, dipole derivatives; bond character, Raman and infrared spectroscopy, optical absorption, Tuminescence, X-ray diffraction and electron microscopy; silicate, borate, borosilicate, germanate and phosphate glasses with $\mathrm{Zn}, \mathrm{Cr}$, $\mathrm{Fe}, \mathrm{Mn}$ and $\mathrm{Ni}$ additions, alkali-alumina-silica and high silica alkali silicate glasses.

UNIVERSITY OF PENNSYLVANIA

386. ELECTROCHEMICAL INVESTIGATION OF NOVEL ELECTRODE MATERIALS

$\$ 75,000$ $03-2$

W. L. Worre11 - Dept. of Metallurgy and Materials Science Phone: (215)-243-8592

New electrode materials from the dichalcogenides of the Group IV and $V$ transition metals intercalated with lithium and/or sodium. Electrochemical cell techniques to measure chemical potential and diffusion of lithium or sodium with compnsition $x$ in LixMS 2 compounds.

\section{UNIVERSITY OF PITTSBURGH}

387. STUDIES FOR THE PRODUCTION OF

SUPER-PURE SILICON NITRIDE

P. E. D. Morgan - Dept. of Metallurgical and Materials Engineering

Phone: (412) $-624-5300$

Synthesis of pure amorphous silicon nitride by three techniques:

Sulfur catalyzing the nitriding of ultra-pure silicon, silicon nitride synthesis from silicon tetrachloride and powdered silicon nitriding in a plasma glow discharge to produce the amorphous form from atomic nitrogen at low temperatures. 
PRINCETON UNIVERSITY

388. CHEMICAL POISONING IN HETEROGENEOUSLY
CATALYZED REACTIONS

$\$ 48,000$

S. L. Bernasek - Dept. of Chemistry

Phone: (609)-452-4986

Poisoning by molecules containing Group Vb and VIb atoms (nitrogen and sulfur). Single crystal surfaces of molybdenum and cobalt characterized by LEED and ESCA to examine catalytic activity. Reactions forming formic acid hydrogenation of carbon monoxide and hydrogenolysis of cyclopropane used as model reactions to study poisoning mechanisms and the kinetics of heterogeneously catalyzed reactions.

PURDUE UNIVERSITY

389. HIGH TEMPERATURE EFFECTS OF INTERNAL GAS PRESSURES IN CERAMICS

$\$ 59,440$

$01-3$

A. A. Solomon - Dept. of Nuclear Engineering

Phone: (317) $-494-6151$

Experimental study of the role of entrapped gases and microstructure on the rate-controlling mechanisms of pressure induced densification and swelling of ceramics; grain size and stoichiometry effects; single and polycrystalline $\mathrm{CoO}$; sintering of $\mathrm{CoO}$, hot pressing and swelling of $\mathrm{ZnO}$.

RENSSELAER POLYTECHNIC INSTITUTE

390. LOCALIZED CORROSION AND STRESS

$\$ 72,000$

$01-1$

CORROSION CRACKING BEHAVIOR OF

AUSTENITIC STAINLESS STEEL WELDMENTS

CONTAINING RETAINED FERRITE

W. F. Savage - Materials Engineering Dept.

Phone: (518)-270-6453

D. J. Duquette - Materials Engineering Dept.

Phone: (518)-270-6448

Corrosion behavior of stainless steels containing welds and stainless steel weldments with particular attention to pitting and stress corrosion cracking in chloride-containing solutions; pitting corrosion studied at room temperature and $290^{\circ} \mathrm{C}$ in pressure vessels utilizing potentiodynamic and galvanokinetic test procedures coupled with optical and electron metallography; stress corrosion cracking studied at slow strain rates in pressure vessels with electrochemical monitoring of potentials. 
RENSSELAER POLYTECHNIC INSTITUTE (Continued)

391. FATIGUE BEHAVIOR OF BCC METALS

N. S. Stoloff - Dept. of Materials

$\$ 43,600$

$01-2$ Engineering

Phone: (518)-270-6495

Fatigue behavior of bcc metal-hydrogen alloys; effects of microstructural, testing and environmental factors; high cycle (stresscontrolled) and low cycle (strain-controlled) conditions; dislocation substructure and hydride phase effects; room and elevated temperatures; transmission electron microscopy; $V, N b, V-H$ and $\mathrm{Nb}-\mathrm{H}$ alioys.

392. CHEMICAL DIFFUSION ON SOLID SUURFACES

J. B. Hudson - Dept. of Materials

$\$ 24.600$

$01-3$ Engineering

Phone: (518)-270-6451

Measurement of rates of migration of adsorbed atoms and molecules over solid surfaces; systems studied: $\mathrm{H}$ on $\mathrm{Ni}, \mathrm{Ag}$ on $\mathrm{Al}_{2} \mathrm{O}_{3}$;

techniques used: AES, mass spectrometry.

393. THE EFFECT OF TENSILE BIAS STRESS

UPON THE ULTRASONIC ATTENUATION

AND VELOCITY OF ULTRA-HIGH PURITY

(UNDOPED AND DOPED) TUNGSTEN,

MOLYBDENUM, TANTALUM, AND NIOBIUM

SINGLE CRYSTALS

J. M. Ruberls - DejL. of Mechantcal

Engineering and Materiale Science

Phone: (713)-527-3590

Effect of tensile bias stress on ultrasonic attenuation and velocity in pure and doped body centered cubic metallic single crystals.; internal friction; physical acoustiçs; dislocations; flow stress; nôndéstructive evaluation.

\section{UNIVERSITY OF ROCHESTER}

394. THF. MATFRTAIS AN M MECHANICS OF

RATE EFFECTS IN BRITTLE FRACTURE

$\$ 55,000 \quad 01-2$

S. J. Burns - Dept. of Mechanical and Aerospace Science

Phone: (716)-275-4082

Slow, steady state crack propagation in PMMA; crack velocity, crack extension force and specimen temperature varied over a wide range and analyzed in the formalism of thermally activated crack propagation; rapid crack propagation data in steels analyzed assuming adiabatic crack propagation; multiple test specimens that differ only in crack area to be tested to determine the crack extension force when the crack starts to propagate. 
UNIVERSIIY OF RUCHESTER (Continued)
395. DIFFUSIONAL CREEP OF MULTI- COMPONENT SYSTEMS
$01-2$
J. C. M. Li - Dept. of Mechanical and Aerospace Sciences
Phone: (716)-275-4038

Impression creep studies on $\mathrm{CU}-\mathrm{Ni}$ single crystals of various compositions and on beta-Sn single crystals of three orientations; tests to be extended to the Bi-Sb system; micro-impression elasticity to measure local elastic modulus using the indentation technique; impression creep studies to be extended to low temperatures; creep mechanisms by selective laser excitation.

ROCKWELL INTERNATIONAL
396. ACOUSTIC EMISSION SIGNATURE ANALYSIS
$\$ 94,147 \quad 01-5$
0 . Buck - Science Center
Phone: (805)-498-4545

Application of acoustic emission to detection of cracking mechanisms in metals; crack growth in embrittled steels; sustained load cracking of hydrogen embrittled steel; multiple transducer fourier frequency analysis of acoustic emissions.

397. SINTERING PHENOMENA OF NON-OXIDE SILICON COMPOUNDS

F. F. Lange - Science Center

Phone: (805) -498-4545

D. R. Clarke - Science Center

Phone: (805)-498-4545

Sintering of non-oxide silicon compounds; volatilization phenomena; liquid phase sintering; grain boundary grooving; transmission electron microscopy, lattice fringe imaging. 
UNIVERSITIES

UNIVERSITY OF SOUTHERN CALIFORNIA

398. ELECTRICAL AND MECHANICAL PROPERTIES

OF OXIDE CERAMICS

F. A. Kroger - Electronic Sciences Laboratory

Phone: (213)-741-6224

Electrical conductivity, transference number, and creep rate as a function of oxygen pressure, dopant concentration, temperature and grain size; rate-controlling defect species; concentration and thermodynamics, separation of bulk and grain boundary effects; sintering; hot pressing; Auger electron spectroscopy; thermal grooving; polycrystalline $\mathrm{Al}_{2} \mathrm{O}_{3}$, pure and doped with $\mathrm{Fe}, \mathrm{Mg}, \mathrm{Ti}$, or co.

399. GRAIN BOUNDARY SLIDING DURING HIGH-TEMPERATURE CREEP

$\$ 88,000$

$01-2$

T. G. Langdun - Dept. of Materials Science and Mechanical Engineering

Phone: (213)-741-2095

Measurement of grain boundary sliding and cavitation in creep of A1 and $\mathrm{Mg}$ alloys; deformation mechanisms related to creep-rupture behavior; grain size effects; deformation maps; diffusion and dislocation controlled creep in alkali-halides and oxides.

400. EVAPORATION DRIVEN LIQUID SINTERING \$53,900 01-1 J. W. Whelan - Dept. of Materials Sciences

Phone: (213)-741-6219

Theoretical and experimental studies of the evaporation driven liquid sintering process; vapor transport; effects of particle size, liquid volume fraction, and sintering temperature; density and microstructure as a function of time; MgO-LiF, WC-Cu, and $\mathrm{Si}_{3} \mathrm{~N}_{4}$ with additives.

401. CHEMISTRY OF ZIRCONIUM RELATED TO THE BEHAVIOR OF NUCLEAR REACTOR

$\$ 75,000$ 03-3

FIJFL CIADCING.

D. Cubicciotti - Dept. of Chemistry

Phone: (415)-326-6200, X3940

Thermodynamics of solid and gaseous zirconium iodides. Kinetics of iodide film growth on zirconium surfaces, kinetics of oxidation of zirconium under low oxygen activity, physical and chemical mechanisms of oxide film disruption, and formation of compounds of zirconium and other elements in the fuel-cladding gap. 
STANFORD UNIVERSITY

402. PHOTOVOLTAIC MATERIALS RESEARCH-

I I-VI HETEROJUNCTIONS AND

$\mathrm{CU}_{2} \mathrm{~S} / \mathrm{CdS}$ THIN FILMS

R. H. Bube - Dept. of Materials Sciences and Engineering

Phone: (415)-497-2534

Energy parameters and transport processes that control the electrical, photoelectronic, and photovoltaic properties of II-VI heterojunctions; preparation of II-VI heterojunctions in film-on-crystal and film-on film form; $n$-ZnCdS/p-CdTe, n-ZnSSSe/p-CdTe, Cu $2 S / C d S, Z n 0 / C d T e$, ITO/CdTe; measurements of $\mathrm{J}-V$ curves in dark and light; junction capacitance; spectral response; diffusion lengths; scanning transmission electron microscopy analysis of heterojunction interfaces; lattice resolution; microdiffraction; vacuum evaporation; spray pyrolysis; rf sputter deposition.
403. SUPERCONDUCTING AND SEMICONDUCTING PROPERTIES OF ELECTRON BEAM EVAPORATED MATERIALS
T. H. Geballe - W. W. Hansen Laboratories of Physics
Phone: (415) $-497-4027$
M. R. Beasley - W. W. Hansen Laboratories of Physics
Phone: (415) $-497-4027$ $\$ 86,400$ $02-2$

This is research to study the high magnetic field properties of superconducting films prepared using newly developed electron beam coevaporation techniques. The materials to be investigated are A15's such as $\mathrm{Nb}_{3} \mathrm{Sn}$ and also ductile alloys. Superconductor parameters as well as strain tolerance, micro-hardness and high temperature mechanical deformation will be studied as a function of composition and microstructure.
404. MODELING OF DEFORMATION AND FRACTURE IN HIGH-TEMPERATURE STRUCTURAL MATERIALS
A. K. Miller - Dept. of Materials Sciences
Phone: (415)-497-2536
0 . D. Sherby - Dept. of Materials Sciences
Phone: (415)-497-2536

Use of a computer based set of constitutive equations for non-elastic deformation, "MATMOD"; solute strengthening in stainless steel; kinematic hardening during cyclic deformation; design of high-strain reversed torsion apparatus; steady state flow at intermediate temperatures in $\mathrm{Al}$; application of constitutive equations to fracture; transient subgrain refinement strengthening. 
UNIVERSITIES

STANFORD UNIVERSITY (Continued)

405. STRUCTURE DEPENDENCE OF HIGH

TEMPERATURE DEFORMATION OF METALS

$\$ 74,800 \quad 01-2$

W. D. Nix - Dept. of Materials Science and Engineering

Phone: (415)-497-4259

Experimental and analytical evaluation of creep-rupture behavior of metals; cavity growth and coalescence, and intercavity ligament yielding in $\mathrm{Ag}$ and $\mathrm{Cu}$ embrittled by $\mathrm{H}_{2} \mathrm{O}$ bubbles at grain boundaries; creep models based on dislocation core diffusion controlled climb or on grain boundary diffusion; effect of $\mathrm{Al}_{2} \mathrm{O}_{3}$ despersoid on twinning and dislocation motion during creep of fine-grained $\mathrm{Ni}$; influence of segregation of $P$ on creep of Fe-base alloys.

406. DIFFUSION OF OXYGEN IN

$\$ 49,640$

$01-3$

LIQUID METAL SYSTEMS

D. A. Stevenson - Dept. of Materials Science

Phone: (415)-497-4251

Oxygen solubility, thermodynamic activity and diffusion in liquid metal alloy solutions; solute-solute interaction studies, calorimetric titration and time dependent currents using oxygen ion conducting solid electrolytes; aging of solid oxide electrolytes; transference numbers by $\mathrm{AC}$ techniques; $\mathrm{Y}_{2} \mathrm{O}_{3}$-doped $\mathrm{ThO}_{2}$ electrolytes; Ga-In-0, $\mathrm{Sb}-\mathrm{Bi}-0$, and $\mathrm{In}-\mathrm{Ca}, \mathrm{Ag}$, etc. systems.

SYRACUSE UNIVERSITY

407. SURFACE CHARACTERIZATION OF CATALYTICALLY ACTIVE METAL ALLOY AND COMPOUND FILMS

$\$ 83,400 \cdot 01-1$

R. W. Vook - Chemical Engineering and Materials Science Dept.

Phone: (315)-423-3466

Correlation of surface structure with catalytic activity of $\mathrm{Pt}$ and $\mathrm{Pd}$ in $\mathrm{CO}$ oxidation; influence of overlayer morphology, defect structure, and elastic strain; techniques used: AES, TEM, KHEEU. 


\section{UNIVERSITY OF TENNESSEE}

408. A COMBINED THERMODYNAMIC STUDY
OF NICKEL-BASE ALLOYS
C. R. Brooks - Dept. of Chemical
and Metallurgical Engineering
Phone: (615)-974-5427
P. J. Meschter - Dept. of Chemical
and Metallurgical Engineering
Phone: (615)-974-6009

Thermodynamic study of nickel-based alloys; $\mathrm{Ni}-\mathrm{Mo}, \mathrm{Ni}-\mathrm{Ta}, \mathrm{Ni}-\mathrm{Nb}$, and $\mathrm{Ni}-\mathrm{W}$, high-temperature Gibbs free-energy data by a galvaniccell method; heat capacities of stable and metastable single-phase alloys; thermodynamic functions between 4 and 1400K; computer coupling to obtain integrated thermodynamics" and phase diagrams; effect of elastic, vibrational, electronic, and ordering terms.

\section{UNIVERSITY OF TEXAS}

409. SYNTHESIS OF NEW FUNCTIONALIZED FLUOROCARBON POLYMERS FOR USE AS

BATTERY SEPARATORS AND MEMBRANES

R. J. Lagow - Dept. of Chemistry

Phone: (512)-471-1032

Synthesis of polymers by oxyfluorination to convert the thermal methyl in pendant groups to acid fluorides which functionalize the polymer and act as sites for further membrane chemistry. Conversion of thin polymer films completely to fluorocarbon material and polymer powders by a two-step process to membranes and separators.

U. S. STEEL CORPORATION

410. STUDIES OF FUNDAMENTAL FACTORS $\$ 67,940 \quad 01-1$ CONTROLLING CATALYZATION OF REACTIONS OF GASES WITH CARBONACEOUS SOLIDS

R. M. Fisher - Research Laboratory

Phone: (412) $-351-3100$, X2904

Metal particle catalyzed gasification of carbon; effect of particle size and number; effect of particle alloy composition; in-situ scanning and transmission electron microscopy; Fe particles on graphite. 


\section{UNIVERSITY OF UTAH}

411. IMPURITY EFFECTS ON THE CREEP

OF POLYCRYSTALLINE MAGNESIUM

AND ALUMINUM OXIDES AT ELEVATED TEMPERATURES

R. S. Gordon - Materials Science and Engineering Division

Phone: (801)-581-6612

Determination of mechanisms of high temperature creep of polycrystalline oxide ceramics; creep deformation maps; role of aliovalent additives in determining roles of diffusion, grain boundary sliding, and dislocation mechanisms of creep; effects of additives, temperature, oxygen pressure and grain size; Mgo and $\mathrm{Al}_{2} \mathrm{O}_{3}$ doped with $\mathrm{Fe}, \mathrm{Cr}$, and $\mathrm{Mn}-\mathrm{Ti}$; deformation maps.

412. ELECTROLYTIC DEGRADATION OF LITHIASTABILIZED $\beta^{\prime \prime}$ ALUMINA

D. K. Shetty - Dept. of Materials Science and Engineering

Phone: (801)-581-5604

A. V. Virkar - Dept. of Materials Science and Engineering

Phone: (801)-581-5396

Electrolytic degradation from stress corrosion and fracture characterized by current density, composition, and time, for $\beta$ and $\beta$ " alumina ceramics immersed in liquid sodium. Surface crack growth and propagation examined and compared with theoretical models.

\section{VARIAN ASSOCIATES}
413. RESEARCH ON LATTICE MISMATCHED SEMICONDUCTOR LAYERS
R. L. Bell - Solid State Laboratory
Phone: (415)-493-4000, X2906
R. L. Moon - Solid State Laboratory
Fhone: $(415)-493=4000, \times 3278$

Morphology and properties of semiconducting III-V compound ternary, quaternary and quinary epitaxial layers grown lattice-mismatched on substrates with reference to their ultimate applications in high efficiency solar cells; characteristics of materials grown by the liquid phase melt depletion lattice parameter grading method; AlGaAsSb and GaAsP systems; incorporation of high densities of ionizable donor and acceptor species; minority carrier lifetimes and surface recombination; high voltage electron microscopy; X-ray topography; dislocation etch pit analysis; pn junction characteristics and analysis by photoluminescence and spectral response; organometallic vapor phase epitaxy; Hall measurements; AlGaAsSb phase diagram calculations. 


\section{VIRGINIA POLYTECHNIC INSTITUTE} AND STATE UNIVERSITY

414. HYDROGEN EMBRITTLEMENT TESTING

M. R. Louthan, Jr. - Dept. of Materials

Engineering

Phone: (703)-951-6825

Evaluation of the effective hydrogen fugacity in electrochemicallycharged steels by comparison with gaseous permeation data; mechanical testing of carbon and low alloy steels either electrochemically charged or in gaseous hydrogen up to $65 \mathrm{MPa}$.

UNIVERSITY OF WISCONSIN

$\$ 75,000$ $07-4$

415. VOID NUCLEATION AND GROWTH

IN HEAVY ION AND ELECTRON

BOMBARDED PURE METALS

G. L. Kulcinski - Dept. of Nuclear Engineering

Phone: (608)-263-2308

P. Wi 7 kes - Dept. of Nuclear Engineering

Phone: (608)-263-2196

Effects of irradiation variables and material parameters influencing void formation in metals; dilatometric studies of irradiation damage annealing; heavy ion and electron simulation of neutron irradiating effects of temperature, fluence, flux and interstitial impurities; swelling; high voltage electron microscopy; $18 \mathrm{MeV}$ copper bombardment of $\mathrm{V}$ and $\mathrm{V}-\mathrm{N}$ alloys; $1 \mathrm{MeV}$ electron bombardment of $\mathrm{Al}$.

416. LOCAL ELECTRONIC PROPERTIES OF SEMICONDUCTOR SURFACES AND INTERFACES

M. G. Lagally - Dept. of Metallurgical and Mineral Engineering

Phone: (608)-263-2078

The local electronic properties of surfaces and interfaces of some elemental and compound semiconductors, e.g. GeS, GeSe, SnS and SnSe will be studied using Auger Electron Spectroscopy (AES). In addition chemisorption of $\mathrm{Cl}$ and 0 on Si will be investigated. AES will be augmented with XPS and UPS in all of these studies. 
UNIVERSITY OF WISCONSIN (Continued)

417. PREDICTION OF THE BEHAVIOR OF $\$ 34,900 \quad 01-4$ STRUCTURAL MATERIALS UNDER

IRRADIATION THROUGH MODELLING

OF THE MICROSTRUCTURE

W. G. Wolfer, Dept. of Nuclear Engineering

Phone: (608)-263-1646

Modelling of nucleation and growth of radiation-induced voids and dislocations; effect of spatial correlations between sinks for point defects and time dependence of their production. 
SECTION C

Summary of

Funding Levels

The summary funding levels for various research categories were determined from the index 1 isting in Section $D$ and estimating the percentage from the project devoted to a particular subject. There is overlap in the figures. For instance, funding for a project on diffusion in oxides at high pressure would appear in all three categorics of diffusion, oxides, and high pressure. 
SUMMARY OF

FUNDING LEVELS

During the fiscal year ending September 30, 1978, the Materials Sciences total support level amounted to about $\$ 59.7$ million in operating funds (budget outlays) and $\$ 5.1$ million in equipment funds. The equipment funds are expended primarily at Laboratories and are not shown in this report. Equipment funds for the University projects are included in the total contract dollars, being part of the operating budget. The following analys is of costs is concerned only with operating funds.

1. By Region of the Country:

Contract

Research (\%)

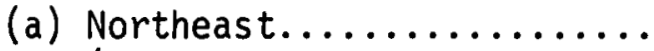

(Mass., Penn., N.Y.,

D.C., Md., Vt., Conn.,

N.H., R.I.)

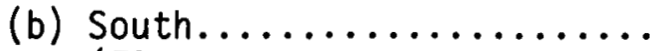

(Fla., N.C., Tenn., Va., Georgia)

(c) Midwest.

(Ohio, Ill., Wisc., Mich.,

Minn., Ind., Iowa, Kan.)

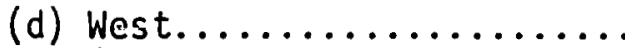

(Ariz., Okla., Wash.,

Texas, Hawaii, N. Mex.,

Calif., Utah, Colo.,

Idaho)

43.9

6.7

19.7

29.7
23.5

37.7

$\underline{20.8}$

100.0

100.0

2. By Academic Jepartment or Laboratory Division:

Contract

Research (\%)

Total

Program $(\%)$

(a) Metallurgy, Materials

Science, Ceramics

(Office Budget Activity

Number's 01-)

61.0

43.0 
Contract

Research (\%)
Total

Program (\%)

(b) Physics, Solid State

Science, Solid State

Physics (Office Budget

Activity Numbers 02-)....

30.4

42.1

(c) Chemistry, Chemical Eng.

(Office Budget Activity

Numbers 03-).

8.6

14.9

100.0

100.0

3. By DOE Laboratory and University:

Total

Program (\%)

(a) University Program (including those laboratories where graduate students are involved in research to a large extent, e.g., LBL, Ames)

$35.9 \%$

(b) Laboratory Program.

$64.1 \%$

$100.0 \%$

4. By Laboratory:

Total

Prngram (\%)

Ames Laboratory....................

9.5

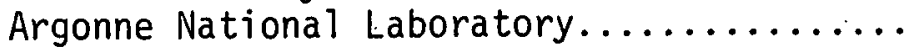

21.7

Brookhaven National Laboratory........... 10.9

Idaho National Engineering Laboratory...... 0.5

Illinois, University of (Materials

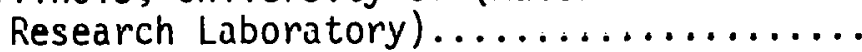

Lawrence Berkeley Laboratory............ 7.5

Lawrence Livermore Laboratory............ 1.7

Los Alamos Scientific Laboratory......... 2.0

Mound Laboratory................... 0.2

Oak Ridge National Laboratory........... 22.6

Pacific Northwest Laboratory............ 2.5

Sandia Laboratory................. 2.0

Contract Research.............. 15.9

100.0 
5. By Selected Areas of Research:

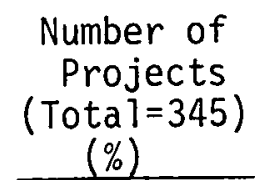

Total

Program \$

$(\%)$

(a) Materials

Polymers

Cerdallics

Semiconductors

Hydrides

Ferrous Metails

(b) Technique

Neutron Scattering

Theory

6.1

11.6

14.5

8.6

1.5

16.0

6.4

4.1

8.3

12.8

7.8

6.1

8.7

9.0

16.6

5.0

3.5

5.1

8.9

10.2

Superconduc
Strength

(d) Environment

Radiation
9.9

13.6 
SECTION D

Index of Investigators,

Materials, Phenomena,

Technique and Environment

The index refers to project numbers in Sections $A$ \& B. 
Abraham, M. M., 194

Ackermann, R. J., 76

Aldred, A. T., 44

Alkire, R. C., 109

Angeregg, J., 39

Anderson, A. C., 120

Anderson, J. L., 169

Anderson, M. S., 26

Appleton, B. R., 194, 200, 201, 202, 203

Arai, T., 70

Arbel, A., 93

Arko, A. J., 43

Arnold, G. W., 222

Atoji, M., 73

Aubry, S., 100

Averback, R. S., 46,54

Axe, J. D., $94,95,96$

Bacarella, A. L., 207

Bader, S. D., 45

Baikerikar, K. G., 40

Bailey, D. M., 12

Barhorst, J. F., 199

Barker, R. E., 209

Barnes, R. G., 24

Barrett, J. H., 197, 200, 202

Baskes, M. I., 228

Batchelor, K., 99

Bates, J. B., 194, 196

Bautista, R. G., $35,36,37$

Beahm, E. C., 208

Beaudry, B. J., 1, 3

Begun, G. M. , 205

Beil, J. T., 205

Benedek, R., 54

Bennett, B. I., 171

Bennett, S. L., 176

Benson, J. E., 31

Bentley, J., 180, 185

Berard, M. F., 8

Berger, A. S., 49

Besmann, T. M., 208

Bevolo, A. J., 26

Birnbaum, H. K., 112

Birtcher, R. C., 53

Bittner, H. F., 205

Bittner, J., 99

Black, J., 100

Blander, M. , 79, 81, 83, 86

Blewitt, T. H., 53

Bl umberg, L., 99
Blume, M., 100

Borie, B. S., 175

Bradley, E. R., 215

Bragg, R. , 141

Brandt, E. H., 29

Braunstein, J., 206

Brawer, S., 163

Brewer, L., 153

Brimha11, J. L., 215

Broach, R. W. , 73

Brodsky, M. B., 43, 45, 46

Brower, K. L., 222

Brown, B. S., 53

Brown, G. M., 204

Brown, R. K., 73

Bruemmer, S. M., 212

Brun, T., 60

Burger, C. P., 21

Burkhart, L. E., 38

Burnet, G. , 34

Busch, R., 217, 219, 220

Busing, W. R., 204

Butler, M. A., 226

Butler, W. H., 174

Cafasso, F. A., 82

Calaway, W., 77

Carlson, 0. N., 2, 3

Carison, P. T., 182

Carpenter, J. M., 59

Carpenter, R. W., 180, 185

Carstens, D. H. W., 169

Cathcart, J. V., 182

Caton, R., 89

Chang, S. J., 195

Charlot, L. A., 215

Chen, C. W. , 15, 16, 18

Chen, H., 41,50

Chen, W. K., 51

Chikalla, T. D., 216

Chiotti, P., 14

Chopra, 0. K., 46

Clark, G.W., 176

Clarke, J., 148

Clel and, J. W. , 194

Clem, J. R., 29

Cline, C. , 160, 161

Clinton, S. D., 209

Coghlan, W. A., 185

Cohen, M., 149

Coltman, R. R., 198 
Cooke, J. F., 197

Corbett, J. D., 32

Cost, J. R., 167

Cox, D. E., 103

Crabtree, G., 65, 66

Crawford, R. K., 59

Culwick, B., 99

Currat, R., 95

Curtiss, L., 83

Cuthrell, R. E., 223

Dahlgren. S. D., 214

Danielson, G. C., 26

DasGupta, A., 184

David, S., 186

Davis, H. L.; '197, 202

Delbecq, C., 62, 69

Depp, M. , 73

Dew-Hughes, D. , 89, 91, 93

Dienes, G. J., 100

Dow, J., 121

Downs, W. F., 108

Brickamer, H. G., 122

Druschel, R. E., 182

Dunläp, B., 66

Dye, D. H., 66

Easton, D. S., 184

Eckert, J., 95, 96, 97

Ellenson, W. D. , 95, 96, 97

Emery, V. J., 100

Engstrom. H. . 194

Evans, A. G., 112

Evans, J. W., 144

Faber, J., 51

Falco, C., 61, 67, 72

Farre 17, K., 185

Faulkner, J. S., 174

Feibelman, P. J., 224

Felcher, G. , 60,65

Ficlds, J., 100

Finch, C. B., 176

Finnemore, D: K., 25

Fisher, E. S., 49, 57

Flotow, H. E., 74

Fluss, M. J., 49

Follstaedt, D. M., 222
Fradin, F. Y., 50

Franzen, H. F., 39

Fraser, H. L., 111

Frazer, B. C., 98, 99, 103

Friedt, J., 66

Frurip, D., 83

Furtak, T. E., 27

Fuchs, R., 28

Galayda, J., 99

Gerrity, D., 73

Gerstein, B. C., 40

Ghosh, A., 105

Gilbert, T. L., 70

Ginley, D. S., 226

Ginsberg, D. M., 123

Gode 1, J., 99

Goland, A. N., 101, 102, 104

Goodwin, G. M., 186

Gordon, R. L., 218

Granato, A. V., 124

Gray, K., 64

Green, W. V., 167

Griffith, R. W., 90

Gronsky, K., 133

Gruen, D. M., 75

Gschneidner, K. A., 1, 3, 9, 11, 13

Gubernatis, J. E., $17 \%$

Gupta, R. P., 49

Guttman, L., 68

Gyorffy, B., 100

Habenschuss, A., 27

Hall, B. H., 55

Hall, R. O. A., 183

Hansen, R. S., 40

Hargis, P. J., 227

Hariharan, A. V., 39

Harmon, B. N., 30

Harris, L. A., 178

Hartman, J. S., 218,219

Hasegawa, T., 47

Hastings, J. B. , 98, 99

Hecker, S. S., 168

Heese, R., 99

Helland, B. J., 31

Henager, C. H. Jr., 211

Hendrick, P. L., 215

Hendricks, R. W., 175

Hess, D. W., 158 
Hinks, D. G., 61, 69

Holbrook, J. H. , 228

Holder, J., 118

Holder, J. D., 176

Holmes, D. K., 197

Holt, B., 78

Hopper, R., 140

Houston, J. E., 224, 225

Howe 1ls, M., 99

Howng, W. Y., 76

Hsiang, T. Y., 25

Hsieh, H., 99

Hsu, C., 70

Hubbard, W. N. , 80

Hubble, B., 78

Hunter, 0., 4

Isaacson, H. R., 78

Iton, L., 65

Jackson, J. J., 69, 71

Jacobson, R. A., 31

Jager, W. B., 54

Jeffries, C., 147

Jena, P., 41, 50

Jenkins, L. H., 202

Jennison, D. R., 224

Johnson, A. W. , 227

Johnson, C. E., 80, 85

Johnson, C. K., 204

Johnson, E., 204

Juhns on, G. K. , 80

Johnson, P. L., 73

Johnson, S., 78

Jonas, J., 113

Jones, R. H., 212

Jorgensen, J. D. , 60

Jura, G., 151

Kamitakahara, W. A., 22

Kammerer, 0., 89

Kampas, F. , 90

Kaneda, T., 196

Kaplan, T., 197

Karim, D., 44

Kassner, T. F., 46

Katovic, V., 33

Kayser, F. X., 17

Kelber, J., 73
Kelly, E. J., 207

Kendig, M. W., 88

Kenik, E. A., 180, 185

Key, J. F., 107

Khan, J., 164

Khatamian, J., 22

Kierstead, H. A., 66

Kim, K., 80

Kim, K. K., 51

Kirk, M. A., 53

Kissinger, H. E., 215

Klabunde, C. E., 198

Kleb, R. K., 59, 60

Klemm, R. A., 29

Kl iewer, K. L., 28

Kline, G. R., 22

Knapp, G. S., 41, 50

Knotek, M. L., 226

Koch, C. C., 184

Kocks, U. F., 47, 48

Koehler, J. S., 129

Koelling, D., 70

Kosel, T. H., 58

Krauss, A. R., 75

Krefft, G, B., 222

Krinsky, S., 99

Kroeger, D. M., 184

Kumar, R., 78

Kustom, R., 59

Laegreid, N., 219, 220

Lam, D. J., 41, 44, 52

Lam, N. Q. , 49

Lander, G. H., 42

Larson, B. C., 194, 199

Lau, K., 70

Lazarus, D., 126

Lee, K., 89

Lefakis, H.; 53

Legvold, S., 23

Leitnaker, J. M., 186

Lessor, D. L., 218

Levinson, L. S., 167

Levy, A., 143

Levy, H. A., 204

Levy, P. W., 101, 102

Lewis, M. B., 185

Lin, J., 175

Lindmer, T. B., 208

Liu, M. B., 75 
Liu, S. H., 30

Loomis, B. A., 53

Lutz, H., 105

Lyles, R. L., Jr. , 46, 54, 56

Lynch, D. W. , 27

Lynch, T., 73

Lynn, K. G., 101, 102

Machida, K., 29

Mansur, L. K., 185

Maroni, W. A., 77

Marshail, S., 62, 69

Mattox, D. M., 223

McBeth, R. L., 75

McCarley, R..E., 33

McClanahan, E. D., 217

McConnel1, K. G., 21

McClung, R. W., 187

MC[lroy, D. L., 183

McKee, R. A., 182

McMasters, 0. D., 9, 13

McMillan, J. A. , 68

Melendres, C., 79, 82

Melius, C. F., 228

Mendelsohn, M. H., 75

Merk le, K'. 'L., 54

Merz, M. D., 213

Milam, D., 161, 162

Miller, D. M. 220

Miller, G. H., 227

Miller, J. F., 49

Miller, R. L., 170

Miyano, J., 67

Moodenbaugh, A., 103

Moore, J. P., 183

Morosin, B. , 226

Murris, J.W., Jr., 134

Morrison, T., 73

Mostollcr, M. E., 197

Mueller, B. A., 166

Mueller, M. H., 42, 57

Mulac, A. J., 227

Mulford, R. A., 48

Muller, R. H., 155

Mundy, J. N. , 19

Murch, G. E.; 76

Murtha, M. J., 34

Myers, C. E., 39

Myers, S. M.; 222
Nagy, Z., 79, 81

Narayan, J., 194, 195, 199, 201

Narten, A. H., 204

Natesan, K., 46

Noda, Y., 95

Noer, R. E., 25

Noggle, T. S., 195, 199, 201

Nolfi, F. V., Jr., 55

Noonan, J. R., 202

Den, 0. S., 197, 201

Ogle, J. C., 181

Ohr, S. M., 195, 199

Okamoto, P. R., 46, 55

01 ander, D., $154^{\prime}$

01 sen, L. C., 210

01 son, C. G., 27

O'Reilly, D., 65

Orent, T. W., 45

Osborne, D. W., 74

Osmun, J. W. , 25

Ostenson, J. E., 25

Packan, N. H., 185

Painter, G. S., 174

Palko, A. A., 207

Pande, C., 89

Panitz, J. A., 224, 225

Papatheodorou, G. , 84, 86

Park, Y. S. , 88

Parkin, D. M., 167

Pask, J. A., 138, 140

Passell, L., 94, 96, 97

Pattern, J. W. , 217

Pawel, R. E., 182

Pawlewicz, W. T., 211, 219

Payne, D. A., 115

Pcercy, P. S., 222

Pelizzari, C., 60

Petersen, G. F., 182

Peterson, D. T., 5

Peterson, N. L., 51

Peterson, S. W., 73

Petrovic, J. J., 168

Petusky, W. , 115

Phillips, N. E., 150

Pick, M., 91

Pickus, M., 132, 137 
Picraux, S. T., 222

Pierson, H. 0., 223

Pines, A., 157

Platov, Y., 101

Polgreen, T. L., 194

Posey, F. A., 207

Postol, T., 60

Potter, D. I., 55

Primak, W. , 69, 71

Pronko, P. P., 194, 200, 203

Pronko, P. P., 52, 56

Pugh, E. N., 110

Rahman, A. , 70

Randich, E., 223

Rasolt, M., 197, 202

Rauh, E. G., 76

Rechtin, M. D., 51, 52

Redman, J. D., 205

Redman, J. K., 198

Rehn, L. E., 46, 55

Reiley, T. C., 187

Reimann, K. J., 57

Reis, A. H., 73

Reyes, J., 28

Richards, P. L., 146

Roach, P. R., 63, 67

Roberto, J. B., 199

Robinson, J., 70

Robinson, M. T., 197

Rohr, D. L., 166

Rosei, R. , 27

Rosner, J. S., 104

Rothman, S. J., 49

Routbort, J. L., 47, 58

Rowland, T. J., 119

Roy, N. K., 34

Roziere, J., 73

Rye, R. R., 224

Saboungi, M., $79,81,86$

Sagues, A. A., 55

Sato, H., 196

Scattergood, R. 0., 48, 58

Schirber, J. E., 226

Schmerr, L. W. , 21

Schmidt, F. A., 1, 2, 3

Schow, O. E. III, 200

Schroeder, H., 185
Schultz, A. J., 73

Schwarz, R. B., 48

Scott, T. E., 5, 6

Searcy, A., 139, 140

Settle, J., 81

Shanks, H. R., 26

Shapiro, S. M. , 94, 95, 96,97

Sheehan, J., 99

Shen, Y., 145

Shenoy, G. , 66

Sherry, E. G. , 73

Shirane, G., 94, 95, 96

Short, D. W., 159

Siegel, R. W., 49

Siegel, S., 82,87

Simmons, R. 0., 125

Simonen, E. P., 215

Simpson, J., 59

Sinha, S. K., 60

Skold, K., 60

Slichter, C. P., 127

Smedskjaer, L. C., 49

Smith, D. Y., 68

Smith, J. F., 11, 12, 21

Smith, R. J., 106

Smith, W. L., 161, 162

Smolik, G. R., 107

Smyrl, W. H., 221

Snead, C. L., 92

Sommer, W. F., 167

Somorjai, G., 156

Sparks, C. J., 175, 179

Specking, W., 184

Spedding, F. H., 27

Stapleton, H. J., 117

Stark, W. A., 169

Stassis, C., 22

Stearley, K., 73

Steinbruche1, D., 75

Stiegler, J. 0., 185

Stocks, G. M.; 174

Storms, E. K., 166

Strongin, M. , . $104,105,106$

Strozier, J., 106

Suenaga, M. , 88, 89

Susman, S., 61,69

Swansiger, W. A., 228

Swanson, N.; 59

Swendsen, R. H., 100

Swenson, C. A., 26 
Taki, T., 40

Talbot, J. B., 209

Tarvin, J. A., 94,97

Taylor, A. , 55, 56

Thiessen, W. E., 204

Thomas, G. J., 130, 133

Thomas, G. J., 228

Thomas, M. T., 212, 214

Thoml inson, W. C., 94, 96, 97

Thompson, N., 203

Thorn, R. J., 76

Tobias, C. W., 152

Torgeson, D. R., 24

Trivedi, R. K., 1, 2

Truhan, J., 159

Turcutte, R. P., 210

Turner, A. P. L., 47, 58

Ulehla, M., 197, 202

Vallet, C. E., 206

Vandermeer, R. A. , 181

Vanier, P., 90

van Steenbergen, A., 99

Vashishta, P., 70

Veal, B. W., Jr., 41, 44, 49, 52

Veleckis, E., 77

Verhoeven, J.E., 10

Vook, F. L., 222, 224, 225

Vora, P., 60

Vyas, Brijesh, 88

Wang, J. C., 194, 196

Wang. R. . 211

Washburn, J., 135

Watson, J. S., 209

Watson, R. E:, 99, 100

Weaver, J. H., 27

Webb, R. , 63, 65

Weber, M., 161, 162, 163

Weber, W. J., 216

Wechsler, M. S., 7, 19, 20

Weeks, J. R., 88

Welch, D. 0., 89, 91

Wendelken, J. F., 202

Wert, C. A., 111

Westbrook, R. D., 194

Westlake, D. G., 49

Wes tmacott, K., 131
White, C. L., 181

White, C. W. , 194, 200, 203

Whittle, D. P., 136

Wiedersich, H., 55

Wilder, D. R., 21

Willemsen, H., 64

Williams, D. E., 1

Williams, J. M., 73

Williams, J. M., 198, 201

Williams, R. K., 183

Williams, W. S. 128

Wilson, S. R., 200, 203

Wilson, W. D., 228

Winslow, G. H., 76

Winter. A. H., 88

Wirtz, G. P., 116

Withrow, S. P., 200

Wittenberg, L. J., 173

Wolf, D. 51

Wolf, E. L., 25

Wood, R. F., 194, 197

Wright, R. B., 75

Yakel, H. L., 175, 179

Yen, C. F., 176, 177

Yoo, M. H., 174

Young, R. T., 194

Youngblood, R., 95

Yu, M. , 106

Yust, C. S., 177, 178

Yuster, P., 62, 69

Zachary, L. W. , 27

Zaluzec, N, , 180

Zehner, D. M., 202

Zịomek, J., 76

Zuthr, R. A.. 200 
Agrawal, A. K., 380

Allen, C. W. , 377

Arde 11, A. J., 307

Argon, A. S. , 354

Argyres, P. N., 371

Ast, D. G., 334

Balluffi, R. W., 355

Bansil, A., 371

Beasley, M. R., 403

Bel1, R. L., 413

Bernasek, S. L., 388

Bonilla, C. F., 327

Bowen, H. K., 356

Bradt, R. C., 382

Brooks, C. R., 408

Broutman, L. J., 350

Bube, R. H., 402

Buck, 0.

Burns, S. J., 394

Butler, G. B., 342

Butt, J. B., 373

Chung, Y.-W., 374

Clarke, D. R., 397

Coble, R. L., 358

Cooper, A. R., 314

Cowley, J. M. , 301

Crawford, J. H., 370

Cubicciotti, D., 401

Devereux, 0. F., 330

Do11, J. D., 369

Donohue, M. C., 322

DuBow, J., 323

Duquette, D. J., 390

Eagar, T., 362

Fisher, R. M., 410

Galligan, J. M., 328

Geballe, T. H., 403

Gibala, R., 318
Göldman, A. M., 364

Gordon, R. S., 411

Grant, N. J., 357

Gurland, J., 303

Halloran, J. W., 383

Hart, E. W., 331, 333

Hartley, C. S., 344

Heldt, L. A., 363

Herley, P. J., 368

Heuer, A. H. , 315

Hogan Esch, T. E., 342

Hoke, J. H., 382

Hren, J. J., 344

Hudson, J. B., 392

Inal, 0. T., 365

Jaccarino, V., 312

Johnson, H. H., 336

Johnson, W. C., 304

Joiner, W. C. H., 321

Katz, J. L., 322

Kingery, W. D., 358

Kohlstedt, D. L., 338

Kuczynski, G. C. . 377

Kulcinski, G. L., 415

Lagally, M. G., 416

Lagow, R. J., 409

Lance, R. H., 333.

Landman, U., 345

Langdon, T. G. , 399

Lange, F. F., 397

Langford, G., 341

Lawrence, W. E., 339

Lax, M. , 366

Li, C. -Y., 33i

Li, J. C. M. , 395

Livesay, B. R., 346

Louthan, Jr., M. R., 414 
Manghnani, M. H., 347

Maple, M. B., 310

Marcinkowski, M. J., 353

Matlock, D. K., 324

McClintock, F. A., 354

McFeely, F. R., 361

Meshii, M., 375

Meschter, P. J., 408

Miller, A. K., 404

Mitche11, T. E., 316

Mockler, R. , 325

Montrol1, E. W., 345

Morgan, P. E. D. , 387

Morral, J. E., 329

Morse, J. G., 323

Moss, S. C. , 349

Moynihan, C. T., 319

Murr, L. E., 365

Myers, C. E., 367

Nix, W. D., 405

Notis, M., 352

Nowick, A. S., 326

O1son, D. L., 324

O'Sullivan, W., 325

Phoenix, S. L., 335

Pipes, P. B., 340

Pong, W., 348

Raj, R., 337

Rapp, R. A., 378

Reed-Hill, R. E., 343

Rice, J. R., 303

Roberts, J. M., 393

Sari, S., 302

Savage, W. F., 390

Schwartz, L. H. , 373

Seidman, D. N., 332

Sekula, S. T., 313

Selman, J. R., 351

Sherby, O. D., 404

Shetty, D. K., 412
Shewmon, P. G. , 379

Shul1, C. G., 359

Simanek, E., 309

Sokol off, J., 372

Solin, S. A., 320

Solomon, A. A., 389

Solomon, E. I., 361

Staehle, R. W., 380

Stein, D. F., 363

Stevenson, D. A., 406

Stoloff, N. S., 391

Stubican, V. S., 383

Summers. G. P., 381

Szekely, J., 362

Thrower, P. A., 384

Troiano, A. R., 317

Tschoegl, N. W. 306

Tuller, H. L., 360

Vaughan, R. W., 305

Virkar, A. V., 412

Vook, R. W., 407

Weyhmann, W. V., 364

Whea t.1ey, J. C., 311

Whelan, J. W., 400

White, W. B., 385

Whitmore, D. H., 376

Whitten, J. L., 369

Wilkes, P. 415

Wolfer, W. F. , 417

Worrel1, W. L., 386

Wuensch, B. J., 356

Yue, A. S., 309

Zimmermann, Jr., W., 364 
Actinide Metals and Compounds

3
14
22
41
42
43
66
73
74
76
80
84
176
197
208

Ceramics

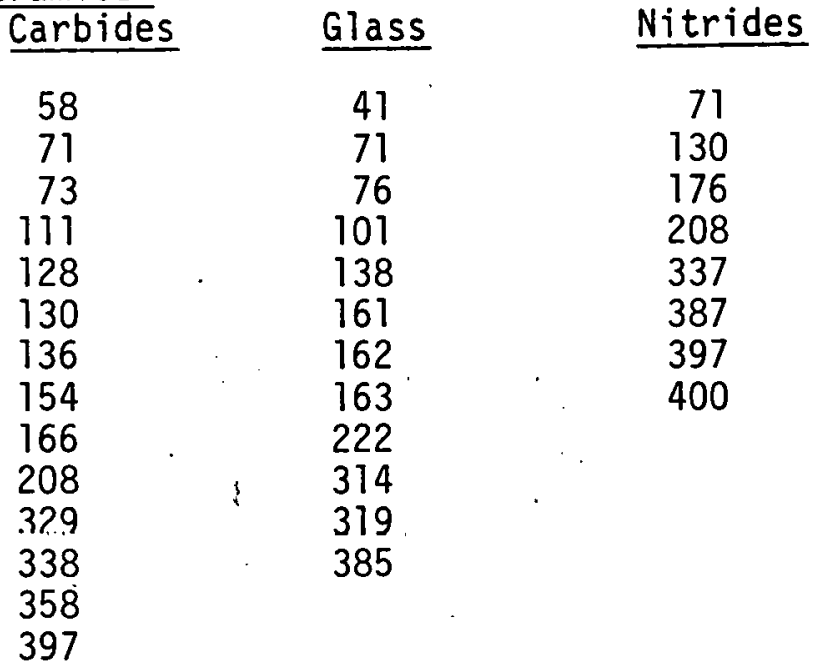


MATERIALS

Al

Composites

$$
\begin{array}{r}
10 \\
89 \\
137 \\
147 \\
335 \\
350
\end{array}
$$

Fash I un Conductors

$$
\begin{array}{rl}
51 & 190 \\
59 & 196 \\
70 & 206 \\
97 & 312 \\
103 & 376 \\
177 & \\
120 & \\
126 &
\end{array}
$$

Graphite, Carbon, and Coal

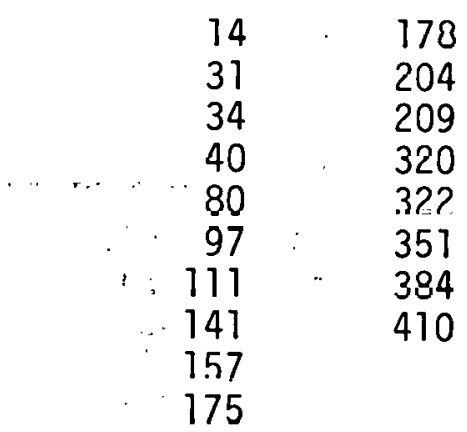

Hydrides

$\begin{array}{rrrrr} & 5 & 59 & 120 & 347 \\ & 24 & 60 & 123 & 349 \\ . & 30 & 66 & 124 & 368 \\ \therefore \quad 41 & 74 & 170 & 391 \\ \therefore \quad 42 & 75 & 190 & \\ . \quad 49 & 80 & 305 & \\ & 42 & \\ & 50 & 91 & 318 & \\ 52 & 112 & 336 & \end{array}$


Intermetallic Compounds

\begin{tabular}{|c|c|}
\hline $\begin{array}{r}32 \\
45 \\
49 \\
53 \\
64 \\
66 \\
70 \\
89 \\
105\end{array}$ & $\begin{array}{l}132 \\
137 \\
184 \\
188 \\
189 \\
191 \\
214 \\
310 \\
321\end{array}$ \\
\hline nic & stals \\
\hline $\begin{array}{l}26 \\
30 \\
60\end{array}$ & $\begin{array}{r}70 \\
73 \\
98 \\
101\end{array}$ \\
\hline
\end{tabular}

Liquids \& Amorphous Materials

$\begin{array}{lllll}15 & 77 & 105 & 204 & 313 \\ 26 & 81 & 135 & 206 & 320 \\ 35 & 82 & 145 & 222 & 327 \\ 36 & 83 & 160 & 223 & 331 \\ 59 & 86 & 163 & 302 & 406 \\ 60 & 90 & 167 & 304 & \\ 68 & 94 & 173 & 311 & \end{array}$

Metals

Alkali

77

79

85

169

173

324

386
BCC Refractory

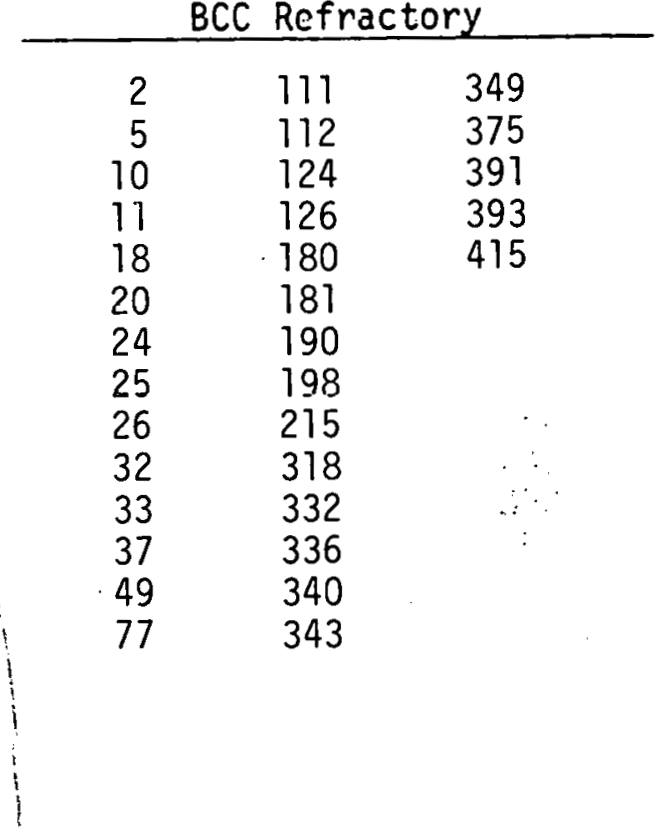

Ferrous

\begin{tabular}{|c|c|c|}
\hline $\begin{array}{r}2 \\
15 \\
47 \\
55 \\
58 \\
77 \\
88 \\
89 \\
130 \\
132 \\
159 \\
168 \\
179 \\
181 \\
185\end{array}$ & $\begin{array}{r}186 \\
188 \\
193 \\
195 \\
199 \\
207 \\
212 \\
212 \\
213 \\
221 \\
222 \\
203 \\
303 \\
317 \\
324 \\
. . \quad 332 \\
336\end{array}$ & $\begin{array}{r}341 \\
354 \\
357 \\
362 \\
363 \\
373 \\
375 \\
379 \\
380 \\
390 \\
396 \\
404 \\
405 \\
414\end{array}$ \\
\hline
\end{tabular}


MHD Materials

$$
\begin{array}{r}
44 \\
71 \\
85 \\
103 \\
115
\end{array}
$$

\section{Polymers}

$\begin{array}{rr}26 & 204 \\ 113 & 306 \\ 114 & 342 \\ 119 & 350 \\ 122 & 394 \\ 161 & 409 \\ 175 & \\ 188 & \end{array}$

Rare Earth Metals and Compounds

$\begin{array}{rrr}1 & 27 & 84 \\ 3 & 30 & 117 \\ 9 & 32 & 188 \\ 11 & 44 & 189 \\ 13 & 61 & 197 \\ 22 & 71 & 317 \\ 23 & 80 & \end{array}$

Semiconductors

$\begin{array}{rrr}1 & 135 & \text { '?'? } \\ 26 & 145 & 226 \\ 27 & 146 & 302 \\ 28 & 147 & 308 \\ 52 & 149 & 334 \\ 61 & 193 & 338 \\ 68 & 194 & 374 \\ 70 & 197 & 402 \\ 90 & 200 & 413 \\ 111 & 203 & 416 \\ 121 & 210 & \\ 129 & 211 & \end{array}$


Acoustic Emission

396

\section{Auger Electron Spectroscopy}

$\begin{array}{ll}181 & 355 \\ 202 & 363 \\ 212 & 392 \\ 224 & 398 \\ 307 & 407 \\ 347 & 416\end{array}$

Computer Simulation

$\begin{array}{rr}12 & 134 \\ 19 & 197 \\ 48 & 319 \\ 70 & 404 \\ 85 & \\ 100 & \end{array}$

\section{Elastic Constants}

$\begin{array}{rr}49 & 370 \\ 124 & 393 \\ 347 & \end{array}$

Electron Microscopy

$\begin{array}{rrrr}5 & 93 & 199 & 352 \\ 6 & 110 & 216 & 365 \\ 18 & 111 & 215 & 373 \\ 47 & 130 & 222 & 375 \\ 49 & 131 & 301 & 377 \\ 51 & 133 & 307 & 383 \\ 52 & 135 & 315 & 384 \\ 54 & 140 & 316 & 385 \\ 55 & 144 & 318 & 390 \\ 56 & 177 & 334 & 391 \\ 58 & 178 & 337 & 397 \\ 88 & 180 & 341 & 402 \\ 89 & 185 & 344 & 410 \\ 91 & 195 & 347 & 415\end{array}$


Electron Spin Resonance

62

69

117

192

312

370

Field Emission and Ion Microscopy

$49 \quad 365$

54

221

225

332

High Temperature Heat Capacity

35

76

183

Infrared Spectroscopy

$67 \quad 196$

$107 \quad 320$

$135 \quad 385$

146

194

Internal Friction

112

124

343

393

Ion Channeling, Scattering and Implantation

$\begin{array}{rr}46 & 191 \\ 52 & 194 \\ 53 & 200 \\ 54 & 203 \\ 55 & 222 \\ 104 & \end{array}$


Laser Beam Scattering

75

145

163

227

325

395

Low Temperature Specific Heat

43

74

150

183

Magnetic Susceptibility

23

43

347

364

Neutron Scattering

$\begin{array}{rrr}22 & 93 & 204 \\ 31 & 94 & 349 \\ 42 & 95 & 359 \\ 57 & 96 & \\ 59 & 97 & \\ 60 & 98 & \\ 73 & 188 & \\ 89 & 189 & \\ 91 & 190 & \end{array}$

Nondestructive Evaluation

$21 \quad 187$

$57 \quad 218$

172393 
Nuclear Magnetic Resonance

$\begin{array}{rr}24 & 305 \\ 40 & 312 \\ 50 & 376 \\ 51 & \\ 63 & \\ 65 & \\ 113 & \\ 119 & \\ 127 & \\ 157 & \end{array}$

\section{Optical Spectroscopy}

$\begin{array}{rr}1 & 192 \\ 27 & 210 \\ 36 & 218 \\ 67 & 302 \\ 68 & 365 \\ 82 & 370 \\ 121 & \\ 135 & \\ 161 & \\ 162 & \\ 173 & \end{array}$

Positron Annihilation

49

92

101

102

Sputtering

211

213

214

217

219

402 
Synchrotron Radiation

\begin{tabular}{|c|c|}
\hline $\begin{array}{r}27 \\
98 \\
99 \\
121 \\
179\end{array}$ & \\
\hline \multicolumn{2}{|l|}{ Theory } \\
\hline $\begin{array}{l}19 \\
28 \\
29 \\
30 \\
41 \\
44 \\
47 \\
48 \\
49 \\
50 \\
70\end{array}$ & $\begin{array}{l}100 \\
114 \\
121 \\
134 \\
149 \\
153 \\
171 \\
174 \\
185 \\
195 \\
197\end{array}$ \\
\hline \multicolumn{2}{|c|}{ Thermal Conducti } \\
\hline $\begin{array}{r}26 \\
183\end{array}$ & \\
\hline \multicolumn{2}{|c|}{ Thermodynamics } \\
\hline $\begin{array}{l}14 \\
26 \\
35 \\
74 \\
77 \\
80 \\
81 \\
84 \\
85 \\
86\end{array}$ & $\begin{array}{r}138 \\
139 \\
153 \\
-\quad 208 \\
327 \\
408\end{array}$ \\
\hline
\end{tabular}


X-Ray Photoelectron Spectroscopy

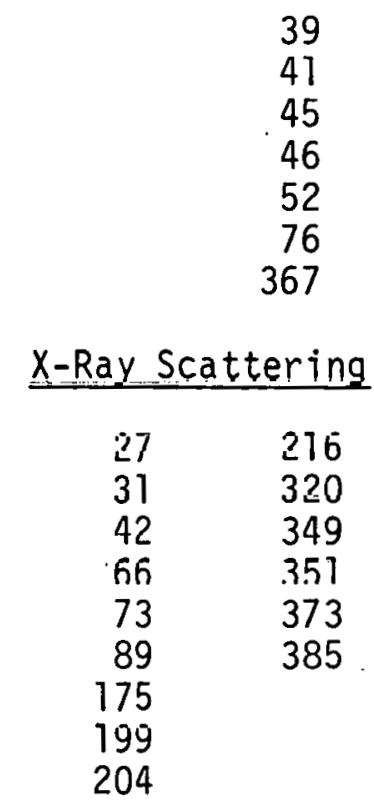




\section{Catalysis}

$\begin{array}{ll}31 & 175 \\ 32 & 202 \\ 33 & 204 \\ 40 & 323 \\ 45 & 373 \\ 65 & 374 \\ 73 & 377 \\ 75 & 388 \\ 82 & 407 \\ 84 & 410 \\ 116 & \\ 117 & \\ 127 & \\ 128 & \\ 139 & \\ 156 & \\ 158 & \\ \text { rrosion } & \end{array}$

$\begin{array}{rrr}26 & 138 & 330 \\ 37 & 144 & 378 \\ 46 & 159 & 380 \\ 77 & 203 & 390 \\ 82 & 205 & 401 \\ 108 & 207 & \\ 109 & 213 & \\ 136 & 324 & \end{array}$

Crystal Structure, Atomic Distribution and Crystal Transformations

$\begin{array}{rr}7 & 153 \\ 12 & 165 \\ 22 & 170 \\ 42 & 171 \\ 60 & 178 \\ 91 & 179 \\ 95 & 180 \\ 97 & 203 \\ 112 & 204 \\ 113 & 216 \\ 122 & 347 \\ 125 & 349 \\ 130 & 385 \\ 133 & \\ 141 & \\ 151 & \end{array}$


PHENOMENA

A20

Diffusion

$\begin{array}{rrr}2 & 182 & 386 \\ 5 & 192 & 392 \\ 8 & 197 & 395 \\ 38 & 206 & 406 \\ 51 & 222 & \\ 76 & 228 & \\ 112 & 314 & \\ 116 & 326 & \\ 126 & 350 & \\ 152 & 355 & \\ 154 & 356 & \\ 155 & 358 & \\ 169 & 383 & \end{array}$

Dislocations

$18 \quad 338$

$48 \quad 344$

$118 \quad 372$

$124 \quad 375$

174

199

328

Erosion

58

109

142

143

177

223

Electron and Ion Conduction

$\begin{array}{rr}4 & .302 \\ 44 & 305 \\ 69 & 319 \\ 116 & 326 \\ 119 & 334 \\ 141 & 358 \\ 152 & 360 \\ 192 & 371 \\ 196 & 376 \\ 206 & 398 \\ 226 & \end{array}$




\section{Electronic Structure}

$\begin{array}{rrr}9 & 42 & 197 \\ 11 & 43 & 312 \\ 24 & 66 & 320 \\ 27 & 98 & 367 \\ 30 & 100 & 381 \\ 39 & 149 & \\ 41 & 174 & \end{array}$

Magnetism

$\begin{array}{rr}15 & 359 \\ 23 & 364 \\ 30 & \\ 60 & \\ 94 & \\ 100 & \\ 188 & \\ 189 & \\ 347 & \end{array}$

Materials Preparation and Characterization

$\begin{array}{rr}3 & 357 \\ 13 & 368 \\ 34 & 387 \\ 61 & 397 \\ 103 & 403 \\ 115 & 409 \\ 158 & \\ 160 & \\ 176 & \\ 193 & \\ 203 & \\ 208 & \\ 217 & \\ 227 & \\ 351 & \end{array}$

Phonons

$\begin{array}{rr}22 & 188 \\ 28 & 190 \\ 50 & 320 \\ 96 & 328 \\ 148 & 339 \\ 149 & 366 \\ 174 & \\ 183 & \end{array}$


Photovoltaic and Photothermal Phenomena

$\begin{array}{rr}1 & 194 \\ 16 & 197 \\ 26 & 200 \\ 27 & 203 \\ 28 & 210 \\ 52 & 211 \\ 68 & 226 \\ 90 & 227 \\ 116 & 308 \\ 121 & 365 \\ 120 & 402 \\ 135 & 413\end{array}$

Point Defects

$\begin{array}{rrr}20 & 121 & 215 \\ 49 & 179 & 216 \\ 51 & 131 & 228 \\ 53 & 133 & 316 \\ 54 & 135 & 326 \\ 62 & 147 & 332 \\ 71 & 167 & 370 \\ 92 & 175 & 375 \\ 101 & 190 & 384 \\ 117 & 198 & 417 \\ 120 & 199 & \end{array}$

Precipitation

\begin{tabular}{cl}
18 & 190 \\
55 & 209 \\
130 & 22 \\
132 & 228 \\
139 & 322 \\
147 & 329 \\
174 & 417 \\
180 & \\
185 & \\
Recovery & and Recrystali1zation \\
\hline \multicolumn{2}{l}{} \\
68 & \\
185 & \\
197 & \\
198 & \\
222 & \\
368
\end{tabular}




\section{Sintering}

$\begin{array}{rr}8 & 377 \\ 132 & 389 \\ 138 & 397 \\ 140 & 400 \\ 352 & \\ 358 & \end{array}$

Solidification

10

160

176

302

313

Strength

Fracture

$\begin{array}{rl}4 & 335 \\ 5 & 336 \\ 6 & 337 \\ 89 & 353 \\ 93 & 363 \\ 110 & 379 \\ 118 & 382 \\ 142 & 394 \\ 181 & 396 \\ 195 & 415 \\ 222 & \end{array}$

303

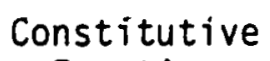

Equations

47

134

331

333

338

404
Fatigue Creep

58

167

353

391

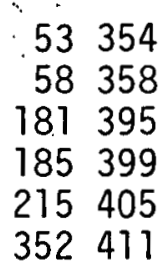

352411
Flow Stress

318

324

338

341

343

375

393

168

.177

.228

306

315

Stress-Corrosion Cracking

$\begin{array}{rr}6 & 221 \\ 88 & 317 \\ 110 & 380 \\ 154 & 390 \\ 207 & 412 \\ 212 & \end{array}$




\section{Superconductivity}

$\begin{array}{rrr}10 & 137 & 310 \\ 22 & 148 & 321 \\ 25 & 149 & 339 \\ 29 & 150 & 340 \\ 50 & 174 & 403 \\ 60 & 184 & \\ 64 & 190 & \\ 72 & 191 & \\ 89 & 197 & \\ 92 & 198 & \\ 104 & 214 & \\ 105 & 301 & \\ 123 & 309 & \end{array}$

Surface Phenomena and Thin Films

$\begin{array}{rrr}16 & 172 & 301 \\ 40 & 1 / 4 & 325 \\ 75 & 182 & 334 \\ 106 & 183 & 346 \\ 139 & 187 & 355 \\ 145 & 202 & 361 \\ 146 & 212 & 363 \\ 149 & 218 & 365 \\ 156 & 219 & 369 \\ 157 & 220 & 383 \\ 158 & 222 & 392 \\ 161 & 224 & 407 \\ 182 & 225 & 416 \\ 164 & 226 & \end{array}$

Welding

107

186

324

362

390 
Gas

Oxidizing

4
46
51
136
177
213
318
Hydrogen

318

336

347

349

368

369

379

391

414

144

169

205

228

303

Magnetic Field

\begin{tabular}{ll}
9 & 189 \\
23 & 312 \\
24 & 403 \\
43 & \\
65 & \\
66 & \\
94 & \\
127 & \\
157 \\
Pressure \\
\hline Above & Atmospheric \\
\hline 113 \\
122 \\
126 \\
151 \\
170 \\
306 \\
310 \\
347
\end{tabular}




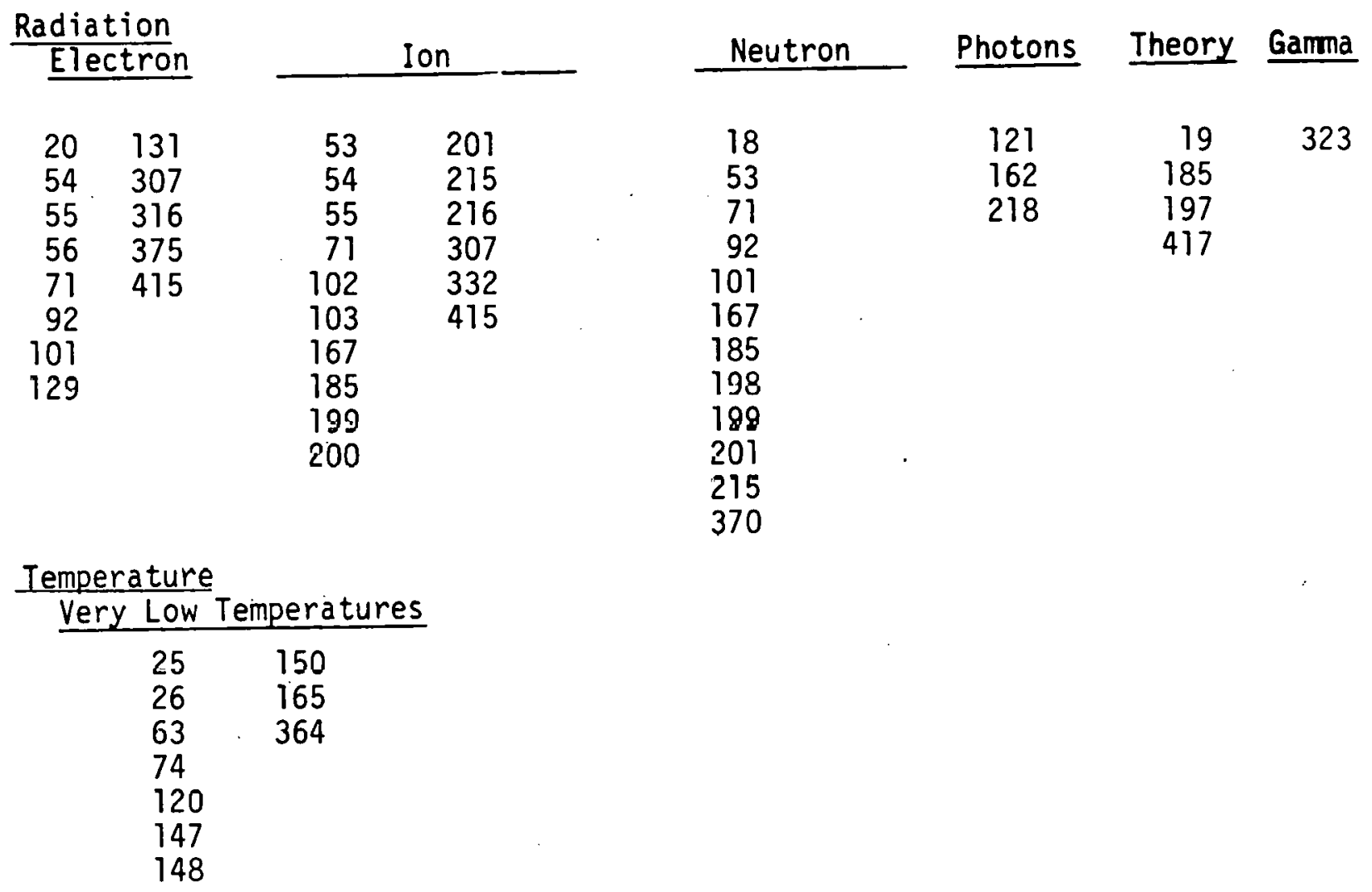

High Temperatures

$\begin{array}{rr}2 & 159 \\ 35 & 166 \\ 36 & 183 \\ 37 & 192 \\ 39 & 321 \\ 44 & 337 \\ 69 & 357 \\ 76 & 360 \\ 77 & 399 \\ 85 & 408 \\ 113 & \\ 139 & \\ 140 & \\ 153 & \end{array}$

